Review

\title{
The Biology of Neisseria Adhesins
}

\section{Miao-Chiu Hung and Myron Christodoulides *}

Neisseria Research, Molecular Microbiology, Clinical and Experimental Sciences, Sir Henry Wellcome Laboratories, Faculty of Medicine, University of Southampton, Southampton General Hospital, Southampton, SO16 6YD, UK; E-Mail: m.hung@soton.ac.uk

* Author to whom correspondence should be addressed; E-Mail: mc4@soton.ac.uk; Tel.:+44-02380-798896; Fax: +44-02380-796992.

Received: 2 May 2013; in revised form: 1 July 2013 / Accepted: 3 July 2013 /

Published: 29 July 2013

\begin{abstract}
Members of the genus Neisseria include pathogens causing important human diseases such as meningitis, septicaemia, gonorrhoea and pelvic inflammatory disease syndrome. Neisseriae are found on the exposed epithelia of the upper respiratory tract and the urogenital tract. Colonisation of these exposed epithelia is dependent on a repertoire of diverse bacterial molecules, extending not only from the surface of the bacteria but also found within the outer membrane. During invasive disease, pathogenic Neisseriae also interact with immune effector cells, vascular endothelia and the meninges. Neisseria adhesion involves the interplay of these multiple surface factors and in this review we discuss the structure and function of these important molecules and the nature of the host cell receptors and mechanisms involved in their recognition. We also describe the current status for recently identified Neisseria adhesins. Understanding the biology of Neisseria adhesins has an impact not only on the development of new vaccines but also in revealing fundamental knowledge about human biology.
\end{abstract}

Keywords: Neisseria; meningitis; gonorrhoea; bacterial adhesin; host cell receptor; structure

\section{Introduction}

The Genus Neisseria (Kingdom Bacteria, Phylum Proteobacterium, Class $\beta$-Proteobacterium, Order Neisseriales, Family Neisseriaceae) includes at least 25 species (Table 1) based on 16S rRNA gene sequence information. Neisseria meningitidis and Neisseria gonorrhoeae are obligate human 
pathogens and the other strains are either commensal organisms in humans and mammalian species and/or have been reported to cause opportunistic human infections. The noted Austrian pathologist and bacteriologist Anton Weichselbaum (1845-1920) first identified a Diplococcus intracellularis meningitidis from the cerebrospinal fluid (CSF) of patients with "epidemic cerebrospinal meningitis" in 1887 [1]. This organism was later reclassified as a member of the genus Neisseria, after the German physician Albert Neisser (1855-1916) who discovered in 1879 the diplococcus known as Neisseria gonorrhoeae. In 1884, the Italian physicians and zoologists Ettore Marchiafava (1847-1935) and Angelo Celli (1857-1914) described the presence of oval micrococci within leucocytes in the CSF of patients dying with meningitis [2], and in 1896, the German physicians and microbiologists Johann Heubner (1843-1926) and F. Kiefer were the first to isolate meningococci from the CSF and throat of living patients [3-5].

Table 1. The Genus Neisseria.

\begin{tabular}{|c|c|c|c|}
\hline & Neisseria species & Colonisation sites & Clinical disease \\
\hline \multirow[t]{2}{*}{$\begin{array}{l}\text { Obligate } \\
\text { pathogen }\end{array}$} & N. meningitidis & Nasopharynx & See text for details \\
\hline & N. gonorrhoeae & Urogenital tract & See text for details \\
\hline \multirow[t]{21}{*}{ Opportunistic } & N. lactamica & Nasopharynx & Meningitis, septicaemia \\
\hline & N. sicca & Nasopharynx & Endocarditis [6], bacteremia [7], meningitis \\
\hline & $\begin{array}{c}\text { N. subflava, which contains previous } \\
\text { spp. N. flava, N. perflava and } \\
\text { N. subflava }\end{array}$ & $\begin{array}{l}\text { Nasopharynx } \\
\text { Urogenital tract }\end{array}$ & Bacteremia [7], meningitis \\
\hline & N. cinerea & Nasopharynx & Newborn ocular infection \\
\hline & N. elongate, including 3 subspecies: & & \\
\hline & $\begin{array}{l}\text { N. elongate subsp. elongate, subsp. } \\
\text { glycolytica and subsp. nitroreducens. }\end{array}$ & Nasopharynx & Septicaemia, endocarditis, brain abscess [8] \\
\hline & N. flavescens & Nasopharynx & Meningitis, septicaemia, endocarditis \\
\hline & N. muсоsa & Nasopharynx & Pneumonia \\
\hline & N. pharyngis & Nasopharynx & Septic arthritis \\
\hline & N. polysaccharea & Nasopharynx & Not known \\
\hline & N. canis & Isolated from the throats of cats & Cat-bite wound infection \\
\hline & N. weaveri & Normal oral flora in dogs & Dog-bite wound infection \\
\hline & N. iguana & Zoonotic & Not known \\
\hline & N. animalis & Isolated from the throats of guinea pigs & Not known \\
\hline & N. denitrificans & Isolated from the throats of guinea pigs & Not known \\
\hline & N. dentiae & $\begin{array}{l}\text { Zoonotic; isolated from dental plaque of } \\
\text { domestic cows }\end{array}$ & Not known \\
\hline & N. zoodegmatis \& N. animaloris & $\begin{array}{l}\text { Commensal organisms in the oral cavity } \\
\text { of dogs and cats }\end{array}$ & $\begin{array}{l}\text { Systemic infections in humans and animals; } \\
\text { dog-bite wound infection [9] }\end{array}$ \\
\hline & N. bacilliformis & Not known & $\begin{array}{l}\text { Wound infection, respiratory tract infection }[10] \text {, } \\
\text { endocarditis }[11,12]\end{array}$ \\
\hline & N. skkuensis & Not known & Isolated from a foot ulcer in a diabetic patient [13] \\
\hline & N. wadsworthii \& N. shayeganii & Not known & Wound infection [14] \\
\hline & $N$. oralis & Healthy subgingival plaque [15] & Not known \\
\hline False & N. caviae, $N$. ovis, $N$. cuniculi $[16]$ & & \\
\hline
\end{tabular}




\subsection{Meningococcal Disease}

Neisseria meningitidis (the meningococcus) causes approximately 500,000 cases of infection per year globally and up to 50,000 deaths [17]. The incidence of meningococcal disease ranges from less than $0.2 / 100,000$ to over $1,000 / 100,000$ population/year and the two peak attack rates occur in children less than one year of age, and in adolescents and young adults [18]. The distinguishing features of meningococcal disease are the fulminant clinical course and the ability to cause large-scale epidemics. The French physician Gaspard Vieusseux (1746-1814) is generally credited with the first detailed description of epidemic meningitis in 1805 in the environs of Geneva, with 33 deaths occurring during a three-month period. His cases show classical clinical signs of meningococcal meningitis in children, with rapid onset and death within 24-48 h [19]. Moreover, children presenting without meningeal irritation showed signs of fulminant disease, including violent abdominal pain, vomiting, diarrhoea and the presence of livid spots on the skin. The clinical manifestations of meningococcal disease can be classified into (1) bacteraemia without sepsis; (2) meningococcaemia without meningitis; (3) meningitis with or without meningococcaemia and (4) meningoencephalitis [20,21]. These clinical presentations are not mutually exclusive and often overlap in individual patients and they are more useful as prognostic predictors [20]. Brandtzaeg et al. recently proposed a clinical classification system for research purposes of (1) shock without meningitis; (2) shock and meningitis; (3) meningitis without shock; and (4) meningococcaemia without shock or meningitis. This classification has been used in clinical studies of meningococcal disease occurring amongst 862 subjects and a higher mortality rate was observed in patients with shock [22].

The most common presentation of invasive meningococcal disease is meningitis, while fulminant meningococcal septicaemia has a higher mortality rate [23]. Critical cases may develop disseminated intravascular coagulation (DIC) and acute adrenal haemorrhage. In cases with severe meningococcaemia, intravascular thrombosis and haemorrhagic necrosis can cause dramatic widespread purpura fulminans with potential infarction and gangrene of limbs [21,23]. Meningococci can also cause pneumonia, which occurs in 5-15\% of patients with invasive meningococcal disease [24]. Other syndromes associated with meningococcal disease include acute respiratory distress syndrome (ARDS), conjunctivitis, otitis media, epiglottitis, urethritis, arthritis, pericarditis, conus medullaris syndrome and cranial nerve dysfunction, especially of the 6th, 7th and 8th cranial nerves. Severe pericarditis, which is likely to result from an immunological reaction thought to be endotoxin-related, can complicate massive tamponade [21,24,25].

Early administration of antibiotics is the key factor leading to full recovery. Empirically, a third-generation cephalosporin (e.g., cefotaxime, ceftriaxone) should be given once the diagnosis is suspected. Penicillin $G$ is still the drug of choice if the antibiotic susceptibility of the causative meningococcus is known. Alternatively, chloramphenicol can also be effective [26]. Despite the availability of effective antibiotics, the mortality rate remains at $10-15 \%$ of all cases [27]. Without treatment, the mortality rate associated with meningococcal disease can be as high as $70-90 \%$. Up to $25 \%$ of survivors of meningococcal disease have lifelong sequelae, such as hearing loss, neurological disability (e.g., mental retardation, seizures and cognitive dysfunction), hydrocephalus, renal failure, skin scarring or loss of a limb [24]. However, survivors who do not display gross neurological damage can often show more subtle neurodevelopmental sequelae, e.g., the impairment of cognitive ability and 
behavioural limitations are factors that can influence academic performance in mathematics, reading and writing $[28,29]$.

\subsection{Gonococcal Disease}

Neisseria gonorrhoeae (the gonococcus) is the causative agent of gonorrhoea, which has affected humans for thousands of years and is still a commonly reported sexually transmitted disease (STD) worldwide. Every year, this exclusively human pathogen afflicts an estimated 62 million people [30]. Gonococcal infection can often be asymptomatic and depending on the anatomical site of exposure, clinical infection can be urogenital, anorectal or pharyngeal gonorrhoea. The major symptoms of urogenital infection in men include urethral discharge and dysuria and the most common localized complication is acute epididymitis: other complications include penile lymphangitis, periurethral abscess, acute prostatitis, and seminal vesiculitis. By contrast, the natural course of gonococcal infection is less well understood in women and there are probably more cases of subclinical infection in women than men. The primary site of female genital infection is the mucosal columnar epithelium in the endocervix, whilst the squamous epithelium of the vaginal mucosa is influenced by oestrogen and not susceptible to gonococcal infection. In women, gonococcal infection can cause cervicitis, endometritis or salpingitis (inflammation in the fallopian tube). Complicated ascending gonococcal infection can lead to pelvic inflammatory disease (PID), ectopic pregnancy and infertility in women [31]. In addition, co-infection with gonococci and Chlamydia trachomatis is common $[32,33]$ and moreover, gonococcal infection can facilitate transmission of human immunodeficiency virus (HIV) [34].

Other local manifestations include gonococcal conjunctivitis, gingivitis, intraoral and cutaneous abscess formation. Pharyngeal gonococcal infections are mostly asymptomatic and resolve spontaneously. Infants born to infected mothers are at high risk of acquiring gonococcal conjunctivitis (ophthalmia neonatorum), which can cause childhood blindness. Gonococcal dissemination through the blood stream, although an uncommon occurrence, can cause "disseminated gonococcal infection" (DGI) and arthritis-dermatitis syndrome is the most common presentation. This arthritis is often asymmetric and involves a few joints, in contrast to polyarthritis, which is caused by immune complex-mediated disorders. Characteristic dermatitis may present as papules and pustules, often with a haemorrhagic component. Occasionally, endocarditis, meningitis, osteomyelitis, septic shock and ARDS are complications of DGI. Although uncommon, direct extension of N. gonorrhoeae or C. trachomatis from the fallopian tube to the liver capsule and adjacent peritoneum can cause acute perihepatitis (Fitz-Hugh-Curtis Syndrome).

Effective treatment is essential for disease control. However, the increase in antibiotic-resistant gonococcal strains worldwide is worrying and from 2010, the Centerfor Disease Control (CDC) no longer recommends oral cephalosporins for treating gonococcal infections [35]. A combination therapy consisting of a single intramuscular injection dose of ceftriaxone $(250 \mathrm{mg})$ and oral azithromycin ( $1 \mathrm{~g})$, is essential to slow down the development of drug resistance [36].

Members of the genus Neisseria colonise exposed mucosal epithelial surfaces of mammalian species, but as demonstrated above in the pathology of Neisseria infections, the ability to disseminate from sites of colonisation also provides the opportunity for bacterial interactions with a wide variety of host cell types and organ systems. In this review, we examine the process of adhesion of Neisseria 
species to target mammalian host cells and tissues, by focusing on the (i) biology and structure of adhesins; and (ii) the mechanisms involved in their interactions. We examine also Neisseria surface structures that are involved in adhesion but not defined strictly as adhesins.

\section{Neisseria Surface Structures Involved in Adhesion}

To colonize host cells successfully, Neisseria spp. need to both establish and maintain an association with host cell surfaces. The first contact between the bacterium and host cells involves the process of adhesion, which can depend on the interaction of specific bacterial surface molecules - adhesins — with specific host cell receptors. Colonization (or maintenance of association with host cells) involves adhesion, bacterial aggregation, microcolony and biofilm formation and the avoidance of host immunity. To begin, we focus on the biology and structure of Neisseria adhesins.

\subsection{Pilus}

The Type IV pilus (Tfp) is probably the best-studied adhesin of Neisseria. Commonly found in Gram-negative bacteria [37], the Tfp imparts twitching motility by rapid extension and retraction [38] and facilitates uptake of foreign DNA to increase transformation frequency [39]. Meningococci are capable of producing two structurally distinct types of pili-Class I and II-whilst gonococci only produce Class I pili. The discriminating murine monoclonal antibody SM1 [40] binds to both meningococcal and gonococcal Class I pili, but not to meningococcal Class II pili [41,42]. Little is known about the expression of Neisserial pili in commensal strains: some strains of $N$. lactamica, $N$. flava, $N$. pharynges and $N$. sicca were non-reactive with SM1 [43] and a comparative analysis of the pilin gene in pathogenic and non-pathogenic Neisseria has demonstrated two distinct structural groups, one consisting of the pilin genes from $N$. lactamica, $N$. cinerea and the Class II pilin-producing subset of $N$. meningitidis isolates, and the other consisting of gonococcal and meningococcal Class I pilin-encoding genes [44]. Moreover, N. sicca, N. subflava, and N. elongata were shown to contain two putative pilE genes arranged in tandem, whilst $N$. polysaccharea, $N$. mucosa, and N. denitrificans harboured only single genes [45]. Recently, the fimbriae of N. elongata were identified as Tfp that are capable of mediating horizontal gene transfer with $N$. gonorrhoeae [46].

Antigenic variation of Tfp expression, which results from both inter- and intra-genomically non-reciprocal DNA recombination between pilS (silent) genes and pilE genes [41,47-50] is known to contribute to evasion mechanisms employed by pathogenic Neisseria [51]. Furthermore, pili from different infection sites of the same patient with meningococcal disease can be antigenically diverse [52]. The frequency of antigenic variation was reported to be 0.13 and 0.03 recombination events per cell with a rate of $4 \times 10^{-3}$ and $1.6 \times 10^{-3}$ events per cell per generation for gonococci [53] and meningococci [54], respectively.

Neisserial pili are hair-like, flexible and helically homopolymeric fibres, $6 \mathrm{~nm}$ in diameter and several microns in length. PilE (the product of the pilE gene) is the pilin subunit that assembles into the multifunctional pilus adhesin and virulence factor [55]. To our knowledge, the first report of the preparation of three-dimensional needle- and plate-shaped crystals of purified $N$. gonorrhoeae pilin (strain MS11 variant C30) was made as long ago as 1987 by Parge and colleagues [56]. The best crystals were diffracted to $2.4 \AA(1 \AA=0.1 \mathrm{~nm})$ resolution using synchrotron radiation [57]. In a 
follow-up paper, Parge and colleagues derived the structure of the fibre-forming pilin protein at $2.6 \AA$ resolution [58]. The crystallographic structure of $N$. gonorrhoeae pilin revealed an $\alpha-\beta$ roll fold with a $85 \AA$ Á $\alpha$-helical spine and an O-linked disaccharide. Key residues were identified that stabilized interactions that allowed sequence hyper-variability, correlating with antigenic variation, within disulphide region $\beta$-strands and connections. The surface shape, hydrophobicity and sequence variation of pilin is believed to constrain pilus assembly to the packing of flat subunit faces against $\alpha 1$ helices. A core of coiled $\alpha 1$ helices is banded by $\beta$-sheet to form the assembled helical fibre, with carbohydrate and hyper-variable sequence regions exposed outwards to solvent. Further X-ray crystallographic refinement of gonococcal pilin to 2.6 Á resolution, along with mass spectrometry of peptide fragments, revealed the presence of phosphorylated serine at position 68 [59]. Dephosphorylation altered the morphology of fibres, but did not affect bacterial adhesion, transformation, piliation or twitching motility. Parge et al. also obtained reassembled pilus fibers and three-dimensional crystals for pilin protein from three gonococcal strains [56], and using synchrotron X-ray radiation (3 Á resolution) they confirmed the "packing" arrangement of the pilin subunits as observed in pilus fibers using electron microscopy (EM). The proposed model is an anti-parallel 4- $\alpha$ helix for the overall polypeptide fold of a pilin subunit. At the same time, cryo-electron microscopy (cryo-EM) and reconstruction provided a structure for gonococcal $\mathrm{Tfp}$, in which spiralling three-helix bundles form the filament core, anchor the globular heads and provide strength and flexibility. Hyper-variable loops were observed to protrude from a "corrugated" pilus surface, which was created by the shielding of conserved functional residues by post-translational modifications in the globular heads [60].

Associated with pilus are 23 proteins, of which 15 (including PilC1/C2, PilD, PilE, PilF, PilG, PilH, PilI, PilJ, PilK, PilM, PilN, PilO, PilP, PilQ and PilW) are essential for Tfp biogenesis, which involves four steps: (1) assembly; (2) functional maturation; (3) counter-retraction; and (4) emergence onto the cell surface [61]. By contrast, seven other proteins (ComP, PilT, PilT2, PilU, PilV, PilX and PilZ) are not necessary for piliation, but are involved in "fine-tuning" Tfp function [62]. The pilM, pilN, pilO, pilP and pilQ genes are organised as an operon and the pili proteins PilD, PilF, PilM, PilN, PilO and PilP are important for pilus assembly. Recently, PilM, PilN, PilO and PilP proteins have been shown to form a pilus subcomplex that is involved in pilus assembly [63]. PilC, PilI, PilJ, PilK and PilW are related to functional maturation [61]. Furthermore, PilC has been demonstrated to mediate fibre retraction [64]. The pilG gene is highly conserved in pathogenic Neisseriae [65] and the PilG protein plays a role in pilus retraction. However, PilG does not appear to be essential for pilus assembly, because apparently normal pili are observed in pilG mutant meningococci [61]. The conserved OM-localized PilQ is a secretin that forms a pore through which Tfp emerge on the bacterial surface [66] and PilW is important for the stability and function of the pilus fibre [67]. Though low in abundance, PilX plays a role in mediating bacterial aggregation, which is important for bacterial adhesion [68]. Recently, another minor (low abundance) pilin, ComP, was reported to have a binding affinity to DNA uptake sequence (DUS) and therefore contributes to selective DNA uptake during transformation [69].

The first three-dimensional structure of the secretin PilQ was resolved at $2.5 \mathrm{~nm} \mathrm{[70],} \mathrm{and} \mathrm{showed}$ that the complex has a 12-fold rotational symmetry and the dominant feature is a $10 \mathrm{~nm}$ deep cavity within the centre of the complex. The quaternary structure of the PilQ secretin from N. meningitidis was analysed by transmission electron microscopy (TEM) with a negative stain [71], to a resolution of 
$\sim 2.6 \mathrm{~nm}$ and describes a dodecameric quaternary structure. Oligomeric PilQ adopts a "doughnut-like" structure and initial measurements determined that the external ring was $16.5 \mathrm{~nm}$ in diameter, surrounding a central cavity that was $6.5 \mathrm{~nm}$ in diameter. PilQ is organized as a ring of 12 identical subunits as shown by the presence of a 12-fold rotational symmetry, following self-rotation and power spectrum analysis. The cavity accommodates neatly the X-ray crystal structure of the $N$. gonorrhoeae pilin subunit. The structure of the N. meningitidis PilQ was further resolved at $12 \AA$ [72].

More recently, the studies of Jain et al. have shown that secretin complexes contain previously unidentified large and flexible extra domains that probably stabilize or assemble Tfp. In this study, secretin complexes of $N$. gonorrhoeae show a double ring structure with a 14-15-fold symmetry in the central ring, and a 14-fold symmetry of the peripheral ring with seven spikes protruding [73]. In contrast, the spikes were absent and the peripheral ring was partly or completely lacking in $N$. meningitidis secretin complexes. When present, the ring has a 19-fold symmetry. Using NMR, Berry et al. derived the structures of the periplasmic domains from N. meningitidis PilQ secretin [74]. In addition, the structure of the entire PilQ dodecamer was also revealed by cryo-EM as a "cage-like" structure that enclosed a large cavity ( $\sim 55 \AA$ in internal diameter at its largest extent). The entire PilQ assembly that spans the periplasm has been reconstructed and NMR chemical shift mapping was used to generate a model for the PilP:PilQ interacting complex, adding further information to the three-dimensional reconstruction of the complex obtained previously at low resolution by TEM [75].

The structures of several other pilus-associated proteins have been resolved. These include solution structures of folded domains of the PilP lipoprotein [76], the high-resolution crystal structure of PilW, the partner lipoprotein of PilQ from N. meningitidis [77], as well as the three-dimensional EM structure of the integral PilG inner membrane protein multimer [78]. Using X-ray crystallography, Helaine and colleagues reported that PilX shows the $\alpha / \beta$ - roll fold shared by all pilins and that PilX protein co-localizes with Tfp [79]. The ultrastructure of the $N$. gonorrhoeae PilT, a biological motor required for the retraction of Tfp, was examined by freeze-etch EM, which revealed a $115 \AA$ outer diameter and 15-35 $\AA$ inner diameter ring [80]. This study also showed that the ultrastructures of gonococcal PilT and a PilT from Aquifex aeolicus (a chemolithotrophic bacterium) are similar to type II and type IV secretion ATPases.

\subsection{Opacity-Associated Proteins: Opa and Opc}

The most abundant protein adhesins in the outer membrane (OM) are Opa and Opc. The colony opacity-associated (Opa) protein (an eight-stranded $\beta$-barrel structure with four surface-exposed loops, $27-31 \mathrm{kDa}$ ), previously known as PII or class 5 protein, is commonly expressed in both meningococci and gonococci. The name "opacity" was coined for colonies that showed an opaque appearance when viewed on a microscope with oblique sub-stage lighting [81]. A single meningococcal strain can harbour 3-4 opa genes (opaA, opaB, opaD and opaJ) [82,83], whilst up to 11 opa genes can be expressed in gonococci at separate loci throughout the genome [84]. The commensal strains $N$. subflava, N. mucosa and $N$. sicca, were shown to harbour one opa gene, whereas two opa genes were found in $N$. flava and in N. lactamica [85-87].

In early structural analyses using rules derived from porin crystal structure and the conservation of sequence homology within transmembrane $\beta$-strands, Malorny et al. generated a two-dimensional 
structural model of Neisserial Opa that presented four surface-exposed loops [88]. Circular dichroism has been used to determine the structure of refolded and purified opacity proteins OpaJ129 and OpaB128 derived from $N$. meningitidis strain H44/76, and this indicated a high content of $\beta$-sheet conformation, which is consistent with the previously proposed topology model [89]. Although the crystal structure of Opa remains unsolved, Opa is structurally similar to the Neisserial surface protein A (NspA), for which a crystal structure was reported in 2003 [90]. Little is known about the role of NspA as an adhesin. Expression of Opa protein exhibits significant phase and antigenic variation. Comparison of amino acid sequences of different Opa proteins show that Loops 2 and 3 are hyper-variable (containing HV1 and HV2 regions), Loop 1 (proximal to the $N$-terminus) is semi-variable and Loop 4 is constant. Antigenic variation is attributable to intra-or inter-genomic recombination [91]. Sequence diversity in the loop regions is responsible for conferring specificity for host cell receptors. Amongst gonococci, an estimated $77 \%$ of Opa diversity is due to recombination within the same isolate, $16 \%$ is due to imported genes from other isolates and only $7 \%$ is due to de novo mutation [92]. Phase variation of Opa expression is determined by the variable number of pentameric coding repeats (5'-CTCTT-3') at the $5^{\prime}$ gene region encoding the leader peptide [93]. The different number of repeats can lead to frame-shifting by slipped-strand mis-pairing during DNA replication and leads to high frequency of phase variation $\left(\sim 1 \times 10^{-3}\right.$ per cell per generation) [94]. The rate of gonococcal Opa phenotype transition was estimated to be about $2 \times 10^{-3}$ per colony forming unit per generation [95]. Phase variation of gonococcal Opa is also affected and regulated by promoter strength, and results in expression levels ranging from no Opa to multiple Opa [96]. A similar translational control mechanism has been reported for meningococcal Opa protein [85] and certain types of Opa protein are more predominant in invasive isolates due to their high virulence properties [97,98]. N. lactamica Opa proteins are more similar genetically to meningococcal Opa (70\% of genetic relatedness). Expression of Opa proteins has been demonstrated in some commensal strains, including $N$. lactamica, $N$. subflava and $N$. flavescens and share a phylogenetical cluster association different from a pathogenic cluster [87].

By contrast, the Opc protein $(27-31 \mathrm{kDa})$, formally known as $5 \mathrm{C}$ protein, is only expressed in $N$. meningitidis [99]. Opc protein is encoded by a single gene, opcA, whilst the opcB is a "pseudogene" found on a second locus in both meningococcal and gonococcal genomes [99]. In a study of opcA gene in commensal strains, only two out of 13 screened $N$. polysaccharea strains harboured the opcA gene, which shared 93\% homology to gonococcal opcA gene [100]. However, significant difference was observed within the region encoding the most surface-exposed loops and there is no evidence of Opc protein expression by these commensal strains with opcA genes. Although amino acid sequence variation amongst different Opc proteins is limited, the levels of Opc protein expression are phase variable. This phase variation is due to the transcriptional regulation of a homopolymeric, variable-length and polycytidine (poly-C) tract, which is located at the promoter region of the $o p c$ gene [101]. The crystal structure of OpcA has been determined to 2.0 Á resolution and shows that this adhesin adopts a 10 -stranded $\beta$-barrel structure; protruding above the predicted membrane surface are extensive loop regions of dramatically different conformation with a high degree of flexibility [102-104]. 


\subsection{Classical Monomeric Autotransporters: App and MspA/AusI}

Neisseria can export monomeric autotransporter adhesins, App and MspA/AusI, through a type Va secretion system [105-107]. The IgA protease of $N$. gonorrhoeae was identified as the first example of a classical autotransporter [108]. The modular structure of autotransporter proteins contains three parts: (1) a $N$-terminal signal peptide; (2) a secreted passenger domain and (3) a $C$-terminal translocator domain. The $N$-terminal signal peptide can target the unfolded passenger domain, crossing the inner membrane to the periplasmic space via Sec machinery. Next, the $C$-terminal translocator domain folds into a $\beta$-barrel (also named as $\beta$-domain) followed by insertion into the $\mathrm{OM}$, a process facilitated by an OM multi-protein machine called the Bam protein complex [109]. The integral translocator domain in the $\mathrm{OM}$ has a central hydrophilic channel, which can act as a pore and is essential for transportation of the passenger domain to the cell surface. During transportation across the OM, the passenger domain can undergo periplasmic and extra-cellular folding via interaction with other proteins, such as chaperones. On secretion, the passenger domain can finally exert its biological functions [109].

The highly conserved Neisserial App (Adhesion and penetration protein, $160 \mathrm{kDa}$, the product of the app gene) shares a high degree of homology to Hap (Haemophilus adhesion and penetration protein, the product of the hap gene) in Haemophilus influenzae [105]. The crystal structure of Haemophilus Hap has been solved [110] and it is defined as a prototype self-associating autotransporter (SAAT), which can mediate bacterial cell-cell adhesion and facilitate bacterial aggregation and biofilm formation. X-ray crystallography (2.2 \& resolution) determined the crystal structure of the Haemophilus Hap s passenger domain, which harbours the SAAT domain. Structural analyses shows that Hap forms intercellular multimeric complexes that are required for bacterial cell-cell interaction and microcolony formation [110]. In the Neisserial App protein, a serine protease motif in the $\beta$-domain pilots the autoproteolytic activity and subsequent secretion of the passenger domain. Mutation of $\operatorname{Ser}^{267}$ has been shown to abolish the autocatalytic cleavage and therefore proves that the catalytic triad in the passenger domain- $\mathrm{His}^{115} \mathrm{Asp}^{158} \mathrm{Ser}^{267}$ - which is also present in Hap protein of $H$. influenzae and in nine other autotransporter proteases, contributes to autoproteolysis [106]. All Neisseria species possess the app gene and the meningococcal App protein amino acid sequence shares $\sim 95 \%$ and $73 \%$ identity with $N$. gonorrhoeae and N. lactamica App, respectively.

MspA (meningococcal serine protease A, $157 \mathrm{kDa}$ ) or AusI (autotransporter serine protease I) was designated due to its homology to App (33\% identity), IgA1 protease (36\% identity) and other autotransporters [107]. The $m s p A$ gene is not present in all meningococcal strains and its expression is also phase variable. Similar to App, MspA also has a catalytic triad $\left(\mathrm{His}^{100} \mathrm{Asp}^{135} \mathrm{Ser}^{241}\right.$ ) in the predicted passenger domain [107]. To our knowledge, no structures have been solved by crystallography/NMR for MspA.

\subsection{Trimeric Autotransporter Adhesins: NadA and NhhA}

The trimeric autotransporter adhesin (TAA) family of secreted Gram-negative OM proteins are organised in obligate homotrimers. The structures of TAAs show a simple "head-stalk-anchor" organisation. Trimerization of the head (passenger domain) is required for stability and adhesive 
ability to host tissue $[111,112]$, the stalk projects the head beyond the membrane and the $\beta$-barrel anchor ( $C$-terminal translocator domain) is responsible for secreting both head and stalk components. In contrast to classical autotransporters, typical autocatalytic cleavage does not occur in TAAs, so the functional passenger domain remains covalently attached to the anchor after being secreted [113]. The prototypical members of this family are the YadA protein of enteropathogenic Yersinia species [114,115] and Hia (Haemophilus influenzae adhesin) and Hsf (Haemophilus surface fibril) adhesins of H. influenzae [116,117]. NadA and NhhA are two TAAs that have been characterised in Neisseria.

NadA (Neisserial Adhesin A, $38 \mathrm{kDa}$ ) is a member of the Oca (Oligomeric coiled-coil adhesins) family, and the protein shares $\sim 32-34 \%$ homology to the UspA2 (ubiquitous surface protein A2) of Moraxella catarrhalis and the Yersinia YadA protein [118]. NadA was predicted to have three main domains: (1) a $\mathrm{COOH}$-terminal anchoring domain ( $\beta$ structure), which is also necessary for auto-translocation to the bacterial surface; (2) a probably coiled domain with a leucine zipper, which might mediate dimerization and oligomerization; (3) a $\mathrm{NH}(2)$-terminal globular head domain [118] that is involved in interactions with human cells. In addition, the apical region of NadA is predicted from EM and structure analysis to form a compact and globular domain [119]. The nadA gene is present in $\sim 50 \%$ of meningococcal strains, but absent in both $N$. gonorrhoeae and $N$. lactamica. Interestingly, in a study of 154 carriage isolates, only $5.1 \%$ of the strains harboured the $\operatorname{nadA}$ gene [120].

NhhA (Neisseria hia/hsf homologue, $57 \mathrm{kDa}$ ) was first identified because of its similarity (47\%) to the adhesin AIDA-I of Escherichia coli [121] and was later defined as a multifunctional TAA with close homology to the Hia and Hsf adhesins of H. influenzae [121,122]. It was suggested to name it Meningococcal surface fibril (Msf), since it is more similar ( $74 \%)$ to Haemophilus surface fibril (Hsf) [123]. Its particularly short $C$-terminal translocation domain (the last 72 residues), defined as a minimal translocation unit, is capable of trimerization to form a complete $\beta$-barrel. NhhA is expressed in N. meningitidis and N. lactamica, but not in N. gonorrhoeae [122].

\subsection{Two-Partner Secretion (TPS) System: HrpA and HrpB}

The two-partner secretion pathway (TPS), composed of a large secreted protein (TpsA, typically $>100 \mathrm{kDa}$ ) with biological function and a transporter protein $(\mathrm{TpsB}, \sim 60 \mathrm{kDa}$ ) forming a $\beta$-barrel pore in the $\mathrm{OM}$, is widely used by Gram-negative bacteria for exporting large proteins. In contrast to autotransporters that are encoded by single genes, TpsA and TpsB are encoded by two separate genes and function as "partners" [124]. The synthesized TpsA is transported to the periplasmic space via Sec machinery. In the following stage, the $N$-terminal TPS targeting domain (250-amino acid residues long) in the TpsA molecule can direct the TpsB protein in the OM, in order to transport TpsA across the $\mathrm{OM}$ via a type $\mathrm{Vb}$ secretion system [125]. The structure of the TPS transporter is very different to the translocator domain of the autotransporter system [126]. The prototype of this family is the filamentous haemagglutinin (FHA) of Bordetella pertussis [126,127], whose crystal structure has been solved [128]. Due to homology with FHA, TpsA and TpsB homologues in meningococci are designated as haemagglutinin/haemolysin-related proteins $\operatorname{HrpA}$ and $\mathrm{HrpB}$, respectively [129]. hrpA (TpsA) genes are present in surveyed 822 meningococcal carriage strains and their encoded proteins can be classified into two groups [129]. N. lactamica only harbours genes encoding group II TPS system $[129,130]$. In a later study of 88 meningococcal disease isolates, the previous group II TPS 
system was further classified into systems 2 and 3. System 1 was ubiquitous, whereas systems 2 and 3 were found to be related to hyperinvasive clonal complexes [131]. In comparison to hrpA (TpsA) gene, the $h r p B$ (TpsB) gene is highly conserved and essential for functional secretion of TpsA [129]. Examination of the specificity of the two TpsB transporter systems, TpsB1 and TpsB2, shows that the TpsB2 system is capable of transporting all types of TpsA domains, whereas TpsB1 is more specific to transportation of its cognate TpsA domains [132]. N. gonorrhoeae does not harbour a hrpA gene, but instead has a disrupted TpsB opening reading frame and thus it lacks a functional copy of a TPS system [131].

\subsection{Other Neisseria Adhesins}

The T-cell stimulating protein A (TspA, $92 \mathrm{kDa})$ of $N$. meningitidis was initially identified as a Tand B-cell stimulating antigen [133] and later shown to be required for efficient adhesion [134]. TspA shares homology with the FimV protein of Pseudomonas aeruginosa and was therefore classified as belonging to the FimV family, members of which are also present in other bacteria such as Legionella pneumophila and Vibrio cholerae [135]. TspA was found in all the meningococcal isolates surveyed, with $>85 \%$ identity. Similar TspA amino acid sequences were also identified in N. polysaccharea, but not in N. lactamica or N. gonorrhoeae [134].

Expression of fructose-1,6-bisphosphate aldolase (FBA, $38 \mathrm{kDa}$ ) is considered a requirement for efficient bacterial adhesion to host cells, although its role in this process in unknown. Moreover, FBA is present in both the cytoplasm and OM. The amino acid sequences of FBA are $>99 \%$ identical between meningococcal isolates and also $70 \%, 67 \%$ and $65 \%$ identical to the class-IIB FBA from Cupriavidus metallidurans, Xanthobacter falvus and Synechocystis spp., respectively [136]. Glyceraldehyde 3-phosphate dehydrogenase (GapA-1, $37 \mathrm{kDa}$ ) is another enzyme with putative adhesin function, which is surface-located and highly conserved in meningococci ( $>97 \%$ identical) and also present in gonococci (99\% identical to strain FA1090) and $N$. lactamica $(90 \%$ identical to strain ST640) [137]. A putative ABC transporter component of a glutamate transporter operon, encoded by gene NMB1966 (29 kDa), has also been reported to mediate adhesion of meningococci to human bronchial epithelial cells [138].

The OmpA (outer membrane protein A)-like protein $(23.4 \mathrm{kDa})$ of gonococci is homologous to OmpA of other Gram-negative species, including E. coli, Salmonella, Yersinia and Pseudomonas spp. (40-44\% identity) [139]. The structure of Neisseria OmpA has not been elucidated. However, the $C$-terminal domain of the meningococcal RmpM (Class 4 protein, reduction-modifiable protein $\mathrm{M}$ ) is homologous to the periplasmic, $C$-terminal domain of $E$. coli OmpA and shares $\sim 35 \%$ amino acid sequence identity [140]. The crystal structure of this domain has been solved at $1.9 \AA$ and shows that the domain adopts a $\beta \alpha \beta \alpha \beta \beta$-fold. By analogy, structural information on both the transmembrane $\beta$-barrel and soluble periplasmic domain of OmpA from E. coli has been reported [141].

In a recent study, Hung et al. identified the meningococcal Adhesin Complex Protein (ACP, $13.3 \mathrm{kDa})$ as a new adhesin [142]. There are 31 different acp DNA alleles which encode 11 types of ACP in sequenced Neisseria isolates present in the original BIGS database of 205 genome-sequenced Neisseriae [143] and within a separate collection of 12 well-characterized meningococcal strains [142]. Meningococci express type I, II and III ACP with one or two amino acid differences (98-99\% similarity). 
Commensal strains such as $N$. lactamica, N. polysaccharea and $N$. sicca also harbour the gene that encodes type I ACP. By contrast, gonococci carry the acp genes encoding two types of ACP, which show 94\% identity to meningococcal ACP [142]. The structures of TspA, FBA, GapA-1, NMB1966 and ACP have not been elucidated.

\subsection{Other Neisseria Surface Structures Influencing Adhesion}

Several other surface structures, although not functioning directly as primary adhesins, can play an accessory role during bacterial interactions or they can modulate the adhesion process itself. These structures include the polysaccharide capsule, lipo-oligosaccharide (LOS) and major OM porin proteins. In addition, many other Neisseria ligands can interact with human cell components, but are not classified as adhesins.

\subsubsection{Polysaccharide Capsule}

The polysaccharide capsule is an important virulence factor for meningococci, enabling this pathogen to avoid complement-mediated killing and phagocytosis. In contrast, gonococci and the well-studied commensal strain, N. lactamica do not have capsules [144]. The highly hydrated capsule most likely ensures meningococcal survival in aerosol droplets (i.e., avoiding desiccation), which is important for survival in fomites and for person-to-person transmission [145]. Many colonizing meningococci are non-capsulated [146], whereas those causing invasive disease are almost invariably capsulated. Additionally, the phase-variable on/off expression of capsule can influence the interactions between meningococci and host cells [147].

To evade host immune recognition, meningococcal capsules also exhibit characteristic antigenic variation and immune mimicry. According to serological reaction to capsules, meningococci are classified into 12 serogroups [148], amongst which serogroup A, B, C, Y and W cause the majority of invasive meningococcal disease. The genes encoding the biosynthesis of sialic acid (NANA, 5- $N$-acetyl-neuramic acid) for serogroups $\mathrm{B}, \mathrm{C}, \mathrm{Y}$ and $\mathrm{W}$ are similar. This similarity can facilitate horizontal gene exchange and result in capsule switching between these invasive serogroups [149]. However, sialic acids are present commonly on human cells and therefore meningococci can avoid recognition by immune molecular mimicry. The most studied example is the serogroup B meningococcal capsule, which contains a $\alpha(2-8)$-linked polysialic acid that is structurally identical to glycosyl residues of human neural cell adhesion molecule (NCAM) [150,151].

Solution conformations of the group B polysaccharide have been analyzed by DQF-COSY and pure absorption 2D NOE NMR [152] and essentially complete ${ }^{1} \mathrm{H}-\mathrm{NMR}$ conformations for serogroup A, C, $\mathrm{W}$ and $\mathrm{Y}$ polysaccharides also have been determined [153]. High resolution-magic angle spinning (HRMAS) NMR spectroscopy has been used to determine the exact structures of serogroup A capsular polysaccharide expressed on meningococci [154]. Structure of the serogroup X polysaccharide has been described using a combination of ${ }^{13} \mathrm{C},{ }^{1} \mathrm{H}$ and ${ }^{31} \mathrm{P}-\mathrm{NMR}$ spectroscopy and total correlation spectroscopy (TOCSY) and ${ }^{1} \mathrm{H}^{-13} \mathrm{C}$ heteronuclear single quantum coherence (HSQC) [155]. More recently, quantification of serogroup X capsular polysaccharide by proton qNMR has been reported [156]. 


\subsubsection{Lipo-Oligosaccharide (LOS)}

LOS is composed of a lipid A, an inner and outer core oligosaccharide and is structurally distinct from lipopolysaccharide (LPS) of Gram-negative enteric bacilli due to the lack of a repeating polysaccharide O-side chain [157]. Both $N$. meningitidis and $N$. gonorrhoeae harbour the lgt genes encoding LOS with high genetic diversity, whereas the lgt gene is not carried by all the commensal strains $[158,159]$. LOS exhibits antigenic variation, which is mostly due to phase variation of the related gene expression [160]. Sialylation of LOS in serogroups B, C, W and Y enables meningococci to mimic host cell surfaces that also express sialic acid [161]; as a consequence, the organism becomes more resistant to antibody and complement-mediated killing and phagocytosis [162,163].

Structural characterisation of Neisseria LOS has a long history, but detailed descriptions are outside the remit of this current review. A variety of biochemical and biophysical techniques have been used for LOS structural determination: these include methylation analysis, specific degradations (e.g., mild acid hydrolysis) and high-pH anion-exchange chromatography of underivatised oligosaccharides with reverse-phase high performance liquid chromatography; pulsed amperometric detection (HPAE-PAD) of oligosaccharides (OS), fluorophore-assisted carbohydrate electrophoresis monosaccharide composition analysis; 1D 500-MHz ${ }^{1} \mathrm{H}-\mathrm{NMR}$ as well as nuclear Overhauser effect experiments; 2D NMR methods [double quantum filtered COSY (DQF-COSY), delayed COSY (D-COSY), homonuclear Hartmann-Hahn spectroscopy (HOHAHA) and pure-absorption 2D NOE NMR]; mass spectrometry techniques (positive ion fast atom bombardment; Fourier transform ion cyclotron resonance mass spectrometry (FTICR-MS); electrospray ionization, collision-induced dissociation, and multiple step) [164-174]. Structural information on LOS has been recorded for meningococci [168,172,174-177], gonococci [178,179] and several commensals ( $N$. canis, N. perflava, N. subflava, N. flava, N. cinerea, N. flavescens, N. caviae, N. sicca) [180-182].

\subsubsection{Porin (Por)}

Porins comprise up to $60 \%$ of the proteins present in the Neisseria OM. Most Neisseria spp. express only one Por, whereas meningococci have both PorA $(\sim 41-42 \mathrm{kDa})$ and PorB $(\sim 34 \mathrm{kDa})$, which allow selective passage of cation and anion across the cell membrane respectively [183]. Recently, PorB was also shown to mediate cation transport [184]. N. gonorrhoeae porB gene exists as two alleles that encode either PorB.1A or PorB.1B protein [185]. Gonococci also have a porA gene, but it is present as a pseudogene due to frame shift or promoter mutation [186]. The porin of $N$. lactamica and $N$. polysaccharea are identical and show similarity to meningococcal PorB and gonococcal PorB.1A and PorB.1B ( 35-37 kDa) [187,188].

Porin structural analysis has mainly been directed towards PorA and PorB; early three-dimensional model structures were derived by comparison of PorA and PorB Neisseria sequences with known E. coli porin structures [187]. Despite the low sequence identity with E. coli porins, Neisseria spp. porins assemble into a model of the 16-strand $\beta$-barrel fold characteristic of porins. Meningococcal PorB forms stable trimers [189] and the X-ray crystal structure was determined to $2.3 \AA$ resolution, which identified three putative solute translocation pathways through the channel pore [190,191]. Recently, the gonococcal PorB.1A was analysed by X-ray crystallography in the presence of 
phosphate and ATP and a detailed structure solved at a resolution of $3.3 \AA$ [192]. Surprisingly, no complete X-ray crystal structure has been provided for meningococcal PorA; only structural analyses on the binding complexes formed between different monoclonal antibodies and different peptide epitopes corresponding to porin subtype variants have been reported [193,194]. Even less is known of porin structure in other Neisseria: however, ribbon diagrams comparing the N. lactamica porin protein with related meningococcal PorB have been published, but structural examination showed that variation in $N$. lactamica porin was less than that observed in the meningococcal porin [188].

\section{Mechanisms of Neisseria Adhesion with Host Cells}

The pathogenic Neisseriae share similar surface structures that are involved in adhesion, but they also display subtle and disparate mechanisms for interacting with the host. Here, we review the adhesion process based on the different histology of host cells and sites of infection, and highlight the bacterial ligand-host cell receptor interaction mechanisms that may dictate tissue tropisms (Figure 1).

Figure 1. (A) Schematic review of Neisseria meningitidis surface molecules and their interactions with human host cell binding ligands. Many of these structures are absent in gonococci, whereas OmpA is specific to this organism (see text). Plasminogen-binding cytosolic proteins include enolase, DnaK and peroxiredoxin; $\mathrm{P}$ to $\mathrm{p}$ denotes conversion of plasminogen to plasmin. Far less is known about surface structures in commensal Neisseria; (B) Interactions between Neisseria Opa and Opc proteins and human host cells involves multiple binding ligands. Opa proteins are expressed by meningococci and gonococci, whereas Opc is only expressed by meningococci. Opa and Opc-mediated binding events are more efficient in the absence of capsule.

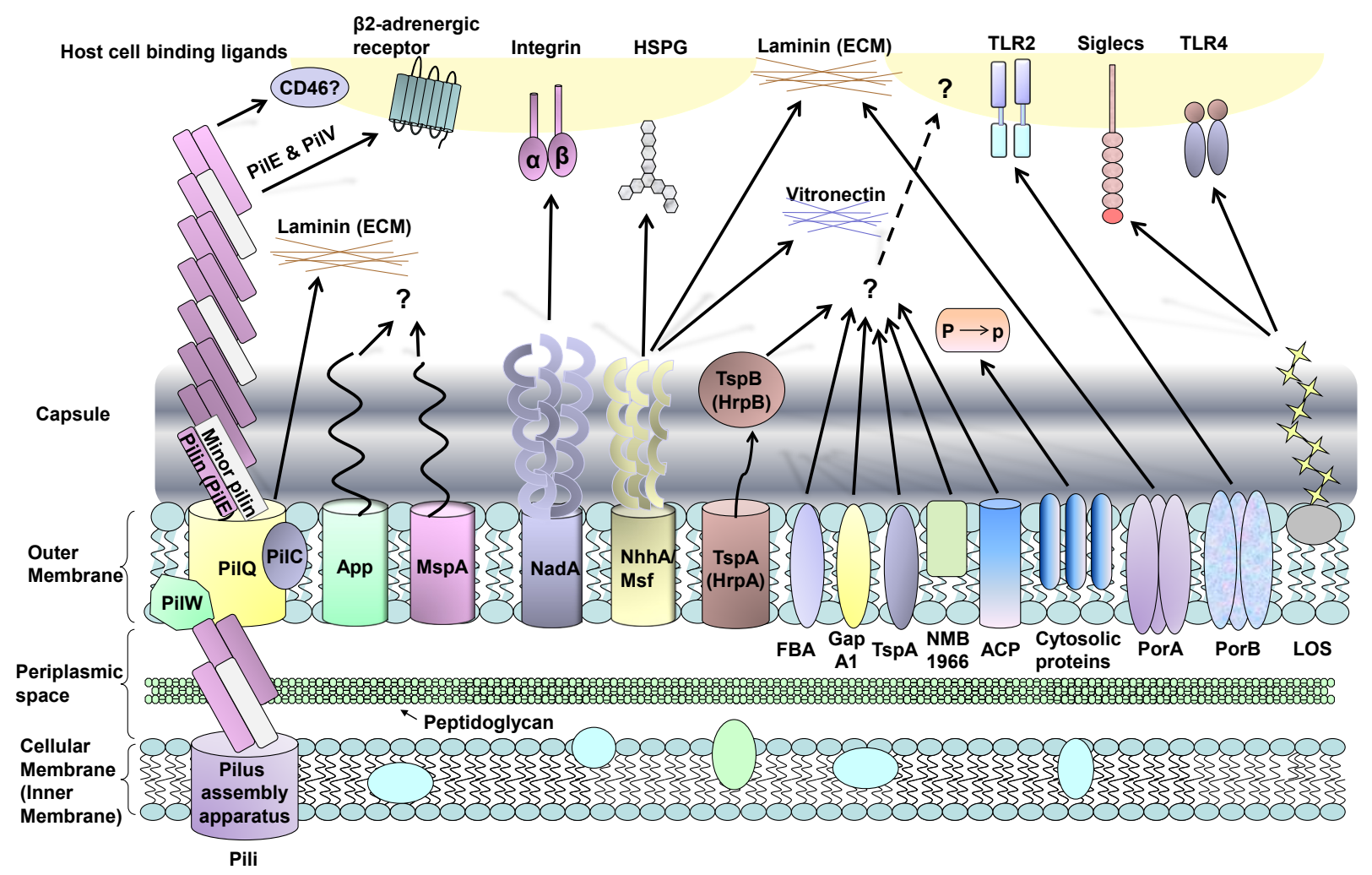


Figure 1. Cont.

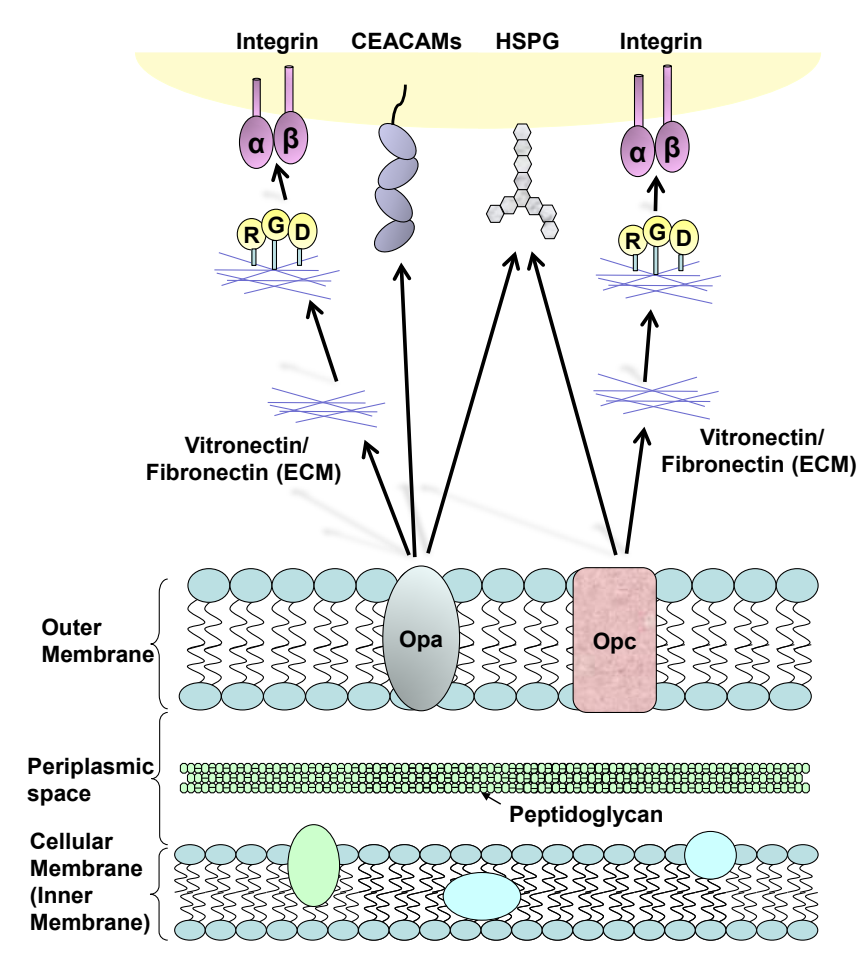

B

\subsection{Neisseria meningitidis Adherence to Nasopharyngeal Epithelial Cells}

The natural habitat of the meningococcus is the surface of the human nasopharyngeal mucous membrane and transmission is mainly through close contact. Increased bacterial cell surface and surface hydrophobicity have been suggested to correlate with increased levels of association with airway epithelial cells [195]. Once meningococci make contact with the human nasopharyngeal epithelium, there are two major steps involved in bacterial adhesion: "initial adhesion" [55] followed by "intimate adhesion" [196].

Pili are the most important adhesin during the "initial" binding of capsulated (and indeed non-capsulated) meningococci to epithelial cells [197]. After initial attachment, pili retract to bring meningococci closer to the host cells and subsequently the bacteria lose piliation [198]. The pilus tip-located protein PilC has been postulated to play an essential role in the adhesion process [199]. PilT protein is essential for the ATP-dependent pilus retraction machinery, which powers bacterial twitching motility [38,200,201]. PilT also mediates loss of piliation and progression from a localised to a diffuse pattern of adherence to epithelial cells [202]. This diffuse pattern is visible as bacteria spreading onto the apical surface of the cells and forming a monolayer, single-cell in depth. Moreover, PilT-driven pilus retraction requires down-regulation of PilC1 [64]. The nature of the target receptor for meningococcal/gonococcal pilus remains elusive. It has been suggested that pili facilitate adhesion by binding to a membrane-located human complement regulatory protein, CD46 (Membrane Cofactor Protein) [203]. Johansson et al. also demonstrated that transgenic mice expressing human CD46 are susceptible to meningococcal infection [204]. However, contradictory studies showed no correlation between the levels of CD46 isoform expression and pilus-mediated adherence of gonococci [205] and that gonococcal pili adherence to urogenital epithelial cells could occur via a CD46-independent process [206]. 
Other adhesins such as App [106], NadA [207], NhhA [122], HrpA-HrpB [129], FBA [136], GapA-1 [137], TspA [134] and ACP [142] have all been shown to mediate adhesion of capsulated bacteria. The involvement of these surface structures has been inferred from infection studies with deletion mutants and the use of purified ligands in cell binding assays. These adhesins are considered to be involved in the initial adhesion process. Regarding known host receptors, NadA binds human $\beta 1$ integrins [208] and NhhA binds laminin and heparin sulphate [122], whereas host cell receptors recognising the other adhesins have not been identified.

A role for plasminogen binding to the bacterial surface could be a contributory mechanism that enables meningococcal interactions with the nasopharyngeal mucosal epithelium. The mucous barrier contains extracellular matrix (ECM) components such as glycoproteins and proteoglycans, which are also found within submucosal tissue and as components of the basal laminae of epithelial and endothelial cell barriers. Meningococcal surface-associated components have been reported to bind plasminogen, which is then converted to enzymatically active plasmin. Significantly, this binding/activation event is not inhibited by the presence of capsule [209]. The meningococcal components identified were enolase (a $46 \mathrm{kDa}$ glycolytic enzyme), DnaK (a $67 \mathrm{kDa}$ heat shock protein) and peroxiredoxin (a $24 \mathrm{kDa}$ protein that contains domains found in reducing enzymes and electron transporters) [209]. Plasminogen conversion to plasmin on the meningococcal surface leads to plasmin-activated collagenase activity. It is possible that this activity enables the bacterium to degrade ECM components within the mucosa, thereby allowing pathogen access to epithelial cells. In addition, meningococcal survival is favoured by the proteolysis of complement and secretory IgA antibodies that are found on mucosal surfaces. Thus, plasminogen binding contributes to meningococcal adherence and survival during colonisation of the host.

Following initial adherence, the presence of capsule can sterically hinder the contribution of surface-expressed, OM-located adhesins that are required for "intimate" adhesion. In order to enable intimate contact, activation of the $\mathrm{CrgA}$ regulatory protein (that represses capsule synthesis and export) down-regulates capsule expression [196]. However, the role of CrgA in down-regulation of capsule and pilus is controversial, since other studies of the CrgA regulatory protein [210,211] could not reproduce the findings of Deghmane et al. [196]. Without the hindrance of capsule and following pilus retraction, "intimate" adhesion involves a different repertoire of adhesins, of which Opa and Opc proteins are the most dominant [212]. PilT also appears to be essential for inducing intimate attachment of meningococci, as demonstrated by infection studies in vitro with T84 intestinal epithelial cells [202].

Opa protein shows a tropism for human receptors, which fall into two major categories. Most Opa proteins bind to members of the human carcinoembryonic antigen (CEACAM) receptor family, whereas a smaller number bind to heparan sulphate proteoglycan (HSPG) [213,214], integrins, ECM proteins such as vitronectin and fibronectin [215,216] and saccharides [217]. The biology of the CEACAM receptor family is outside the scope of this review, but the interested reader is directed towards the review of Gray-Owen and Blumberg [218]. Within the CEACAM family, there is one secreted and 11 cell surface glycoproteins and of these, CEACAM 1, CEACAM3, CEACAM5 (CEA, the first member of the family [219]) and CEACAM6 bind to Neisseria Opa proteins [220-228]. CEACAM proteins are expressed on apical surfaces of polarized cells, whereas HSPGs are not. CEACAM1 is expressed by epithelial and endothelial cells, neutrophils and lymphocytes; CEACAM3 is exclusively expressed by neutrophils; CEACAM5 is found in epithelial cells of the gastrointestinal 
and urogenital tracts and CEACAM6 is expressed in different organ epithelial cells and by neutrophils. Most of the studies of Opa-CEACAM interactions have been done in vitro using cell lines transfected to express human CEACAM proteins. Although Opa interactions are most efficient in the absence of capsule, Opa-mediated interactions of capsulated bacteria have been reported [229], but only to human cells expressing a high density of CEACAM1 [222]. Thus, it is possible that capsulated meningococci can penetrate epithelial cell barriers without a need to down-regulate capsule expression.

The inflammatory milieu and viral infection can also influence Opa-mediated interactions of meningococci with epithelial cells [229,230]. Meningococcal adherence is increased when cells are exposed to IFN $\gamma$ (but not TNF- $\alpha$ or IL-1 $\beta$ ), and this is due to Opa expression acting in tandem with IFN $\gamma$ to drive de novo synthesis of CEACAM1 on the surface of epithelial cells. It has also been suggested that innate immune responses are down-regulated by Opa-CEACAM interactions. In a study with primary pulmonary epithelial cells, meningococcal Opa-CEACAM1 interactions lead to reduced

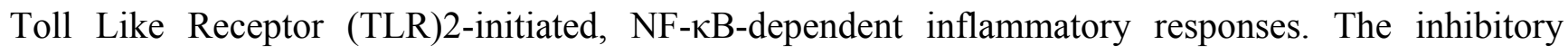
mechanism involves tyrosine phosphorylation of the ITIM (immunoreceptor tyrosine-based inhibitory motif) of CEACAM1 and by recruitment of the phosphatase SHP-1, which negatively regulates TLR2-dependent activation of the phosphatidylinositol 3-OH kinase-Akt kinase pathway [231].

Meningococci and gonococci that express Opa appear to bind to the $N$-domain region of CEACAM proteins, within the 1-108 amino acid region [221,225,227]. Opa recognition is a function of the non-glycosylated CEACAM backbone [222,232], and the binding surface is composed of the $\beta$-strands C' ', C', C, F and G and appears to require $\mathrm{Tyr}^{34}$ and $\mathrm{Ile}^{91}$ exposed residues [233]. Variation of amino acid residues 27-29 found in different CEACAMs directs differential binding of Opa to CEACAM1, 5 or 6 [227]. Specific conformational interactions between the hypervariable (HV1, HV2) regions within Opa loops appear to be necessary for binding to CEACAM [234] and despite high levels of sequence variation in Opa HV regions, the binding sites for CEACAM do show significant conservation. In studies with $N$. meningitidis strain H44/76, which expresses OpaA and OpaJ binding to CEACAM1 and OpaB and OpaD binding to CEACAM1 and CEACAM5, respectively, a comparison of the binding of hybrid variants of Opa HV1 and HV2 demonstrated the presence of a conserved binding motif in the HV2 region of all four Opa proteins [235]. This motif consists of Gly ${ }^{172}$, $\mathrm{Ile}^{174}$ and Gln ${ }^{176}$.

Opc acts independently in adhesion and invasion of meningococci into epithelial and endothelial cells [236] and the host cell receptors that recognise Opc include HSPG [237], integrin and ECM proteins [238,239]. Opc is an important adhesin that binds to the cytoskeletal protein $\alpha$-actinin of epithelial and endothelial cells after bacterial invasion [240]. Furthermore, a low expression level of Opc can allow more Opa-dependent invasion of primary nasopharyngeal cells [241]. However, it remains unclear how Opa and Opc proteins interact with each other during adhesion, or indeed invasion.

Little information is known regarding the role of other adhesins for intimate contact. Capecchi et al. demonstrated that a non-capsulated MC58 NadA deletion mutant ( $\triangle \mathrm{NadA})$ had a reduced ability to invade into Chang epithelial cells compared to wild-type MC58 [207], but there were no differences in terms of total association. GapA-1 has been shown to play a role in the association of non-capsulated MC58 to Hep-2 cells [137]. Without the presence of the capsule, pili, Opa and Opc, an MC58 ACP deletion mutant $(\triangle \mathrm{ACP})$ showed reduced association with Chang epithelial cells compared to its parent strain [142]. Whether these adhesins work in concert or independently remains to be confirmed. 
Following initial attachment, successful colonisation of epithelial cells by meningococci and adaptation to the nasopharyngeal niche requires bacterial aggregation for micro-colony formation and resistance to biophysical clearance mechanisms. Initially, PilX enables bacterial aggregation before Tfp-mediated adherence to the nasopharyngeal epithelium [68]. Tfp also form bacterial aggregates associated with host cells, and the Tfp-mediated adhesion process triggers cortical plaque formation within epithelial cells. The components of the cortical plaque include CD44v3 (a HSPG), EGFR (epidermal growth factor receptor, a receptor tyrosine kinase), CD44/ICAM-1 (adhesion molecules) and f-actin and ezrin (a component that links the membrane components to the actin cytoskeleton) [242]. In response to cross-talk with Neisseriae, the clustering of membrane proteins that correlate with cytoskeletal rearrangements has been demonstrated on host cells. This process might enable more avid binding of bacterial ligands with host cell receptors and result in greater resistance to detachment by shear stress [242]. Tfp-mediated adhesion can also contribute to a phase-variable post-translational modification, in which addition of phosphoglycerol to pili allows detachment of bacteria from the bacterial aggregates and dissemination to other sites [243]. In addition, gonococcal Tfp and PorB.1B have been reported to perturb the trafficking of lysosome-associated membrane protein (Lamp) 1 in A431 cells (derived from an epithelioid carcinoma) or T84 colorectal epithelial cells by triggering separate and distinct $\mathrm{Ca}^{2+}$-dependent exocytotic processes [244,245]. This results in bringing Lamp1 to the cell membrane, where it becomes accessible to cleavage by IgA protease.

Nasopharyngeal carriage of meningococci that is established after successful colonisation, can last, in extremis, up to 10 months [246], suggesting the possibility of biofilm existence as a mechanism to explain persistence. A biofilm is defined as an "intimately associated bacterial community included within an exopolymeric matrix" composed of lipid, polysaccharides, proteins, membrane vesicles, cell debris and extracellular DNA, with the material predominantly produced by the organism [247]. The biofilm forming process involves bacterial adherence, aggregation and microcolony formation [247,248] and this microbial community can resist mechanical forces and protect bacteria from host immunity. However, there is limited clinical evidence of meningococcal biofilm formation [249]. In the laboratory, biofilm formation on an abiotic polystyrene surface was a feature of $\sim 30 \%$ of meningococcal carriage isolates, compared to $\sim 13 \%$ of disease-causing isolates [250]. Capsulated isolates show a reduced biofilm-forming capability on abiotic surfaces [251] and pili are not required for biofilm formation. However, the importance of pili-associated proteins in biofilm formation is supported by evidence that a pilQ mutant formed biofilms that were thinner than those formed by wild-type bacteria [250]. PilX has been shown also to support biofilm formation indirectly [251]. Both capsulated and non-capsulated meningococci formed biofilms on monolayers of human bronchial epithelial cells [252]: thus, the limitation of capsulated meningococcal biofilm formation on abiotic surfaces suggests the importance of host cell factors in this process and/or a general phenomenon dependent on hydrophobic interactions with cell surfaces [253]. Additionally, surface-located HrpA plays a role in meningococcal biofilm formation on human bronchial epithelial cells [254]. Although incompletely understood, meningococcal biofilm formation depends on the functional properties of extracellular DNA, which serves to support initial attachment to the substratum and also to mechanically stabilize the growing biofilm structure [253]. The DNA for initial attachment is released during normal growth by the actions of membrane-bound enzymes such as the lytic transglycosylase A/B (MltA/B) and $\mathrm{N}$-acetylmuramyl-L-alanine amidase (AmpD), which are involved in normal physiological cell wall 
recycling [255]. However, the roles of other adhesins in meningococcal biofilm formation have not been investigated.

\subsection{Neisseria Gonorrhoeae Adhesion to the Urogenital Tract}

\subsubsection{Gonococcal Infection of the Human Lower Reproductive Tract}

In contrast to meningococci, gonococci do not express capsule or Opc protein. The major adhesins of gonococci include pili, LOS, Opa and porin. The interactions of gonococci with host epithelial cells depend on cell histology, site of infection and gender. For example, Opa ${ }^{+}$and $\mathrm{Opa}^{-}$strains are distributed in different areas of the urogenital tracts. Clinically, $\mathrm{Opa}^{+}$strains are related to more asymptomatic but invasive disease, whereas $\mathrm{Opa}^{-}$strains cause more symptomatic but non-invasive disease [256].

Gonococci primarily infect and colonise the exposed mucosal epithelium of the human reproductive tract and subtly different mechanisms of bacterial interaction have been observed between sexes. Infection of the male urethra is believed to occur in a two-step process that involves the interactions of gonococcal surface ligands with specific host cell receptors. Adherence to the urethral mucosal epithelium is mediated initially by the binding of pilus to the I-domain region of $\alpha_{1} \beta_{1}$ or $\alpha_{2} \beta_{1}$ integrins [256]. Next, the gonococcus-bearing integrin forms a transient interaction with the asialoglycoprotein receptor (ASPG-R), which leads to a tight interaction between the gonococcal and urethral cell plasmalemma membranes. In addition, ASPG-R also recognises and binds the terminal galactose of gonococcal LOS [256,257]. The evidence for this mechanism comes from infection studies using primary male urethral epithelial cells, whole urethra tissue and from examination of clinical samples of urethral exudates.

Surprisingly, the mechanism of gonococcal transmission from partner-to-partner has not been studied in great detail. However, piliated gonococci do show higher levels of adherence than non-piliated bacteria to human sperm [258] and a binding interaction between LOS and ASGP-R on the surface of sperm cells has been reported [259]. Gonococcal adherence has no deleterious effects on sperm motility or viability [260]. How gonococci detach from sperm and/or seminal fluid proteins during ejaculation and attach to partner urogenital or ano-rectal epithelial tissue is not known. Moreover, how gonococci establish an association with the mucosal epithelium in the healthy female genital tract during transmission is still unclear, particularly the mechanisms by which the organism successfully competes with an established microflora and bypasses the environmental and innate immune barriers.

In the female urogenital tract, gonococcal first-contact is with mucosal epithelial cells of the cervix and an elegant model describing the process has been described recently by Edwards and Butler [261], using information from studies of gonococcal-positive clinical biopsies and bacterial infection of human primary cervical epithelial cells (abbr. pex) in vitro. The infection process is clearly influenced by the menstrual cycle and involves the alternative complement pathway. Pex secrete all of the proteins that constitute the pathway and complement protein $\mathrm{C} 3$, in particular, is critical for the gonococcal infection process. During the luteal phase and menses, C3 is released into the environment and is converted to $\mathrm{C} 3 \mathrm{~b}$ during gonococcal infection. $\mathrm{C} 3 \mathrm{~b}$ binds to the gonococcal surface and is cleaved to form inactivated iC3b. Clinically isolated gonococci contain iC3b on their surface [262], which binds naturally to the I-domain of CR3. The human cervix expresses high levels of CR3 (the $\alpha_{\mathrm{m}} \beta_{2}$ integrin also known as CD11b/CD18) [263] and hence gonococci have been observed to co-localize 
with CR3 in vivo [263]. A glycan moiety on pilus also allows pilus binding to the CR3 I-domain and draws the gonococcus to the epithelial cell surface [264,265]. In addition, a tight association between gonococcus and receptor is effected through the interactions of $\mathrm{iC} 3 \mathrm{~b}$ and porin (PorB.1A or PorB.1B), which also bind to the CR3 I-domain [266]. CR3 engagement also results in the release of gonococcal components such as phospholipase D, which is suggested to aid colonization [261]. Furthermore, factor $\mathrm{H}$ has been reported to facilitate gonococcal adherence to eukaryotic cells by forming a "bridge" with CR3 [267].

ASPG-R receptors are present on mucosal surfaces of the female urogenital tract, but do not appear to mediate LOS-dependent gonococcal adherence to pex. In addition, Opa proteins do not mediate gonococcal association with primary epithelial cells [264,268,269]. Nevertheless, data from in vitro studies do suggest that LOS and Opa may be involved in adherence of gonococci with immortalised and/or transfected cell lines. Mutation of LOS encoded by $\lg F$ was shown to reduce gonococcal interactions with ME-180 cervical carcinoma cells in vitro, suggesting a possible role of particular LOS types for association [270]. Gonococci expressing OpaA have been shown to associate tightly with HeLa cells [271], possibly through HSPG interactions [272]. Opa interactions with HSPG require vitronectin and fibronectin ECM components, which function as a "molecular bridge" to mediate adherence with an integrin co-receptor $\left(\alpha_{v} \beta_{1}, \alpha_{v} \beta_{3}, \alpha_{v} \beta_{5}\right)$ [215,216,273]. The Opa-CEACAM interaction(s) does not require ECM component bridges and is a direct protein-protein binding event [222,233], although it is still unclear whether CEACAM-gonococcus interactions occur during cervical infection in vivo [261].

The ability of gonococci to cause asymptomatic infection raises the speculation that gonococci can persist in the female reproductive tract in biofilms. Gonococci can form biofilms in continuous-flow chambers in vitro, both on glass surfaces and on cultured human primary urogenital tract epithelial and cervical epithelial cells [274]. In the study of Greiner et al. the entire cervical epithelial cell culture was covered by a gonococcal biofilm, without obvious damage to the cells, even after eight days. Moreover, in vivo, there are reports of gonococcal biofilm formation on cervical cell biopsy specimens obtained from patients with gonococal infection and of bacterial presence on intrauterine devices [275,276]. OM blebbing appears to be essential for matrix formation and for stabilising the gonococcal biofilm structure [276]. However, little is known regarding the roles of surface adhesins/other molecules in biofilm formation and a detailed review of their composition and the metabolic phenotype of gonococcal biofilms is available elsewhere [277]. Within a biofilm, the interactions of gonococci with host cells can range from weak, leading to bacterial detachment, to persistent, which is a consequence of extracellular polymer binding. Subsequent to gonococcal adhesion, pathogen-induced activation of signalling pathways and membrane/cytoskeletal rearrangements occur in the host cells, leading to invasion. The mechanisms involved in gonococcal invasion of cervical epithelial cells are outside the scope of this review, but outlined in the comprehensive review of Edwards and Butler [261].

\subsubsection{Ascending Gonococcal Infection}

Gonococcal colonization of the cervical mucosal epithelium provides a platform for the organism to colonize exposed mucosal surfaces in the upper reproductive tract. The exact mechanisms used by 
gonococci to disseminate from the lower reproductive tract to the upper reproductive tract are not known. Fluid movement of planktonic bacteria is likely to be involved, possibly after detachment from motile ascending sperm and/or release from an established biofilm in the cervix. Ascending infection of gonococci into the body of the uterus can cause endometritis, which is possibly the transition zone between uncomplicated cervicitis and complicated PID. Gonococci have been shown to adhere to and invade transformed human endometrial adenocarcinoma cells (HEC-1B cells) [278] and primary endometrial cells [279] in vitro. Interestingly, vaginal Lactobacillus spp. can inhibit gonococcal interactions with endometrial cells [280] and Lactobacillus jensenii releases a surface protein, as yet uncharacterised, which is considered to mediate this process [281]. Gonococcal pili and Opa co-operate during adherence to and invasion of HEC-1B cells [282]. This co-operative interaction was reported to co-localise with ASPG-R and CEACAM receptors on epithelial cells of the endometrium [283], suggesting that expression of these host cell receptors is possibly important for ascending infection. In addition, OmpA protein has been shown to mediate gonococcal adhesion to human cervical carcinoma and endometrial epithelial cells in vitro [139].

Gonococcal infection can ascend further to involve the fallopian tubes (FT) and cause salpingitis and other complications of PID [284]. Gonococcal adherence to and invasion into FT epithelial cells were demonstrated using a FT explant organ culture model $[285,286]$. Specific attachment of gonococci to non-ciliated FT epithelial cells is probably mediated by pili and Opa [287]. Piliation has been reported to enhance gonococcal adherence to FT explant epithelium within $3 \mathrm{~h}$ of infection in vitro, but thereafter does not offer gonococci any advantage in colonizing the epithelial cell surface [288]. However, pilus does appear to inhibit several key elements of the initial inflammatory response, thus facilitating sustained infection of the FT [288]. Different Opa-expressing variants of $N$. gonorrhoeae show differences in attachment to FT mucosa and damage to mucosal cells [289]. Gonococcal LOS and Opa were shown to interact with TREM-2 (triggering receptor expressed on myeloid cells-2) on genitourinary and FT epithelial cells [290]. Binding of gonococcal Opa to human CEA on transgenic mouse urogenital cells has been shown to trigger expression of the transforming growth factor receptor CD105, which is a member of the transforming growth factor- $\beta 1$ receptor (TGF $\beta 1 \mathrm{R}$ ) family and affects integrin expression. The resulting activation of integrin expression could enhance cell adhesion and suppress epithelial cell exfoliation, which is used by the host as a mechanism to protect the mucosa [291]. In addition, gonococci adherent to FT epithelial cells in vitro have evolved a mechanism to protect host cells from undergoing TNF- $\alpha$-mediated apoptosis (which is responsible for FT mucosal epithelium damage) and this modulation of the host innate response probably contributes to establishment of infection [292].

Expression of PorB.1A has been observed to correlate with severe DGI [185,293,294]. PorB.1A, but not PorB.1B, mediates a phosphate-sensitive invasion mechanism [266] and a specific binding to human heat shock glycoprotein (Gp96) and the scavenger receptor (SREC) on epithelial cells during gonococcal invasion has been demonstrated [295].

\subsection{Adherence of Neisseria spp. to Endothelial Cells}

Survival of $N$. meningitidis in the blood is determined by virulence factor expression and host innate and adaptive immune mechanisms. Even if meningococci successfully enter the blood via 
micro-vessels or capillaries, they can be killed by host effector immune cells responding to the induction of a transient bacteraemia. However, if meningococci survive in the blood as a result of ineffective innate and adaptive immune responses they can multiply rapidly, disseminate to multiple organs and cause overwhelming septicaemia and/or meningitis.

Prevention of phagocytosis and binding of complement and antibody is crucial for meningococcal survival in the blood. Capsule and LOS are the most essential virulence factors that enable survival [296] and both are also associated with resistance to complement-mediated killing [297,298]. Shedding of excessive OM forming "blebs" [299] also allows meningococci to divert antibodies and complement away from the bacterial surface. LOS can cause coagulopathy, endothelial disruption and circulatory collapse [300,301]. To evade complement-mediated killing, meningococci can interact with host complement regulatory proteins to down-regulate the complement cascade (Figure 2). For example, PorA protein has been shown to bind C4bp (complement regulatory protein C4b-binding protein), the main inhibitor of the classical pathway [302]. Moreover, meningococcal factor $\mathrm{H}$ binding protein (fHbp) and NspA bind to factor $\mathrm{H}$ on human complement and down-regulate the alternative pathway [303,304]. Gonococci can also resist serum complement-mediated bactericidal activity and this mechanism is dependent on the binding of human $\mathrm{C} 4 \mathrm{bp}$ and factor $\mathrm{H}$ by porins and sialylated LOS. Within gonococcal PorB.1A, surface-exposed Loop 1 is necessary for binding to C4bp, whereas Loops 5 and 7 of PorB.1B are believed to form a negatively charged C4bp-binding domain. The binding site of PorB.1A for factor $\mathrm{H}$ has been identified on Loop 5 [305-307]. Binding of activated vitronectin by meningococcal NhhA/Msf has been reported to down-regulate the terminal phase of the complement pathway [123] and NhhA has also been shown to prevent phagocytosis and complement-mediated killing [308].

Conversely, the binding of several Neisseria components can play a role in controlling bacterial growth in the blood. Binding of meningococcal Opa and PorB proteins by the the serum collectin mannose-binding lectin (MBL) is a possible mechanism that accelerates complement activation and increases bacterial killing [309]. The core structure of gonococcal LOS can also bind MBL, but binding is reduced following LOS sialylation [310] (Figure 2).

Rapid multiplication of meningococci in the blood promotes vascular colonisation, i.e., an adherence of bacteria to luminal endothelial cells. This involves several steps: (1) initial adhesion; (2) proliferation, aggregation and formation of micro-colonies; and (3) dissemination. Pili, Opa and Opc remain the most important adhesins for pathogenic Neisseria to interact with endothelial cells. Recently, an in vivo model of human dermal microvessels introduced into SCID/Beige mice by xenografting of human skin has been used to examine meningococcal interactions with vessel endothelium in situ [311]. Type IV pili were the primary mediators of association with dermal microvessels and association was accompanied by a potent inflammatory response, the recruitment of inflammatory cells, and local vascular damage resulting in purpura. Importantly, this animal model replicates clinical presentation in human infection. Moreover, meningococci lacking pili were non-adhesive and non-inflammatory. 
Figure 2. Interaction of Neisserial surface molecules with the complement system. The interactions of Neisseria molecules with components of the human complement system can have inhibitory or stimulatory effects. (i) Lectin pathway activation: binding of meningococcal $(\mathrm{Nm})$ Opa and PorB proteins by MBL (mannose-binding lectin) is a possible mechanism that accelerates complement activation and increases bacterial killing. The core structure of LOS can also bind MBL, but binding is reduced following LOS sialylation; (ii) Classical pathway down-regulation: Nm PorA, gonococcal (Ng) PorB.1A and PorB.1B and LOS can also bind C4bp (complement regulatory protein C4b-binding protein), which is the main inhibitor of the classical pathway; (iii) Alternative pathway down-regulation: $\mathrm{Nm}$ fHbp and $\mathrm{NspA}$, LOS and $\mathrm{Ng}$ PorB.1A and PorB.1B bind to complement-inhibitory regulator serum factor $\mathrm{H}$ and down-regulate the alternative pathway. Gonococcal strains expressing PorB.1A bind factor $\mathrm{H}$ (and/or C4bp) avidly, whereas strains expressing PorB.1B bind factor $\mathrm{H}$ weakly. However, sialylation of LOS increases binding of PorB.1B to factor $\mathrm{H}$. The binding of some strains expressing PorB.1B to $\mathrm{C} 4 \mathrm{bp}$ can occur regardless of LOS sialylation.

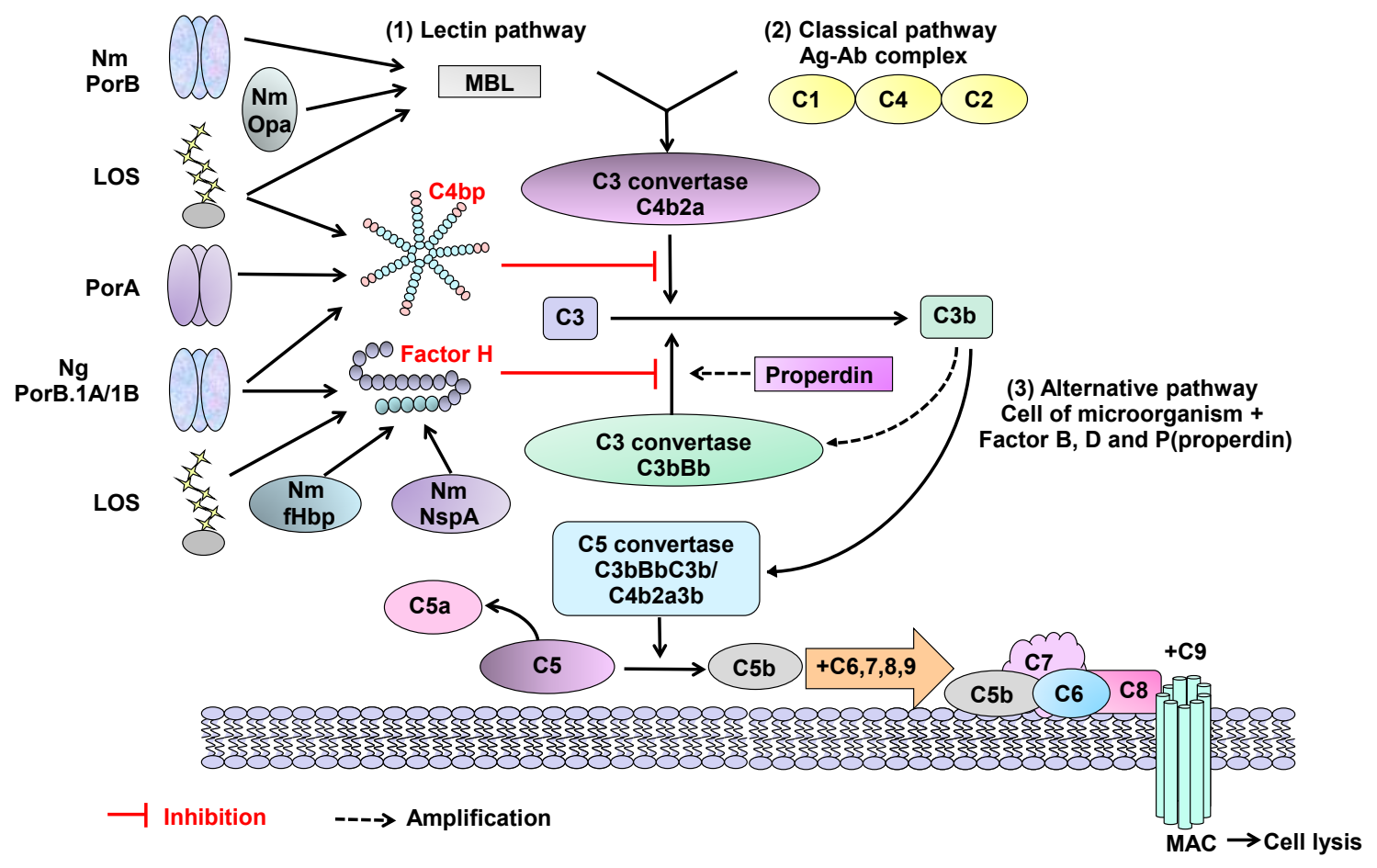

Opc is the most effective protein in increasing meningococcal interaction with human umbilical vein endothelial cells (HUVECs) [212], whereas, in contrast, an OpaB-expressing strain showed lower association with HUVECs compared to Chang epithelial cells [212]. Binding of meningococcal Opc to HUVECs is mediated through a tri-molecular complex that includes serum vitronectin and fibronectin connected to integrins in the presence of the amino acid sequence arginine-glycine-aspartic acid (RGD) "bridge" [238]. Similar findings using human brain microvascular endothelial cells (HBMEC) have also been reported [239]. The integrin receptors for vitronectin and fibronectin are $\alpha_{v} \beta_{3}$ and $\alpha_{5} \beta_{1}$, respectively. Sulphated tyrosines of activated vitronectin have been identified as the targets of Opc binding for adherence to and subsequent invasion of HBMEC [312]. CEACAM1 is also found on endothelial cells and therefore a likely target for Opa-binding: indeed, as a consequence of meningococcal 
(and indeed gonococcal) stimulation of TNF $\alpha$ during intravascular dissemination, CEACAM1 expression is found in increased levels on endothelial cells [228,313]. As expected, binding of Opa-expressing Neisseriae to endothelial surfaces is dramatically increased.

Other adhesins are involved in endothelial cell interactions, although the recognition receptors are not known. FBA and GapA-1 mediate association of meningococci to HBMEC in a capsule-independent manner [137]. Hung et al. also demonstrated that meningococcal ACP mediates adhesion to HUVECs, independent of capsulation [142]. MspA can mediate adhesion to human bronchial epithelial cells and HBMEC, but this study was done using E. coli expressing MspA rather than with Msp-expressing meningococci [107]. Comparative studies of MC58 $\Delta \mathrm{MspA}$ and wild-type bacterial interactions would confirm if MspA is important for meningococcal adhesion to human cells.

The ability to resist shear stress in the blood flow is a requirement for meningococcal adherence to endothelial cells. Soyer and Dumenil have defined shear stress as the "tangential force exerted per unit area by a fluid moving near a stationary wall" [314]. PilV was shown to trigger plasma membrane reorganisation and to recruit cholesterol to form filopodia in endothelial cells, a mechanism that leads to enhanced micro-colony cohesion. These lipid rafts enable meningococci to form membrane protrusions on the endothelial surface and to secure the micro-colony from shear stress [315]. Recently, meningococcal PilE and PilV have been reported to bind the $\beta 2$-adrenoceptor/ $\beta$-arrestin pathway in order to enable meningococci to cross the brain microvasculature endothelium [316]. However, meningococcal adherence to epithelial cells does not involve the PilE/PilV: $\beta 2$-adrenoceptor/ $\beta$-arrestin binding events [317]. PilX plays a role in conformational changes of meningococcal Tfp during signalling to endothelial cells [318].

As one would expect from the absence of significant case reports of DGI, little is known regarding the interactions of gonococci with vascular endothelial cells. Virji et al. demonstrated that gonococcal pili are important for adhering to HUVECs and that pili variants showed differences in the extent of adhesion [319]. Both purified gonococcal and meningococcal PilC proteins were shown to bind HUVECs [320]. In addition, different gonococcal Opa proteins display different affinities in binding to CD66 (CEACAM) receptors, which could contribute to conferring cell tropism [226,321].

\subsection{Interactions of Neisseriae with Immune Effector Cells}

Once in the blood, meningococci (and gonococci during disseminated infection) interact with immune effector cells, including neutrophils, monocytes, macrophages, dendritic cells and $\mathrm{B}$ and $\mathrm{T}$ cells. There is a significant amount of knowledge regarding Neisseria interactions with neutrophils, which are facilitated by the down-regulation of sialic acid on LOS and capsule [322]. Originally, Opa proteins were called "leucocyte association proteins" [323] and hence the majority of Opa-expressing Neisseria interact with neutrophils. As with non-myeloid cells, Opa mediates "intimate" interactions with neutrophils, and some protein variants are involved in adherence, whereas others promote phagocytosis. Recently, the Tfp of pathogenic Neisseria have been shown to mediate adhesion to the uropod of polarized neutrophils. This binding was PilC1/PilC2-dependent for meningococci, but not for gonococci [324]. Gonococci within gonorrhoeal exudates are observed attached and within neutrophils and bacterial attachment is effected by the co-operative interactions of Opa, pili, porin and LOS [325]. LOS modifications that are known to influence Neisseria interactions with host cells, 
including neutrophils, are phosphoethanolamine (PEA) substitution on lipid A or oligosaccharide, and sialylation of the oligosaccharide terminal Galb1-4GlcNac epitopes. For further details regarding the interactions between pathogenic Neisseria and neutrophils, including Opa-CEACAM1, 3 and 6 interactions, phagocytic uptake of both meningococci and gonococci and stimulation of bactericidal oxidative burst response, the reader is referred to the excellent reviews from Sadarangani and colleagues [326], Johnson and Criss [325] and Criss and Seifert [327].

Studies with purified, but non-native conformational PorA, PorB, Opa and Opc from meningococci show that Opa induces the strongest T-lymphocyte proliferative responses in vitro [328]. However, conflicting data have been obtained using Opa in its native conformation, as presented in OMV and on whole bacteria. For example, the activation and proliferation of CD4+ T-lymphocytes to various stimuli in vitro is abrogated by treatment with Opa-containing OMV from meningococci and the effect is due to Opa binding to CEACAM1 [329]. Furthermore, Opa present on whole gonococci has been reported to suppress CD4+ T-lymphocyte activation and proliferation through the same CEACAM1 binding event [330]. A possible mechanism to explain Opa-mediated inhibition of CD4+ T-lymphocytes has been described by Sadarangani et al [326]: normally, T-cell activation occurs when antigen presented with MHC Class II by antigen-presenting cells, is bound by the T-cell receptor, leading to Src kinase stimulation, which phosphorylates cytoplasmic tyrosine residues of CEACAM1 and activates downstream signalling pathways. However, binding of Opa to CEACAM1 recruits the tyrosine phosphatases SHP-1 and SHP-2, which dephosphorylate CEACAM1, the T-cell receptor and intracellular signalling pathway proteins, leading to inhibition of T-cell activation. It is not clear whether Opa-induced activation or inhibition of T-cell responses occurs in vivo; despite the fact that antibodies to Opa are observed after natural meningococcal infection or vaccination (albeit with wide variation in antibody levels) [331], the potential ability to down-regulate immune responses is not an attractive quality for a vaccine antigen. It has also been suggested that gonococcal Opa-CEACAM1 interactions inhibit B lymphocyte antibody production by inducing cell death [332], although (Opa-dependent) gonococcal association per se could be a significant inducer of cell death, rather than a consequence of the specific ligand-host cell receptor interaction.

Although not important as adhesion events that enable bacterial colonization, activation of immune effector cells has been reported for other Neisseria ligands: purified recombinant PorA protein can activate monocyte-derived dendritic cells and direct T-cell differentiation towards a Th2 type response [333], NadA can stimulate inflammatory cytokine production by human monocyte-macrophages [334] and NhhA can induce apoptosis of macrophages [335]. Recently, whole meningococci have been reported to bind to galectin-3 and increase interaction with phagocytic cells [336]. LOS sialylation can lead to increased susceptibility to host clearance mechanisms: in this context, the interaction between LOS and sialic acid-binding immunoglobulin-like lectins (siglecs), which are expressed predominantly in the cells of the haemopoietic and immune systems, are important. Sialoadhesin (Sn, siglec-1) and siglec-5 bind to terminal NeuAca2,3Gal on meningococcal LOS and have been shown to contribute to increased macrophagocytosis of bacteria [337]. In addition, the class A scavenger receptor on macrophages can bind to meningococcal proteins NMB1220, NMB0278, and NMB0667 [338] and enhance bacterial uptake. Serum C-reactive protein can also bind to phosphorylcholine on meningococcal pili and increase opsonophagocytic uptake by macrophages and neutrophils [339]. 
However, there is a significant amount of knowledge regarding immune effector cell activation by Neisseria occurring through the repertoire of known host cell TLRs. TLR recognition of Neisseria-associated molecular patterns (NAMPs) plays a critical role in host innate and inflammatory defence against infections caused by these organisms. Several NAMP-TLR interactions have been reported and most studies have focused on LOS/LPS and porin B interactions with both myeloid and non-myeloid cells. In general, cell activation in response to Gram-negative LPS depends on sequential LPS interactions with LPS-binding protein (LBP), CD14, MD-2 and TLR4. Endotoxin lipid A interacts directly with MD-2 to activate TLR4 and there is a correlation between variations in the structure of the lipid A, which can influence the binding affinity of meningococcal LOS for human recombinant MD-2 and the subsequent activation of TLR4 that leads to cytokine production by human macrophages [340,341]. Recently, three-dimensional molecular simulations have been used to identify and characterize the interactions between TLR4-MD-2 with meningococcal and E. coli LPS molecules, which control TLR4 dimerization. Significantly, differences in the surface structure of the MD-2-LPS complex correlate with the ability of variably acylated LPS molecules to activate the innate immune system via TLR4 [342]. Conversely, inhibition of inflammation can be observed following a LPS-TLR4 interaction, but this is dependent on negative regulation by CEACAM1. Treatment of neutrophils with LPS has been reported to trigger the formation of a TLR4-pSyk-CEACAM1 complex, and subsequent recruitment of SHP-1 to the CEACAM1 ITIMs inhibits the production of IL-1 $\beta$ by the inflammasome [343]. This mechanism bears an interesting similarity with Opa-CEACAM down-regulation of other innate immune responses.

Activation by non-LPS NAMPs has also been reported to occur through TLR4 (Table 2), although this interpretation must be tempered by consideration of the presence of contaminating LPS in any of the preparations. Generally, bacterial proteins/lipoproteins are believed to interact with TLR2, or TLRs other than TLR4. The meningococcal porin B protein has been extensively studied and binds directly to a TLR2-TLR1 heterodimer [344,345], which mediates cell activation and protects cells from apoptosis. PorB can act through TLR2 as a B-cell mitogen [346] and porin-induced dendritic cell activation is MyD88 and TLR2 dependent [347].

Table 2. Role of TLRs in the recognition of Neisseria molecules.

\begin{tabular}{ccc}
\hline Neisseria ligand & TLR, cell expression and host response & Reference \\
\hline Neisseria LPS & TLR4 & See text for details \\
Neisseria PorB & TLR2 & See text for details \\
Meningococcal NhhA & TLR4 activation in macrophages & {$[348]$} \\
Product of meningococcal NMB1468 (Ag-473) & TLR4 activation in bone marrow-derived dendritic cells & {$[349]$} \\
Meningococcal penicillin-binding proteins & TLR4 activation of dendritic cells & {$[350]$} \\
Meningococcal recombinant NadA(A351-405) & Binds to monocyte HSP90 and forms a transducing & {$[351]$} \\
Meningococcal CPS & complex of HSP90/HSP70/TLR4 & {$[352]$} \\
Meningococcal membrane-associated proteins & Macrophage recognition via TLR2- and & TLR4-MD-2 pathways. \\
(LPS ${ }^{-}$background) & Activate TLR2-CD14 in monocytes/macrophages & {$[353,354]$} \\
\hline
\end{tabular}


The $N$. lactamica PorB is also a TLR2 ligand, but its binding specificity for TLR2 is different from that of meningococcal PorB, and it induces lower inflammatory responses [356]. Recently, the resolved crystal structure of PorB ( $2.3 \AA$ resolution) suggests that TLR2-mediated recognition may be initiated by a non-specific electrostatic attraction [191]. Toussi and colleagues identified amino acid residues present in Loops 5 and 7 of meningococcal PorB that influenced TLR2 interactions, but conceded that the surface-exposed loops were not uniquely responsible for PorB-TLR2 interactions, and proposed the presence of a hypothetical "TLR2-binding signature" within the loops [357].

\subsection{Interaction of Neisseria with the Meninges}

The exact mechanism by which Neisseria spp. enter the CSF-filled subarachnoid space (SAS) compartment to induce meningitis is not known. The blood-brain barrier (BBB) in this context is less relevant than the blood-CSF barrier (BCSFB), as bacteria do not seem to invade the brain parenchyma. One route of entry for bacteria into the CSF could be through the choroid plexus, but although meningococci adhere to the endothelium of choroid plexus capillaries [358], it is unclear how bacteria would penetrate the choroid plexus epithelium. Meningococci were not detected inside or between choroidal epithelial cells [358], suggesting that bacteria are unable to penetrate the tight junctions of the choroidal epithelium. A recent study of intranasally infected mice, has suggested that meningococci can pass directly from the nasopharynx to meninges through the olfactory nerve system in the absence of bacteraemia [359]. However, bacteraemia is normally a prerequisite for meningococcal invasion into the CSF and it is more likely that thin-walled veins in the SAS are the primary routes of entry for bacteria into the SAS [360]. Furthermore, it is probable that bacteria enter the CSF and SAS through the same pathways that polymorphonuclear leucocytes take from the blood to the CSF. Meningococcal pili have been shown to maintain adherence to cerebral endothelial cells under high flow conditions in vitro [361] and PilQ and PorA proteins have been identified as ligands for the 37/67-kDa laminin receptor on the surface of rodent and human BMEC [362]. Subsequently, internalised meningococci might reach the meninges via transcytosis or disruption of intercellular junctions [51].

Although the molecular basis of the interactions that occur between Neisseria spp. and human epithelial, endothelial and immune effector cells have been studied in detail, little is known on the events that occur within the SAS after bacterial entry. The interactions of Neisseria spp. with cells of the leptomeninges (i.e., the arachnoid mater, pia mater and trabeculae that traverse the SAS) play a fundamental role in meningitis. Animal models have been described for studying the pathological consequences that occur following the interactions between bacteria and the meninges, but there are significant anatomical differences between the human leptomeninges and the meninges in experimental animals [360]. Arachnoid trabeculae are absent in the mouse leptomeninx, the SAS is restricted in rodents and zonula adhaerens are present between rat arachnoid cells, whereas desmosomal junctions are found in humans. Moreover, the culture of primary human leptomeningeal cells as a surrogate in vitro model is unreliable [363]. Thus, information on the nature of the Neisseria ligands mediating binding to the leptomeninges has been collected from in vitro studies using frozen human brain tissue samples and cultured primary meningioma cells.

Meningioma cells are derived from benign tumours (meningiomas) of the human leptomeninges and they share the same morphology, cytological structure and expression of cell markers (desmosomal 
desmoplakin, cytokeratin, vimentin and epithelial membrane antigen) as normal leptomeningeal cells [363-365]. The capsulated and piliated phenotype of $N$. meningitidis, which is normally isolated from the CSF [299], shows a specific predilection for binding to the leptomeninges and meningeal blood vessels but not to the cerebral cortex [366]. Meningococci adhere similarly to meningioma cells in culture [366]. Notably, $N$. gonorrhoeae and the commensal $N$. lactamica also adhere to the leptomeninges and meningioma cells [367], which is unsurprising, since leptomeningitis caused by these organisms has been reported to occur as a rare event during disseminated infection $[368,369]$.

The major surface ligand that mediates adherence of meningococci to the leptomeninges and meningioma cells is the pilus [366]. Although the levels of adherence are similar for bacteria expressing either Class I or Class II pili, variation in Class I pilin influences the ability of piliated meningococci to interact with leptomeningeal cells, which has also been observed with epithelial and endothelial cells [370,371]. Meningococci expressing $\mathrm{Pil}_{\mathrm{Ib}}{ }^{+}$show significantly reduced association to both fresh human brain sections and meningioma cells, compared to $\mathrm{Pil}_{\mathrm{Ia}}{ }^{+}$expressing bacteria. How pilin variation influences the adherence of meningococci to leptomeningeal cells is unclear, but variable expression of the PilC1 protein is not a factor and neither the presence nor the absence of capsule interferes with $\mathrm{Pil}_{1 \mathrm{a}}$-mediated adherence [366]. It is possible that post-translational modifications of pilin molecules [372,373], or the ability to form bundled pili [374], are important. Expression of Opa protein does not influence the ability of capsulated meningococci expressing high affinity $\mathrm{Pil}_{1 \mathrm{a}}$ to adhere, but Opa protein expression does increase the adherence of meningococci that express the low adhesive pilin $\mathrm{Pil}_{1 \mathrm{~b}}$ [366]. In contrast, Opc protein does not play a role in meningococcal adhesion to meningioma cells. The role of other meningococcal adhesins for interacting with meningeal cells is not clear. In one study, decreased association of a TspA mutant of MC58 with meningioma cells has been reported, but the data were not shown [134]. More recently, ACP protein has been shown to mediate adherence of capsulated meningococci to meningioma cells in vitro [142]. In addition, during meningococcal meningitis, innate recognition of both LPS and non-LPS modulins is dependent on the expression of non-TLR pattern recognition receptors on cells of the meninges [375].

\section{Conclusions}

Bacterial adhesion to eukaryotic cells is a critical step in colonization, whether we consider the natural commensal flora or the introduction of competing species with pathogenic potential. A great wealth of knowledge is now available on the biology of Neisseria adhesins and the target human cell receptors as well as the molecular bases of their interactions. Despite a vast literature, our understanding of Neisseria adhesion to human cells and the host response to bacterial contact is still incomplete. In this review we have focused specifically on the structure and biology of Neisseria adhesins and the nature of the Neisseria ligand-host cell receptor interactions, but we have not discussed in detail the changes that occur to both the bacterium and the host cell as a consequence of adhesion. In-depth analyses of these changes are outside the scope of this review, but initial contact is known to stimulate global gene transcription for both Neisseria and host cells [376-380]. Membrane dynamics are altered with significant remodelling of the bacterial OM and host cell plasmalemma and the recruitment of host cell proteins. Contact also stimulates signalling pathways (signalosomes) in both the bacterium and host cell. Although these mechanisms remain incompletely understood, several 
excellent reviews that consider modulation of Neisseria and host cell biology after adhesion are recommended reading [51,163,381-386].

Why do Neisseria spp. have so many adhesins? Redundancy of adhesins may be a well-designed strategy for Neisseria to evade host immunity during either colonization or invasive disease. Generating the repertoire of known adhesins has also encouraged studies of their vaccine potential, although the (hyper-)variability and phase variation of many of these adhesins, e.g., pili and Opa proteins, likely precludes their use. However, meningococcal ligands that bind human cells but show greater sequence conservation, e.g., NadA and fHbp, are already included in the first generation of potentially “universal” vaccines, i.e., Bexsero ${ }^{\circledR}$ [387] and rLP2086 [388]. Other adhesins are also likely to be promising vaccine candidates that merit further study, in particular for the development of second-generation "universal" meningococcal vaccines and for re-energizing research into gonococcal vaccines, which has been intractable for decades. Understanding the biology of Neisseria adhesins could also lead to the development of anti-adhesin strategies, based on interrupting bacterial ligand-receptor interactions, but such strategies are still in their infancy.

A perusal of Table 1 highlights our lack of knowledge on the interactions of commensal Neisseria organisms; in particular, how important are these organisms in niche occupation within the microbiomes of the respiratory (and possibly urogenital) tracts? Are these microbiomes stable or dynamic (due to continual horizontal intra- and inter-species gene transfer) and do commensal species use the same adhesion mechanisms, e.g., the detection of Opa-CEACAM binding in N. subflava (strain C450) [87]; or the expression of Tfp and other adhesins? Indeed, comparative genomics of commensal Neisseria spp. has revealed that these organisms share a large repertoire of virulence-associated alleles with meningococci and gonococci and also with other bacterial genera [130,389]. Moreover, amongst the commensal organisms, the largest set of virulence-associated alleles is found in N. lactamica. Thus, the genetic propensity for causing disease is available to commensals and diseases are occasionally reported (Table 1). Although commensal Neisseria contain genes encoding virulence factors, they probably do not normally express the profile of virulence-associated proteins required for infection. If commensal organisms and obligate pathogens share similar adhesins, would vaccines containing adhesin proteins influence the stability of the Neisserial commensal flora? Does this even matter? Indeed, how do adhesion mechanisms used by obligate pathogens allow these organisms to successfully compete with the commensal flora? Conversely, can commensal organisms be used to out-compete pathogens, as recently reported in studies of $N$. lactamica acquisition interfering with subsequent colonization by meningococci [390]?

In conclusion, the evolution of specific Neisseria adhesins that enable primary colonization and subsequent maintenance of a commensal state or transient carriage is in many respects driven by a compliant host (Figure 3). The biological relevance of this compliance reflects homeostasis between the bacterial flora and host immune selection pressures. Nevertheless, what is certain is that adhesins expressed by the pathogenic Neisseria provide these organisms with the potential for host-to-host transmission, which is essential for survival of the species. Defining the roles played by Neisseria adhesins in pathogenesis present new opportunities for developing strategies to combat Neisseria infections. 
Figure 3. The interplay between Neisseria adhesins/virulence factors, host immune status and mucosal environment determine host colonisation or infection.

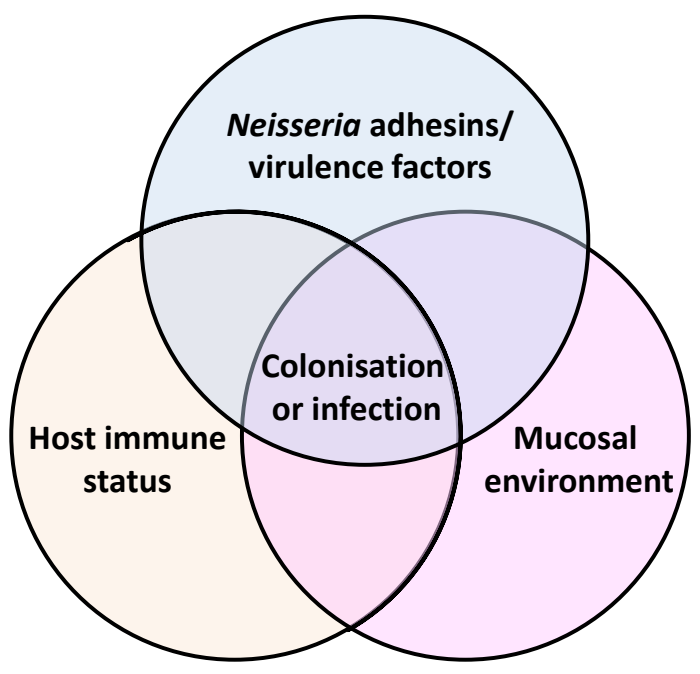

\section{Acknowledgements}

MC Hung is a Meningitis UK-funded postdoctoral research fellow (Grant 6015). Neisseria gonorrhoeae work in our laboratory is supported by the Wellcome Trust (Grant 090301). We are grateful to the reviewers of this manuscript for their thoughtful suggestions and comments and for ensuring accuracy, especially as the published literature on Neisseria interactions can be overwhelming and still continues to grow.

\section{Conflict of Interest}

The authors declare no conflict of interest.

\section{References}

1. Weichselbaum, A. Ueber die Aetiologie der akuten meningitis cerebro-spinalis. Fortschr. Med. 1887, 5, 573-583; 620-626.

2. Marchiafava, E.; Celli, A. Spra i micrococchi della meningite cerebrospinale epidemica. Gazzetta Osp. 1884, 5, 59 .

3. Heubner, J.O.L. Beobachtungen und versuche über den meningokokkus intracellularis (Weichselbaum-Jaeger). Jb Kinderheilk 1896, 43, 1-22.

4. Kiefer, F. Zur differentialdiagnose des erregers der epidemischen cerebrospinal-meningitis und der gonorrhoe. Berl. Klin. Wochenschr. 1896, 33, 628-630.

5. Goodwin, M.E.; von Sholly, A.I. The frequent occurrence of meningococci in the nasal cavities of meningitis patients and of those in direct contact with them. Public Health Pap. Rep. 1905, 31, 21-34.

6. Sommerstein, R.; Ramsay, D.; Dubuis, O.; Waser, S.; Aebersold, F.; Vogt, M. Fatal Neisseria sicca endocarditis. Infection 2013, 41, 747-749. 
7. Jung, J.J.; Vu, D.M.; Clark, B.; Keller, F.G.; Spearman, P. Neisseria sicca/subflava bacteremia presenting as cutaneous nodules in an immunocompromised host. Pediatr. Infect. Dis. J. 2009, $28,661-663$.

8. Hsiao, J.F.; Lee, M.H.; Chia, J.H.; Ho, W.J.; Chu, J.J.; Chu, P.H. Neisseria elongata endocarditis complicated by brain embolism and abscess. J. Med. Microbiol. 2008, 57, 376-381.

9. Vandamme, P.; Holmes, B.; Bercovier, H.; Coenye, T. Classification of centers for disease control group eugonic fermenter (EF)-4a and EF-4b as Neisseria animaloris sp. nov. and Neisseria zoodegmatis sp. nov., respectively. Int. J. Syst. Evol. Microbiol. 2006, 56, 1801-1805.

10. Han, X.Y.; Hong, T.; Falsen, E. Neisseria bacilliformis sp. nov. isolated from human infections. J. Clin. Microbiol. 2006, 44, 474-479.

11. Masliah-Planchon, J.; Breton, G.; Jarlier, V.; Simon, A.; Benveniste, O.; Herson, S.; Drieux, L. Endocarditis due to Neisseria bacilliformis in a patient with a bicuspid aortic valve. J. Clin. Microbiol. 2009, 47, 1973-1975.

12. Abandeh, F.I.; Balada-Llasat, J.M.; Pancholi, P.; Risaliti, C.M.; Maher, W.E.; Bazan, J.A. A rare case of Neisseria bacilliformis native valve endocarditis. Diagn. Microbiol. Infect. Dis. 2012, 73, $378-379$.

13. Lee, M.Y.; Park, E.G.; Choi, J.Y.; Cheong, H.S.; Chung, D.R.; Peck, K.R.; Song, J.H.; Ko, K.S. "Neisseria skkuensis" sp. nov., isolated from the blood of a diabetic patient with a foot ulcer. J. Med. Microbiol. 2010, 59, 856-859.

14. Wolfgang, W.J.; Carpenter, A.N.; Cole, J.A.; Gronow, S.; Habura, A.; Jose, S.; Nazarian, E.J.; Kohlerschmidt, D.J.; Limberger, R.; Schoonmaker-Bopp, D.; et al. Neisseria wadsworthii sp. nov. and Neisseria shayeganii sp. nov., isolated from clinical specimens. Int. J. Syst. Evol. Microbiol. 2011, 61, 91-98.

15. Wolfgang, W.J.; Passaretti, T.V.; Jose, R.; Cole, J.; Coorevits, A.; Carpenter, A.N.; Jose, S.; van Landschoot, A.; Izard, J.; Kohlerschmidt, D.J.; et al. Neisseria oralis sp. nov. isolated from healthy gingival plaque and clinical samples. Int. J. Syst. Evol. Microbiol. 2013, 63, 1323-1328.

16. Veron, M.; Lenvoise-Furet, A.; Coustere, C.; Ged, C.; Grimont, F. Relatedness of three species of "false Neisseriae," Neisseria caviae, Neisseria cuniculi, and Neisseria ovis, by DNA-DNA hybridizations and fatty acid analysis. Int. J. Syst. Bacteriol. 1993, 43, 210-220.

17. Initiative for Vaccine Research (IVR). Bacterial Infections-Meningococcal Disease. Available online: http://www.who.int/vaccine_research/diseases/soa_bacterial/en/index1.html/ (accessed on 1 July 2013).

18. Stephens, D.S. Conquering the meningococcus. FEMS Microbiol. Rev. 2007, 31, 3-14.

19. Vieusseux, M. Memoire sur la maladie qui a regne a Geneve au printemps de 1805. J. Med. Chir. Pharmacol. 1805, 11, 163-182.

20. Wolf, R.E.; Birbara, C.A. Meningococcal infections at an army training center. Am. J. Med. 1968, 44, 243-255.

21. Apicella, M.A. Neisseria meningitidis. In Mandell, Douglas, and Bennett's Principles and Practice of Infectious Diseases, 7th ed.; Mandell, G.L., Douglas, R.G., Bennett, J.E., Dolin, R., Eds.; Elsevier/Churchill Livingstone: Philadelphia, PA, USA, 2010; Chapter 211, pp. 2737-2752. 
22. Brandtzaeg, P.; van Deuren, M. Classification and Pathogenesis of Meningococcal Infections. In Neisseria meningitidis: Advanced Methods and Protocols; Christodoulides, M., Ed.; Humana Press: New York, NY, USA, 2012; Chapter 4, pp. 21-35.

23. Stephens, D.S.; Greenwood, B.; Brandtzaeg, P. Epidemic meningitis, meningococcaemia, and Neisseria meningitidis. Lancet 2007, 369, 2196-2210.

24. Rosenstein, N.E.; Perkins, B.A.; Stephens, D.S.; Popovic, T.; Hughes, J.M. Meningococcal disease. N. Engl. J. Med. 2001, 344, 1378-1388.

25. Brasier, A.R.; Macklis, J.D.; Vaughan, D.; Warner, L.; Kirshenbaum, J.M. Myopericarditis as an initial presentation of meningococcemia. Unusual manifestation of infection with serotype W135. Am. J. Med. 1987, 82, 641-644.

26. Varon, J.; Chen, K.; Sternbach, G.L. Rupert waterhouse and carl friderichsen: Adrenal apoplexy. J. Emerg. Med. 1998, 16, 643-647.

27. Girard, M.P.; Preziosi, M.P.; Aguado, M.T.; Kieny, M.P. A review of vaccine research and development: Meningococcal disease. Vaccine 2006, 24, 4692-4700.

28. Fellick, J.M.; Sills, J.A.; Marzouk, O.; Hart, C.A.; Cooke, R.W.; Thomson, A.P. Neurodevelopmental outcome in meningococcal disease: A case-control study. Arch. Dis. Child. 2001, 85, 6-11.

29. Koomen, I.; van Furth, A.M.; Kraak, M.A.; Grobbee, D.E.; Roord, J.J.; Jennekens-Schinkel, A. Neuropsychology of academic and behavioural limitations in school-age survivors of bacterial meningitis. Dev. Med. Child. Neurol. 2004, 46, 724-732.

30. Initiative for Vaccine Research (IVR). Sexually Transmitted Diseases - Gonorrhoea. Available online: http://www.who.int/vaccine_research/diseases/soa_std/en/index $2 . h t m l /$ (accessed on 1 July 2013).

31. Marrazzo, J.M.; Handsfield, H.H.; Sparling, F.P. Neisseria gonorrhoeae. In Mandell, Douglas, and Bennett's Principles and Practice of Infectious Diseases, 7th ed.; Mandell, G.L., Douglas, R.G., Bennett, J.E., Dolin, R., Eds.; Elsevier/Churchill Livingstone: Philadelphia, PA, USA, 2010; Chapter 212, pp. 2753-2769.

32. Miller, W.C.; Ford, C.A.; Morris, M.; Handcock, M.S.; Schmitz, J.L.; Hobbs, M.M.; Cohen, M.S.; Harris, K.M.; Udry, J.R. Prevalence of chlamydial and gonococcal infections among young adults in the United States. JAMA 2004, 291, 2229-2236.

33. Kahn, R.H.; Mosure, D.J.; Blank, S.; Kent, C.K.; Chow, J.M.; Boudov, M.R.; Brock, J.; Tulloch, S. Chlamydia trachomatis and Neisseria gonorrhoeae prevalence and coinfection in adolescents entering selected US juvenile detention centers, 1997-2002. Sex. Transm. Dis. 2005, 32, 255-259.

34. Fleming, D.T.; Wasserheit, J.N. From epidemiological synergy to public health policy and practice: The contribution of other sexually transmitted diseases to sexual transmission of HIV infection. Sex. Transm. Infect. 1999, 75, 3-17.

35. CDC. Update to CDC's Sexually transmitted diseases treatment guidelines, 2010: Oral cephalosporins no longer a recommended treatment for gonococcal infections. MMWR Morb. Mortal. Wkly. Rep. 2012, 61, 590-594.

36. Campos-Outcalt, D. CDC update on gonorrhea: Expand treatment to limit resistance. J. Fam. Pract. 2011, 60, 736-740. 
37. Strom, M.S.; Lory, S. Structure-function and biogenesis of the type IV pili. Annu. Rev. Microbiol. 1993, 47, 565-596.

38. Merz, A.J.; So, M.; Sheetz, M.P. Pilus retraction powers bacterial twitching motility. Nature 2000, 407, 98-102.

39. Fussenegger, M.; Rudel, T.; Barten, R.; Ryll, R.; Meyer, T.F. Transformation competence and type-4 pilus biogenesis in Neisseria gonorrhoeae-A review. Gene 1997, 192, 125-134.

40. Virji, M.; Heckels, J.E. Antigenic cross-reactivity of Neisseria pili: Investigations with type- and species-specific monoclonal antibodies. J. Gen. Microbiol. 1983, 129, 2761-2768.

41. Perry, A.C.; Nicolson, I.J.; Saunders, J.R. Neisseria meningitidis C114 contains silent, truncated pilin genes that are homologous to Neisseria gonorrhoeae pil sequences. J. Bacteriol. 1988, 170, 1691-1697.

42. Hitchcock, P.J. Unified nomenclature for pathogenic Neisseria species. Clin. Microbiol. Rev. 1989, 2, S64-S65.

43. Virji, M.; Heckels, J.E.; Potts, W.J.; Hart, C.A.; Saunders, J.R. Identification of epitopes recognized by monoclonal antibodies SM1 and SM2 which react with all pili of Neisseria gonorrhoeae but which differentiate between two structural classes of pili expressed by Neisseria meningitidis and the distribution of their encoding sequences in the genomes of Neisseria spp. J. Gen. Microbiol. 1989, 135, 3239-3251.

44. Aho, E.L.; Keating, A.M.; McGillivray, S.M. A comparative analysis of pilin genes from pathogenic and nonpathogenic Neisseria species. Microb. Pathog. 2000, 28, 81-88.

45. Aho, E.L.; Urwin, R.; Batcheller, A.E.; Holmgren, A.M.; Havig, K.; Kulakoski, A.M.; Vomhof, E.E.; Longfors, N.S.; Erickson, C.B.; Anderson, Z.K.; et al. Neisserial pilin genes display extensive interspecies diversity. FEMS Microbiol. Lett. 2005, 249, 327-334.

46. Higashi, D.L.; Biais, N.; Weyand, N.J.; Agellon, A.; Sisko, J.L.; Brown, L.M.; So, M. $N$. elongata produces type IV pili that mediate interspecies gene transfer with $N$. gonorrhoeae. PLoS One 2011, 6, e21373:1-e21373:7.

47. Hagblom, P.; Segal, E.; Billyard, E.; So, M. Intragenic recombination leads to pilus antigenic variation in Neisseria gonorrhoeae. Nature 1985, 315, 156-158.

48. Haas, R.; Meyer, T.F. The repertoire of silent pilus genes in Neisseria gonorrhoeae: Evidence for gene conversion. Cell 1986, 44, 107-115.

49. Segal, E.; Hagblom, P.; Seifert, H.S.; So, M. Antigenic variation of gonococcal pilus involves assembly of separated silent gene segments. Proc. Natl. Acad. Sci. USA 1986, 83, 2177-2181.

50. Perry, A.C.; Hart, C.A.; Nicolson, I.J.; Heckels, J.E.; Saunders, J.R. Inter-strain homology of pilin gene sequences in Neisseria meningitidis isolates that express markedly different antigenic pilus types. J. Gen. Microbiol. 1987, 133, 1409-1418.

51. Carbonnelle, E.; Hill, D.J.; Morand, P.; Griffiths, N.J.; Bourdoulous, S.; Murillo, I.; Nassif, X.; Virji, M. Meningococcal interactions with the host. Vaccine 2009, 27, B78-B89.

52. Tinsley, C.R.; Heckels, J.E. Variation in the expression of pili and outer membrane protein by Neisseria meningitidis during the course of meningococcal infection. J. Gen. Microbiol. 1986, 132, 2483-2490.

53. Criss, A.K.; Kline, K.A.; Seifert, H.S. The frequency and rate of pilin antigenic variation in Neisseria gonorrhoeae. Mol. Microbiol. 2005, 58, 510-519. 
54. Helm, R.A.; Seifert, H.S. Frequency and rate of pilin antigenic variation of Neisseria meningitidis. J. Bacteriol. 2010, 192, 3822-3823.

55. Nassif, X.; Beretti, J.L.; Lowy, J.; Stenberg, P.; Ogaora, P.; Pfeifer, J.; Normark, S.; So, M. Roles of pilin and PilC in adhesion of Neisseria-meningitidis to human epithelial and endothelial cells. Proc. Natl. Acad. Sci. USA 1994, 91, 3769-3773.

56. Parge, H.E.; McRee, D.E.; Capozza, M.A.; Bernstein, S.L.; Getzoff, E.D.; Tainer, J.A. Three dimensional structure of bacterial pili. Antonie Van Leeuwenhoek 1987, 53, 447-453.

57. Parge, H.E.; Bernstein, S.L.; Deal, C.D.; McRee, D.E.; Christensen, D.; Capozza, M.A.; Kays, B.W.; Fieser, T.M.; Draper, D.; So, M. Biochemical purification and crystallographic characterization of the fiber-forming protein pilin from Neisseria gonorrhoeae. J. Biol. Chem. 1990, 265, 2278-2285.

58. Parge, H.E.; Forest, K.T.; Hickey, M.J.; Christensen, D.A.; Getzoff, E.D.; Tainer, J.A. Structure of the fibre-forming protein pilin at 2.6 A resolution. Nature 1995, 378, 32-38.

59. Forest, K.T.; Dunham, S.A.; Koomey, M.; Tainer, J.A. Crystallographic structure reveals phosphorylated pilin from Neisseria: Phosphoserine sites modify type IV pilus surface chemistry and fibre morphology. Mol. Microbiol. 1999, 31, 743-752.

60. Craig, L.; Volkmann, N.; Arvai, A.S.; Pique, M.E.; Yeager, M.; Egelman, E.H.; Tainer, J.A. Type IV pilus structure by cryo-electron microscopy and crystallography: Implications for pilus assembly and functions. Mol. Cell. 2006, 23, 651-662.

61. Carbonnelle, E.; Helaine, S.; Nassif, X.; Pelicic, V. A systematic genetic analysis in Neisseria meningitidis defines the Pil proteins required for assembly, functionality, stabilization and export of type IV pili. Mol. Microbiol. 2006, 61, 1510-1522.

62. Brown, D.R.; Helaine, S.; Carbonnelle, E.; Pelicic, V. Systematic functional analysis reveals that a set of seven genes is involved in fine-tuning of the multiple functions mediated by type IV pili in Neisseria meningitidis. Infect. Immun. 2010, 78, 3053-3063.

63. Georgiadou, M.; Castagnini, M.; Karimova, G.; Ladant, D.; Pelicic, V. Large-scale study of the interactions between proteins involved in type IV pilus biology in Neisseria meningitidis: Characterization of a subcomplex involved in pilus assembly. Mol. Microbiol. 2012, 84, 857-873.

64. Morand, P.C.; Bille, E.; Morelle, S.; Eugene, E.; Beretti, J.L.; Wolfgang, M.; Meyer, T.F.; Koomey, M.; Nassif, X. Type IV pilus retraction in pathogenic Neisseria is regulated by the PilC proteins. EMBO J. 2004, 23, 2009-2017.

65. Tonjum, T.; Freitag, N.E.; Namork, E.; Koomey, M. Identification and characterization of pilG, a highly conserved pilus-assembly gene in pathogenic Neisseria. Mol. Microbiol. 1995, 16, 451-464.

66. Drake, S.L.; Koomey, M. The product of the pilQ gene is essential for the biogenesis of type IV pili in Neisseria gonorrhoeae. Mol. Microbiol. 1995, 18, 975-986.

67. Carbonnelle, E.; Helaine, S.; Prouvensier, L.; Nassif, X.; Pelicic, V. Type IV pilus biogenesis in Neisseria meningitidis: PilW is involved in a step occurring after pilus assembly, essential for fibre stability and function. Mol. Microbiol. 2005, 55, 54-64.

68. Helaine, S.; Carbonnelle, E.; Prouvensier, L.; Beretti, J.L.; Nassif, X.; Pelicic, V. PilX, a pilus-associated protein essential for bacterial aggregation, is a key to pilus-facilitated attachment of Neisseria meningitidis to human cells. Mol. Microbiol. 2005, 55, 65-77. 
69. Cehovin, A.; Simpson, P.J.; McDowell, M.A.; Brown, D.R.; Noschese, R.; Pallett, M.; Brady, J.; Baldwin, G.S.; Lea, S.M.; Matthews, S.J.; et al. Specific DNA recognition mediated by a type IV pilin. Proc. Natl. Acad. Sci. USA 2013, 110, 3065-3070.

70. Collins, R.F.; Ford, R.C.; Kitmitto, A.; Olsen, R.O.; Tonjum, T.; Derrick, J.P. Three-dimensional structure of the Neisseria meningitidis secretin PilQ determined from negative-stain transmission electron microscopy. J. Bacteriol. 2003, 185, 2611-2617.

71. Collins, R.F.; Davidsen, L.; Derrick, J.P.; Ford, R.C.; Tonjum, T. Analysis of the PilQ secretin from Neisseria meningitidis by transmission electron microscopy reveals a dodecameric quaternary structure. J. Bacteriol. 2001, 183, 3825-3832.

72. Collins, R.F.; Frye, S.A.; Kitmitto, A.; Ford, R.C.; Tonjum, T.; Derrick, J.P. Structure of the Neisseria meningitidis outer membrane PilQ secretin complex at 12 A resolution. J. Biol. Chem. 2004, 279, 39750-39756.

73. Jain, S.; Moscicka, K.B.; Bos, M.P.; Pachulec, E.; Stuart, M.C.; Keegstra, W.; Boekema, E.J.; van der Does, C. Structural characterization of outer membrane components of the type IV pili system in pathogenic Neisseria. PLoS One 2011, 6, e16624:1-e16624:11.

74. Berry, J.L.; Phelan, M.M.; Collins, R.F.; Adomavicius, T.; Tonjum, T.; Frye, S.A.; Bird, L.; Owens, R.; Ford, R.C.; Lian, L.Y.; et al. Structure and assembly of a trans-periplasmic channel for type IV pili in Neisseria meningitidis. PLoS Pathog. 2012, 8, e1002923:1-e1002923:15.

75. Balasingham, S.V.; Collins, R.F.; Assalkhou, R.; Homberset, H.; Frye, S.A.; Derrick, J.P.; Tonjum, T. Interactions between the lipoprotein PilP and the secretin PilQ in Neisseria meningitidis. J. Bacteriol. 2007, 189, 5716-5727.

76. Golovanov, A.P.; Balasingham, S.; Tzitzilonis, C.; Goult, B.T.; Lian, L.Y.; Homberset, H.; Tonjum, T.; Derrick, J.P. The solution structure of a domain from the Neisseria meningitidis lipoprotein PilP reveals a new beta-sandwich fold. J. Mol. Biol. 2006, 364, 186-195.

77. Trindade, M.B.; Job, V.; Contreras-Martel, C.; Pelicic, V.; Dessen, A. Structure of a widely conserved type IV pilus biogenesis factor that affects the stability of secretin multimers. J. Mol. Biol. 2008, 378, 1031-1039.

78. Collins, R.F.; Saleem, M.; Derrick, J.P. Purification and three-dimensional electron microscopy structure of the Neisseria meningitidis type IV pilus biogenesis protein PilG. J. Bacteriol. 2007, 189, 6389-6396.

79. Helaine, S.; Dyer, D.H.; Nassif, X.; Pelicic, V.; Forest, K.T. 3D structure/function analysis of PilX reveals how minor pilins can modulate the virulence properties of type IV pili. Proc. Natl. Acad. Sci. USA 2007, 104, 15888-15893.

80. Forest, K.T.; Satyshur, K.A.; Worzalla, G.A.; Hansen, J.K.; Herdendorf, T.J. The pilus-retraction protein PilT: Ultrastructure of the biological assembly. Acta Crystallogr. D Biol. Crystallogr. 2004, 60, 978-982.

81. Swanson, J. Studies on gonococcus infection. XIV. Cell wall protein differences among color/opacity colony variants of Neisseria gonorrhoeae. Infect. Immun. 1978, 21, 292-302.

82. Parkhill, J.; Achtman, M.; James, K.D.; Bentley, S.D.; Churcher, C.; Klee, S.R.; Morelli, G.; Basham, D.; Brown, D.; Chillingworth, T.; et al. Complete DNA sequence of a serogroup A strain of Neisseria meningitidis Z2491. Nature 2000, 404, 502-506. 
83. Tettelin, H.; Saunders, N.J.; Heidelberg, J.; Jeffries, A.C.; Nelson, K.E.; Eisen, J.A.; Ketchum, K.A.; Hood, D.W.; Peden, J.F.; Dodson, R.J.; et al. Complete genome sequence of Neisseria meningitidis serogroup B strain MC58. Science 2000, 287, 1809-1815.

84. Bhat, K.S.; Gibbs, C.P.; Barrera, O.; Morrison, S.G.; Jahnig, F.; Stern, A.; Kupsch, E.M.; Meyer, T.F.; Swanson, J. The opacity proteins of Neisseria gonorrhoeae strain MS11 are encoded by a family of 11 complete genes. Mol. Microbiol. 1991, 5, 1889-1901.

85. Stern, A.; Meyer, T.F. Common mechanism controlling phase and antigenic variation in pathogenic Neisseriae. Mol. Microbiol. 1987, 1, 5-12.

86. Wolff, K.; Stern, A. Identification and characterization of specific sequences encoding pathogenicity associated proteins in the genome of commensal Neisseria species. FEMS Microbiol. Lett. 1995, 125, 255-263.

87. Toleman, M.; Aho, E.; Virji, M. Expression of pathogen-like Opa adhesins in commensal Neisseria: Genetic and functional analysis. Cell Microbiol. 2001, 3, 33-44.

88. Malorny, B.; Morelli, G.; Kusecek, B.; Kolberg, J.; Achtman, M. Sequence diversity, predicted two-dimensional protein structure, and epitope mapping of neisserial Opa proteins. J. Bacteriol. 1998, 180, 1323-1330.

89. De Jonge, M.I.; Bos, M.P.; Hamstra, H.J.; Jiskoot, W.; van Ulsen, P.; Tommassen, J.; van, A.L.; van der Ley, P. Conformational analysis of opacity proteins from Neisseria meningitidis. Eur. J. Biochem. 2002, 269, 5215-5223.

90. Vandeputte-Rutten, L.; Bos, M.P.; Tommassen, J.; Gros, P. Crystal structure of Neisserial surface protein A (NspA), a conserved outer membrane protein with vaccine potential. J. Biol. Chem. 2003, 278, 24825-24830.

91. Hobbs, M.M.; Malorny, B.; Prasad, P.; Morelli, G.; Kusecek, B.; Heckels, J.E.; Cannon, J.G.; Achtman, M. Recombinational reassortment among opa genes from ET-37 complex Neisseria meningitidis isolates of diverse geographical origins. Microbiology 1998, 144, 157-166.

92. Bilek, N.; Ison, C.A.; Spratt, B.G. Relative contributions of recombination and mutation to the diversification of the opa gene repertoire of Neisseria gonorrhoeae. J. Bacteriol. 2009, 191, 1878-1890.

93. Stern, A.; Brown, M.; Nickel, P.; Meyer, T.F. Opacity genes in Neisseria gonorrhoeae: Control of phase and antigenic variation. Cell 1986, 47, 61-71.

94. Belland, R.J.; Morrison, S.G.; van der Ley, P.; Swanson, J. Expression and phase variation of gonococcal P.II genes in Escherichia coli involves ribosomal frameshifting and slipped-strand mispairing. Mol. Microbiol. 1989, 3, 777-786.

95. Mayer, L.W. Rates in vitro changes of gonococcal colony opacity phenotypes. Infect. Immun. 1982, 37, 481-485.

96. Belland, R.J.; Morrison, S.G.; Carlson, J.H.; Hogan, D.M. Promoter strength influences phase variation of neisserial opa genes. Mol. Microbiol. 1997, 23, 123-135.

97. Callaghan, M.J.; Jolley, K.A.; Maiden, M.C. Opacity-associated adhesin repertoire in hyperinvasive Neisseria meningitidis. Infect. Immun. 2006, 74, 5085-5094.

98. Callaghan, M.J.; Buckee, C.; McCarthy, N.D.; Ibarz Pavon, A.B.; Jolley, K.A.; Faust, S.; Gray, S.J.; Kaczmarski, E.B.; Levin, M.; Kroll, J.S.; et al. Opa protein repertoires of disease-causing and carried meningococci. J. Clin. Microbiol. 2008, 46, 3033-3041. 
99. Zhu, P.; Morelli, G.; Achtman, M. The opcA and (psi)opcB regions in Neisseria: Genes, pseudogenes, deletions, insertion elements and DNA islands. Mol. Microbiol. 1999, 33, 635-650.

100. Zhu, P.; Klutch, M.J.; Derrick, J.P.; Prince, S.M.; Tsang, R.S.; Tsai, C.M. Identification of opcA gene in Neisseria polysaccharea: Interspecies diversity of Opc protein family. Gene 2003, 307, 31-40.

101. Sarkari, J.; Pandit, N.; Moxon, E.R.; Achtman, M. Variable expression of the Opc outer membrane protein in Neisseria meningitidis is caused by size variation of a promoter containing poly-cytidine. Mol. Microbiol. 1994, 13, 207-217.

102. Prince, S.M.; Achtman, M.; Derrick, J.P. Crystal structure of the OpcA integral membrane adhesin from Neisseria meningitidis. Proc. Natl. Acad. Sci. USA 2002, 99, 3417-3421.

103. Luan, B.; Caffrey, M.; Aksimentiev, A. Structure refinement of the OpcA adhesin using molecular dynamics. Biophys. J. 2007, 93, 3058-3069.

104. Cherezov, V.; Liu, W.; Derrick, J.P.; Luan, B.; Aksimentiev, A.; Katritch, V.; Caffrey, M. In meso crystal structure and docking simulations suggest an alternative proteoglycan binding site in the OpcA outer membrane adhesin. Proteins 2008, 71, 24-34.

105. Hadi, H.A.; Wooldridge, K.G.; Robinson, K.; Ala'Aldeen, D.A. Identification and characterization of App: An immunogenic autotransporter protein of Neisseria meningitidis. Mol. Microbiol. 2001, 41, 611-623.

106. Serruto, D.; Adu-Bobie, J.; Scarselli, M.; Veggi, D.; Pizza, M.; Rappuoli, R.; Arico, B. Neisseria meningitidis App, a new adhesin with autocatalytic serine protease activity. Mol. Microbiol. 2003, 48, 323-334.

107. Turner, D.P.; Marietou, A.G.; Johnston, L.; Ho, K.K.; Rogers, A.J.; Wooldridge, K.G.; Ala'Aldeen, D.A. Characterization of MspA, an immunogenic autotransporter protein that mediates adhesion to epithelial and endothelial cells in Neisseria meningitidis. Infect. Immun. 2006, 74, 2957-2964.

108. Pohlner, J.; Halter, R.; Beyreuther, K.; Meyer, T.F. Gene structure and extracellular secretion of Neisseria gonorrhoeae IgA protease. Nature 1987, 325, 458-462.

109. Van Ulsen, P. Protein Folding in Bacterial Adhesion: Secretion and Folding of Classical Monomeric Autotransporters. In Bacterial Adhesion: Chemistry, Biology and Physics; Linke, D., Goldman, A., Eds.; Springer: Dordrecht, Germany, 2011; Chapter 8, pp. 125-142.

110. Meng, G.; Spahich, N.; Kenjale, R.; Waksman, G.; St. Geme, J.W. Crystal structure of the Haemophilus influenzae Hap adhesin reveals an intercellular oligomerization mechanism for bacterial aggregation. EMBO J. 2011, 30, 3864-3874.

111. Cotter, S.E.; Surana, N.K.; St. Geme, J.W. Trimeric autotransporters: A distinct subfamily of autotransporter proteins. Trends Microbiol. 2005, 13, 199-205.

112. Cotter, S.E.; Surana, N.K.; Grass, S.; St. Geme, J.W. Trimeric autotransporters require trimerization of the passenger domain for stability and adhesive activity. J. Bacteriol. 2006, 188, 5400-5407.

113. Lyskowski, A.; Leo, J.C.; Goldman, A. Structure and biology of trimeric autotransporter adhesins. In Bacterial Adhesion: Chemistry, Biology and Physics; Linke, D., Goldman, A., Eds.; Springer: Dordrecht, Germany, 2011; Chapter 9, pp. 143-158. 
114. El Tahir, Y.; Skurnik, M. YadA, the multifaceted Yersinia adhesin. Int. J. Med. Microbiol. 2001, 291, 209-218.

115. Koretke, K.K.; Szczesny, P.; Gruber, M.; Lupas, A.N. Model structure of the prototypical non-fimbrial adhesin YadA of Yersinia enterocolitica. J. Struct. Biol. 2006, 155, 154-161.

116. St. Geme, J.W.; Cutter, D. The Haemophilus influenzae Hia adhesin is an autotransporter protein that remains uncleaved at the $\mathrm{C}$ terminus and fully cell associated. J. Bacteriol. 2000, $182,6005-6013$.

117. Cotter, S.E.; Yeo, H.J.; Juehne, T.; St. Geme, J.W. Architecture and adhesive activity of the Haemophilus influenzae Hsf adhesin. J. Bacteriol. 2005, 187, 4656-4664.

118. Comanducci, M.; Bambini, S.; Brunelli, B.; du-Bobie, J.; Arico, B.; Capecchi, B.; Giuliani, M.M.; Masignani, V.; Santini, L.; Savino, S.; et al. NadA, a novel vaccine candidate of Neisseria meningitidis. J. Exp. Med. 2002, 195, 1445-1454.

119. Tavano, R.; Capecchi, B.; Montanari, P.; Franzoso, S.; Marin, O.; Sztukowska, M.; Cecchini, P.; Segat, D.; Scarselli, M.; Arico, B.; et al. Mapping of the Neisseria meningitidis NadA cell-binding site: Relevance of predicted \{alpha\}-helices in the NH2-terminal and dimeric coiled-coil regions. J. Bacteriol. 2011, 193, 107-115.

120. Comanducci, M.; Bambini, S.; Caugant, D.A.; Mora, M.; Brunelli, B.; Capecchi, B.; Ciucchi, L.; Rappuoli, R.; Pizza, M. NadA diversity and carriage in Neisseria meningitidis. Infect. Immun. 2004, 72, 4217-4223.

121. Peak, I.R.; Srikhanta, Y.; Dieckelmann, M.; Moxon, E.R.; Jennings, M.P. Identification and characterisation of a novel conserved outer membrane protein from Neisseria meningitidis. FEMS Immunol. Med. Microbiol. 2000, 28, 329-334.

122. Scarselli, M.; Serruto, D.; Montanari, P.; Capecchi, B.; Adu-Bobie, J.; Veggi, D.; Rappuoli, R.; Pizza, M.; Arico, B. Neisseria meningitidis NhhA is a multifunctional trimeric autotransporter adhesin. Mol. Microbiol. 2006, 61, 631-644.

123. Griffiths, N.J.; Hill, D.J.; Borodina, E.; Sessions, R.B.; Devos, N.I.; Feron, C.M.; Poolman, J.T.; Virji, M. Meningococcal surface fibril (Msf) binds to activated vitronectin and inhibits the terminal complement pathway to increase serum resistance. Mol. Microbiol. 2011, 82, 1129-1149.

124. Hodak, H.; Jacob-Dubuisson, F. Current challenges in autotransport and two-partner protein secretion pathways. Res. Microbiol. 2007, 158, 631-637.

125. Hodak, H.; Clantin, B.; Willery, E.; Villeret, V.; Locht, C.; Jacob-Dubuisson, F. Secretion signal of the filamentous haemagglutinin, a model two-partner secretion substrate. Mol. Microbiol. 2006, 61, 368-382.

126. Jacob-Dubuisson, F.; Fernandez, R.; Coutte, L. Protein secretion through autotransporter and two-partner pathways. Biochim. Biophys. Acta 2004, 1694, 235-257.

127. Jacob-Dubuisson, F.; Locht, C.; Antoine, R. Two-partner secretion in Gram-negative bacteria: A thrifty, specific pathway for large virulence proteins. Mol. Microbiol. 2001, 40, 306-313.

128. Clantin, B.; Hodak, H.; Willery, E.; Locht, C.; Jacob-Dubuisson, F.; Villeret, V. The crystal structure of filamentous hemagglutinin secretion domain and its implications for the two-partner secretion pathway. Proc. Natl. Acad. Sci. USA 2004, 101, 6194-6199. 
129. Schmitt, C.; Turner, D.; Boesl, M.; Abele, M.; Frosch, M.; Kurzai, O. A functional two-partner secretion system contributes to adhesion of Neisseria meningitidis to epithelial cells. J. Bacteriol. 2007, 189, 7968-7976.

130. Snyder, L.A.; Saunders, N.J. The majority of genes in the pathogenic Neisseria species are present in non-pathogenic Neisseria lactamica, including those designated as "virulence genes". BMC Genomics 2006, 7, 128:1-128:11.

131. Van Ulsen, P.; Rutten, L.; Feller, M.; Tommassen, J.; van der Ende, A. Two-partner secretion systems of Neisseria meningitidis associated with invasive clonal complexes. Infect. Immun. 2008, 76, 4649-4658.

132. Ur Rahman, S.; van Ulsen, P. System specificity of the TpsB transporters of coexpressed two-partner secretion systems of Neisseria meningitidis. J. Bacteriol. 2013, 195, 788-797.

133. Kizil, G.; Todd, I.; Atta, M.; Borriello, S.P.; Ait-Tahar, K.; Ala'aldeen, D.A. Identification and characterization of TspA, a major CD4(+) T-cell- and B-cell-stimulating Neisseria-specific antigen. Infect. Immun. 1999, 67, 3533-3541.

134. Oldfield, N.J.; Bland, S.J.; Taraktsoglou, M.; Dos Ramos, F.J.; Robinson, K.; Wooldridge, K.G.; Ala'aldeen, D.A. T-cell stimulating protein A (TspA) of Neisseria meningitidis is required for optimal adhesion to human cells. Cell Microbiol. 2007, 9, 463-478.

135. Semmler, A.B.; Whitchurch, C.B.; Leech, A.J.; Mattick, J.S. Identification of a novel gene, fimV, involved in twitching motility in Pseudomonas aeruginosa. Microbiology 2000, 146, 1321-1332.

136. Tunio, S.A.; Oldfield, N.J.; Berry, A.; Ala'Aldeen, D.A.; Wooldridge, K.G.; Turner, D.P. The moonlighting protein fructose-1, 6-bisphosphate aldolase of Neisseria meningitidis: Surface localization and role in host cell adhesion. Mol. Microbiol. 2010, 76, 605-615.

137. Tunio, S.A.; Oldfield, N.J.; Ala'Aldeen, D.A.; Wooldridge, K.G.; Turner, D.P. The role of glyceraldehyde 3-phosphate dehydrogenase (GapA-1) in Neisseria meningitidis adherence to human cells. BMC Microbiol. 2010, 10, 280:1-280:10.

138. Li, M.S.; Chow, N.Y.; Sinha, S.; Halliwell, D.; Finney, M.; Gorringe, A.R.; Watson, M.W.; Kroll, J.S.; Langford, P.R.; Webb, S.A. A Neisseria meningitidis NMB1966 mutant is impaired for invasion of respiratory epithelial cells, survival in human blood and for virulence in vivo. Med. Microbiol. Immunol. 2009, 198, 57-67.

139. Serino, L.; Nesta, B.; Leuzzi, R.; Fontana, M.R.; Monaci, E.; Mocca, B.T.; Cartocci, E.; Masignani, V.; Jerse, A.E.; Rappuoli, R.; et al. Identification of a new OmpA-like protein in Neisseria gonorrhoeae involved in the binding to human epithelial cells and in vivo colonization. Mol. Microbiol. 2007, 64, 1391-1403.

140. Grizot, S.; Buchanan, S.K. Structure of the OmpA-like domain of RmpM from Neisseria meningitidis. Mol. Microbiol. 2004, 51, 1027-1037.

141. Danoff, E.J.; Fleming, K.G. The soluble, periplasmic domain of OmpA folds as an independent unit and displays chaperone activity by reducing the self-association propensity of the unfolded OmpA transmembrane beta-barrel. Biophys. Chem. 2011, 159, 194-204.

142. Hung, M.C.; Heckels, J.E.; Christodoulides, M. The Adhesin Complex Protein (ACP) of Neisseria meningitidis is a new adhesin with vaccine potential. mBio 2013, 4, e00041:1-e00041:13,

143. Jolley, K.A.; Maiden, M.C. BIGSdb: Scalable analysis of bacterial genome variation at the population level. BMC Bioinf. 2010, 11, 595:1-595:11. 
144. Schoen, C.; Blom, J.; Claus, H.; Schramm-Gluck, A.; Brandt, P.; Muller, T.; Goesmann, A.; Joseph, B.; Konietzny, S.; Kurzai, O.; et al. Whole-genome comparison of disease and carriage strains provides insights into virulence evolution in Neisseria meningitidis. Proc. Natl. Acad. Sci. USA 2008, 105, 3473-3478.

145. Swain, C.L.; Martin, D.R. Survival of meningococci outside of the host: Implications for acquisition. Epidemiol. Infect. 2007, 135, 315-320.

146. Claus, H.; Maiden, M.C.; Maag, R.; Frosch, M.; Vogel, U. Many carried meningococci lack the genes required for capsule synthesis and transport. Microbiology 2002, 148, 1813-1819.

147. Frosch, M.; Vogel, U. Structure and Genetics of the Meningococcal Capsule. In Handbook of Meningococcal Disease: Infection Biology, Vaccination, Clinical Management; Frosch, M., Maiden, M.C.J., Eds.; Wiley-VCH: Weinheim, Germany, 2006; Chapter 8, pp. 145-162.

148. Harrison, O.B.; Claus, H.; Jiang, Y.; Bennett, J.S.; Bratcher, H.B.; Jolley, K.A.; Corton, C.; Care, R.; Poolman, J.T.; Zollinger, W.D.; et al. Description and nomenclature of Neisseria meningitidis capsule locus. Emerg. Infect. Dis. 2013, 19, 566-573.

149. Swartley, J.S.; Marfin, A.A.; Edupuganti, S.; Liu, L.J.; Cieslak, P.; Perkins, B.; Wenger, J.D.; Stephens, D.S. Capsule switching of Neisseria meningitidis. Proc. Natl. Acad. Sci. USA 1997, 94, 271-276.

150. Finne, J.; Leinonen, M.; Makela, P.H. Antigenic similarities between brain components and bacteria causing meningitis. Implications for vaccine development and pathogenesis. Lancet 1983, 2, 355-357.

151. Finne, J.; Finne, U.; Deagostini-Bazin, H.; Goridis, C. Occurrence of alpha 2-8 linked polysialosyl units in a neural cell adhesion molecule. Biochem. Biophys. Res. Commun. 1983, $112,482-487$.

152. Yamasaki, R.; Bacon, B. Three-dimensional structural analysis of the group B polysaccharide of Neisseria meningitidis 6275 by two-dimensional NMR: The polysaccharide is suggested to exist in helical conformations in solution. Biochemistry 1991, 30, 851-857.

153. Lemercinier, X.; Jones, C. Full 1H NMR assignment and detailed O-acetylation patterns of capsular polysaccharides from Neisseria meningitidis used in vaccine production. Carbohydr. Res. 1996, 296, 83-96.

154. Gudlavalleti, S.K.; Szymanski, C.M.; Jarrell, H.C.; Stephens, D.S. In vivo determination of Neisseria meningitidis serogroup A capsular polysaccharide by whole cell high-resolution magic angle spinning NMR spectroscopy. Carbohydr. Res. 2006, 341, 557-562.

155. Xie, O.; Bolgiano, B.; Gao, F.; Lockyer, K.; Swann, C.; Jones, C.; Delrieu, I.; Njanpop-Lafourcade, B.M.; Tamekloe, T.A.; Pollard, A.J.; et al. Characterization of size, structure and purity of serogroup X Neisseria meningitidis polysaccharide, and development of an assay for quantification of human antibodies. Vaccine 2012, 30, 5812-5823.

156. Garrido, R.; Puyada, A.; Fernandez, A.; Gonzalez, M.; Ramirez, U.; Cardoso, F.; Valdes, Y.; Gonzalez, D.; Fernandez, V.; Verez, V.; et al. Quantitative proton nuclear magnetic resonance evaluation and total assignment of the capsular polysaccharide Neisseria meningitidis serogroup X. J. Pharm. Biomed. Anal. 2012, 70, 295-300.

157. Kahler, C.M.; Stephens, D.S. Genetic basis for biosynthesis, structure, and function of meningococcal lipooligosaccharide (endotoxin). Crit. Rev. Microbiol. 1998, 24, 281-334. 
158. Arking, D.; Tong, Y.; Stein, D.C. Analysis of lipooligosaccharide biosynthesis in the Neisseriaceae. J. Bacteriol. 2001, 183, 934-941.

159. Zhu, P.; Klutch, M.J.; Bash, M.C.; Tsang, R.S.; Ng, L.K.; Tsai, C.M. Genetic diversity of three lgt loci for biosynthesis of lipooligosaccharide (LOS) in Neisseria species. Microbiology 2002, $148,1833-1844$.

160. Jennings, M.P.; Srikhanta, Y.N.; Moxon, E.R.; Kramer, M.; Poolman, J.T.; Kuipers, B.; van der Ley, P. The genetic basis of the phase variation repertoire of lipopolysaccharide immunotypes in Neisseria meningitidis. Microbiology 1999, 145, 3013-3021.

161. Mandrell, R.E.; Griffiss, J.M.; Macher, B.A. Lipooligosaccharides (LOS) of Neisseria gonorrhoeae and Neisseria meningitidis have components that are immunochemically similar to precursors of human blood group antigens. Carbohydrate sequence specificity of the mouse monoclonal antibodies that recognize crossreacting antigens on LOS and human erythrocytes. $J$. Exp. Med. 1988, 168, 107-126.

162. Vogel, U.; Hammerschmidt, S.; Rosch, M. Sialic acids of both the capsule and the sialylated lipooligosaccharide of Neisseria meningitis serogroup B are prerequisites for virulence of meningococci in the infant rat. Med. Microbiol. Immunol. 1996, 185, 81-87.

163. Hill, D.J.; Griffiths, N.J.; Borodina, E.; Virji, M. Cellular and molecular biology of Neisseria meningitidis colonization and invasive disease. Clin. Sci. (Lond.) 2010, 118, 547-564.

164. Takayama, K.; Qureshi, N.; Hyver, K.; Honovich, J.; Cotter, R.J.; Mascagni, P.; Schneider, H. Characterization of a structural series of lipid A obtained from the lipopolysaccharides of Neisseria gonorrhoeae. Combined laser desorption and fast atom bombardment mass spectral analysis of high performance liquid chromatography-purified dimethyl derivatives. J. Biol. Chem. 1986, 261, 10624-10631.

165. Michon, F.; Beurret, M.; Gamian, A.; Brisson, J.R.; Jennings, H.J. Structure of the L5 lipopolysaccharide core oligosaccharides of Neisseria meningitidis. J. Biol. Chem. 1990, 265, $7243-7247$.

166. Yamasaki, R.; Bacon, B.E.; Nasholds, W.; Schneider, H.; Griffiss, J.M. Structural determination of oligosaccharides derived from lipooligosaccharide of Neisseria gonorrhoeae F62 by chemical, enzymatic, and two-dimensional NMR methods. Biochemistry 1991, 30, 10566-10575.

167. Gamian, A.; Beurret, M.; Michon, F.; Brisson, J.R.; Jennings, H.J. Structure of the L2 lipopolysaccharide core oligosaccharides of Neisseria meningitidis. J. Biol. Chem. 1992, 267, 922-925.

168. Kulshin, V.A.; Zahringer, U.; Lindner, B.; Frasch, C.E.; Tsai, C.M.; Dmitriev, B.A.; Rietschel, E.T. Structural characterization of the lipid A component of pathogenic Neisseria meningitidis. J. Bacteriol. 1992, 174, 1793-1800.

169. Wakarchuk, W.W.; Gilbert, M.; Martin, A.; Wu, Y.; Brisson, J.R.; Thibault, P.; Richards, J.C. Structure of an alpha-2,6-sialylated lipooligosaccharide from Neisseria meningitidis immunotype L1. Eur. J. Biochem. 1998, 254, 626-633.

170. Cox, A.D.; Li, J.; Brisson, J.R.; Moxon, E.R.; Richards, J.C. Structural analysis of the lipopolysaccharide from Neisseria meningitidis strain BZ157 galE: Localisation of two phosphoethanolamine residues in the inner core oligosaccharide. Carbohydr. Res. 2002, 337, $1435-1444$. 
171. Leavell, M.D.; Leary, J.A.; Yamasaki, R. Mass spectrometric strategy for the characterization of lipooligosaccharides from Neisseria gonorrhoeae 302 using FTICR. J. Am. Soc. Mass Spectrom. 2002, 13, 571-576.

172. Cox, A.D.; Wright, J.C.; Gidney, M.A.; Lacelle, S.; Plested, J.S.; Martin, A.; Moxon, E.R.; Richards, J.C. Identification of a novel inner-core oligosaccharide structure in Neisseria meningitidis lipopolysaccharide. Eur. J. Biochem. 2003, 270, 1759-1766.

173. Swanson, K.V.; Griffiss, J.M. Separation and identification of neisserial lipooligosaccharide oligosaccharides using high-performance anion-exchange chromatography with pulsed amperometric detection. Carbohydr. Res. 2006, 341, 388-396.

174. Choudhury, B.; Kahler, C.M.; Datta, A.; Stephens, D.S.; Carlson, R.W. The structure of the L9 immunotype lipooligosaccharide from Neisseria meningitidis NMA Z2491. Carbohydr. Res. 2008, 343, 2971-2979.

175. Kahler, C.M.; Datta, A.; Tzeng, Y.L.; Carlson, R.W.; Stephens, D.S. Inner core assembly and structure of the lipooligosaccharide of Neisseria meningitidis: Capacity of strain NMB to express all known immunotype epitopes. Glycobiology 2005, 15, 409-419.

176. Jennings, H.J.; Beurret, M.; Gamian, A.; Michon, F. Structure and immunochemistry of meningococcal lipopolysaccharides. Antonie Van Leeuwenhoek 1987, 53, 519-522.

177. Pavliak, V.; Brisson, J.R.; Michon, F.; Uhrin, D.; Jennings, H.J. Structure of the sialylated L3 lipopolysaccharide of Neisseria meningitidis. J. Biol. Chem. 1993, 268, 14146-14152.

178. Phillips, N.J.; John, C.M.; Reinders, L.G.; Gibson, B.W.; Apicella, M.A.; Griffiss, J.M. Structural models for the cell surface lipooligosaccharides of Neisseria gonorrhoeae and Haemophilus influenzae. Biomed. Environ. Mass Spectrom. 1990, 19, 731-745.

179. Kerwood, D.E.; Schneider, H.; Yamasaki, R. Structural analysis of lipooligosaccharide produced by Neisseria gonorrhoeae, strain MS11mk (variant A): A precursor for a gonococcal lipooligosaccharide associated with virulence. Biochemistry 1992, 31, 12760-12768.

180. Johnson, K.G.; Perry, M.B.; McDonald, I.J.; Russel, R.R. Cellular and free lipopolysaccharides of some species of Neisseria. Can. J. Microbiol. 1975, 21, 1969-1980.

181. Johnson, K.G.; Perry, M.B.; McDonald, I.J. Studies of the cellular and free lipopolysaccharides form Neisseria canis and N. subflava. Can. J. Microbiol. 1976, 22, 189-196.

182. Tong, Y.; Reinhold, V.; Reinhold, B.; Brandt, B.; Stein, D.C. Structural and immunochemical characterization of the lipooligosaccharides expressed by Neisseria subflava 44. J. Bacteriol. 2001, 183, 942-950.

183. Tommassen, J.; Vermeij, P.; Struyve, M.; Benz, R.; Poolman, J.T. Isolation of Neisseria meningitidis mutants deficient in class 1 (porA) and class 3 (porB) outer membrane proteins. Infect. Immun. 1990, 58, 1355-1359.

184. Kattner, C.; Zaucha, J.; Jaenecke, F.; Zachariae, U.; Tanabe, M. Identification of a cation transport pathway in Neisseria meningitidis porb. Proteins 2013, 81, 830-840.

185. Cannon, J.G.; Buchanan, T.M.; Sparling, P.F. Confirmation of association of protein I serotype of Neisseria gonorrhoeae with ability to cause disseminated infection. Infect. Immun. 1983, 40, 816-819.

186. Feavers, I.M.; Maiden, M.C. A gonococcal porA pseudogene: Implications for understanding the evolution and pathogenicity of Neisseria gonorrhoeae. Mol. Microbiol. 1998, 30, 647-656. 
187. Derrick, J.P.; Urwin, R.; Suker, J.; Feavers, I.M.; Maiden, M.C. Structural and evolutionary inference from molecular variation in Neisseria porins. Infect. Immun. 1999, 67, 2406-2413.

188. Bennett, J.S.; Callaghan, M.J.; Derrick, J.P.; Maiden, M.C. Variation in the Neisseria lactamica porin, and its relationship to meningococcal PorB. Microbiology 2008, 154, 1525-1534.

189. Minetti, C.A.; Tai, J.Y.; Blake, M.S.; Pullen, J.K.; Liang, S.M.; Remeta, D.P. Structural and functional characterization of a recombinant PorB class 2 protein from Neisseria meningitidis. Conformational stability and porin activity. J. Biol. Chem. 1997, 272, 10710-10720.

190. Tanabe, M.; Iverson, T.M. Expression, purification and preliminary X-ray analysis of the Neisseria meningitidis outer membrane protein PorB. Acta Crystallogr. Sect. F Struct. Biol. Cryst. Commun. 2009, 65, 996-1000.

191. Tanabe, M.; Nimigean, C.M.; Iverson, T.M. Structural basis for solute transport, nucleotide regulation, and immunological recognition of Neisseria meningitidis PorB. Proc. Natl. Acad. Sci. USA 2010, 107, 6811-6816.

192. Zeth, K.; Kozjak-Pavlovic, V.; Faulstich, M.; Fraunholz, M.; Hurwitz, R.; Kepp, O.; Rudel, T. Structure and function of the PorB porin from disseminating Neisseria gonorrhoeae. Biochem. J. 2013, 449, 631-642.

193. Derrick, J.P.; Maiden, M.C.; Feavers, I.M. Crystal structure of an Fab fragment in complex with a meningococcal serosubtype antigen and a protein G domain. J. Mol. Biol. 1999, 293, 81-91.

194. Tzitzilonis, C.; Prince, S.M.; Collins, R.F.; Achtman, M.; Feavers, I.M.; Maiden, M.C.; Derrick, J.P. Structural variation and immune recognition of the P1.2 subtype meningococcal antigen. Proteins 2006, 62, 947-955.

195. Bartley, S.N.; Tzeng, Y.L.; Heel, K.; Lee, C.W.; Mowlaboccus, S.; Seemann, T.; Lu, W.; Lin, Y.H.; Ryan, C.S.; Peacock, C.; et al. Attachment and invasion of Neisseria meningitidis to host cells is related to surface hydrophobicity, bacterial cell size and capsule. PLoS One 2013, 8, e55798:1-e55798:15.

196. Deghmane, A.E.; Giorgini, D.; Larribe, M.; Alonso, J.M.; Taha, M.K. Down-regulation of pili and capsule of Neisseria meningitidis upon contact with epithelial cells is mediated by CrgA regulatory protein. Mol. Microbiol. 2002, 43, 1555-1564.

197. Virji, M.; Saunders, J.R.; Sims, G.; Makepeace, K.; Maskell, D.; Ferguson, D.J. Pilus-facilitated adherence of Neisseria meningitidis to human epithelial and endothelial cells: Modulation of adherence phenotype occurs concurrently with changes in primary amino acid sequence and the glycosylation status of pilin. Mol. Microbiol. 1993, 10, 1013-1028.

198. Nassif, X.; Pujol, C.; Morand, P.; Eugene, E. Interactions of pathogenic Neisseria with host cells. Is it possible to assemble the puzzle? Mol. Microbiol. 1999, 32, 1124-1132.

199. Rudel, T.; Scheurerpflug, I.; Meyer, T.F. Neisseria PilC protein identified as type-4 pilus tip-located adhesin. Nature 1995, 373, 357-359.

200. Wolfgang, M.; Lauer, P.; Park, H.S.; Brossay, L.; Hebert, J.; Koomey, M. PilT mutations lead to simultaneous defects in competence for natural transformation and twitching motility in piliated Neisseria gonorrhoeae. Mol. Microbiol. 1998, 29, 321-330.

201. Wolfgang, M.; Park, H.S.; Hayes, S.F.; van Putten, J.P.; Koomey, M. Suppression of an absolute defect in type IV pilus biogenesis by loss-of-function mutations in pilT, a twitching motility gene in Neisseria gonorrhoeae. Proc. Natl. Acad. Sci. USA 1998, 95, 14973-14978. 
202. Pujol, C.; Eugene, E.; Marceau, M.; Nassif, X. The meningococcal PilT protein is required for induction of intimate attachment to epithelial cells following pilus-mediated adhesion. Proc. Natl. Acad. Sci. USA 1999, 96, 4017-4022.

203. Kallstrom, H.; Liszewski, M.K.; Atkinson, J.P.; Jonsson, A.B. Membrane cofactor protein (MCP or CD46) is a cellular pilus receptor for pathogenic Neisseria. Mol. Microbiol. 1997, 25, 639-647.

204. Johansson, L.; Rytkonen, A.; Bergman, P.; Albiger, B.; Kallstrom, H.; Hokfelt, T.; Agerberth, B.; Cattaneo, R.; Jonsson, A.B. CD46 in meningococcal disease. Science 2003, 301, 373-375.

205. Tobiason, D.M.; Seifert, H.S. Inverse relationship between pilus-mediated gonococcal adherence and surface expression of the pilus receptor, CD46. Microbiology 2001, 147, 2333-2340.

206. Kirchner, M.; Heuer, D.; Meyer, T.F. CD46-independent binding of neisserial type IV pili and the major pilus adhesin, PilC, to human epithelial cells. Infect. Immun. 2005, 73, 3072-3082.

207. Capecchi, B.; du-Bobie, J.; di Marcello, F.; Ciucchi, L.; Masignani, V.; Taddei, A.; Rappuoli, R.; Pizza, M.; Arico, B. Neisseria meningitidis NadA is a new invasin which promotes bacterial adhesion to and penetration into human epithelial cells. Mol. Microbiol. 2005, 55, 687-698.

208. Nagele, V.; Heesemann, J.; Schielke, S.; Jimenez-Soto, L.F.; Kurzai, O.; Ackermann, N. Neisseria meningitidis adhesin NadA targets betal integrins: Functional similarity to Yersinia invasin. J. Biol. Chem. 2011, 286, 20536-20546.

209. Knaust, A.; Weber, M.V.; Hammerschmidt, S.; Bergmann, S.; Frosch, M.; Kurzai, O. Cytosolic proteins contribute to surface plasminogen recruitment of Neisseria meningitidis. J. Bacteriol. 2007, 189, 3246-3255.

210. Morelle, S.; Carbonnelle, E.; Nassif, X. The REP2 repeats of the genome of Neisseria meningitidis are associated with genes coordinately regulated during bacterial cell interaction. $J$. Bacteriol. 2003, 185, 2618-2627.

211. Ieva, R.; Alaimo, C.; Delany, I.; Spohn, G.; Rappuoli, R.; Scarlato, V. CrgA is an inducible LysR-type regulator of Neisseria meningitidis, acting both as a repressor and as an activator of gene transcription. J. Bacteriol. 2005, 187, 3421-3430.

212. Virji, M.; Makepeace, K.; Ferguson, D.J.P.; Achtman, M.; Moxon, E.R. Meningococcal Opa and Opc proteins: Their role in colonization and invasion of human epithelial and endothelial cells. Mol. Microbiol. 1993, 10, 499-510.

213. Chen, T.; Belland, R.J.; Wilson, J.; Swanson, J. Adherence of pilus- Opa+ gonococci to epithelial cells in vitro involves heparan sulfate. J. Exp. Med. 1995, 182, 511-517.

214. Van Putten, J.P.; Paul, S.M. Binding of syndecan-like cell surface proteoglycan receptors is required for Neisseria gonorrhoeae entry into human mucosal cells. EMBO J. 1995, 14, 2144-2154.

215. Gomez-Duarte, O.G.; Dehio, M.; Guzman, C.A.; Chhatwal, G.S.; Dehio, C.; Meyer, T.F. Binding of vitronectin to opa-expressing Neisseria gonorrhoeae mediates invasion of HeLa cells. Infect. Immun. 1997, 65, 3857-3866.

216. Duensing, T.D.; Putten, J.P. Vitronectin binds to the gonococcal adhesin OpaA through a glycosaminoglycan molecular bridge. Biochem. J. 1998, 334, 133-139.

217. Moore, J.; Bailey, S.E.; Benmechernene, Z.; Tzitzilonis, C.; Griffiths, N.J.; Virji, M.; Derrick, J.P. Recognition of saccharides by the OpcA, OpaD, and OpaB outer membrane proteins from Neisseria meningitidis. J. Biol. Chem. 2005, 280, 31489-31497. 
218. Gray-Owen, S.D.; Blumberg, R.S. CEACAM1: Contact-dependent control of immunity. Nat. Rev. Immunol. 2006, 6, 433-446.

219. Gold, P.; Freedman, S.O. Demonstration of tumor-specific antigens in human colonic carcinomata by immunological tolerance and absorption techniques. J. Exp. Med. 1965, 121, $439-462$.

220. Chen, T.; Gotschlich, E.C. CGM1a antigen of neutrophils, a receptor of gonococcal opacity proteins. Proc. Natl. Acad. Sci. USA 1996, 93, 14851-14856.

221. Virji, M.; Makepeace, K.; Ferguson, D.J.; Watt, S.M. Carcinoembryonic antigens (CD66) on epithelial cells and neutrophils are receptors for Opa proteins of pathogenic Neisseriae. Mol. Microbiol. 1996, 22, 941-950.

222. Virji, M.; Watt, S.M.; Barker, S.; Makepeace, K.; Doyonnas, R. The $N$-domain of the human CD66a adhesion molecule is a target for Opa proteins of Neisseria meningitidis and Neisseria gonorrhoeae. Mol. Microbiol. 1996, 22, 929-939.

223. Bos, M.P.; Grunert, F.; Belland, R.J. Differential recognition of members of the carcinoembryonic antigen family by Opa variants of Neisseria gonorrhoeae. Infect. Immun. 1997, $65,2353-2361$.

224. Chen, T.; Grunert, F.; Medina-Marino, A.; Gotschlich, E.C. Several carcinoembryonic antigens (CD66) serve as receptors for gonococcal opacity proteins. J. Exp. Med. 1997, 185, 1557-1564.

225. Gray-Owen, S.D.; Dehio, C.; Haude, A.; Grunert, F.; Meyer, T.F. CD66 carcinoembryonic antigens mediate interactions between Opa-expressing Neisseria gonorrhoeae and human polymorphonuclear phagocytes. EMBO J. 1997, 16, 3435-3445.

226. Gray-Owen, S.D.; Lorenzen, D.R.; Haude, A.; Meyer, T.F.; Dehio, C. Differential Opa specificities for CD66 receptors influence tissue interactions and cellular response to Neisseria gonorrhoeae. Mol. Microbiol. 1997, 26, 971-980.

227. Popp, A.; Dehio, C.; Grunert, F.; Meyer, T.F.; Gray-Owen, S.D. Molecular analysis of neisserial Opa protein interactions with the CEA family of receptors: Identification of determinants contributing to the differential specificities of binding. Cell Microbiol. 1999, 1, 169-181.

228. Muenzner, P.; Dehio, C.; Fujiwara, T.; Achtman, M.; Meyer, T.F.; Gray-Owen, S.D. Carcinoembryonic antigen family receptor specificity of Neisseria meningitidis Opa variants influences adherence to and invasion of proinflammatory cytokine-activated endothelial cells. Infect. Immun. 2000, 68, 3601-3607.

229. Rowe, H.A.; Griffiths, N.J.; Hill, D.J.; Virji, M. Co-ordinate action of bacterial adhesins and human carcinoembryonic antigen receptors in enhanced cellular invasion by capsulate serum resistant Neisseria meningitidis. Cell Microbiol. 2007, 9, 154-168.

230. Griffiths, N.J.; Bradley, C.J.; Heyderman, R.S.; Virji, M. IFN-gamma amplifies NFkappaBdependent Neisseria meningitidis invasion of epithelial cells via specific upregulation of CEA-related cell adhesion molecule 1. Cell Microbiol. 2007, 9, 2968-2983.

231. Slevogt, H.; Zabel, S.; Opitz, B.; Hocke, A.; Eitel, J.; N'guessan, P.D.; Lucka, L.; Riesbeck, K.; Zimmermann, W.; Zweigner, J.; et al. CEACAM1 inhibits Toll-like receptor 2-triggered antibacterial responses of human pulmonary epithelial cells. Nat. Immunol. 2008, 9, 1270-1278. 
232. Bos, M.P.; Kuroki, M.; Krop-Watorek, A.; Hogan, D.; Belland, R.J. CD66 receptor specificity exhibited by neisserial Opa variants is controlled by protein determinants in CD66 N-domains. Proc. Natl. Acad. Sci. USA 1998, 95, 9584-9589.

233. Virji, M.; Evans, D.; Hadfield, A.; Grunert, F.; Teixeira, A.M.; Watt, S.M. Critical determinants of host receptor targeting by Neisseria meningitidis and Neisseria gonorrhoeae: Identification of Opa adhesiotopes on the $N$-domain of CD66 molecules. Mol. Microbiol. 1999, 34, 538-551.

234. Bos, M.P.; Kao, D.; Hogan, D.M.; Grant, C.C.; Belland, R.J. Carcinoembryonic antigen family receptor recognition by gonococcal Opa proteins requires distinct combinations of hypervariable Opa protein domains. Infect. Immun. 2002, 70, 1715-1723.

235. De Jonge, M.I.; Hamstra, H.J.; van Alphen, L.; Dankert, J.; van der Ley, P. Mapping the binding domains on meningococcal Opa proteins for CEACAM1 and CEA receptors. Mol. Microbiol. 2003, 50, 1005-1015.

236. Virji, M.; Makepeace, K.; Ferguson, D.J.; Achtman, M.; Sarkari, J.; Moxon, E.R. Expression of the Opc protein correlates with invasion of epithelial and endothelial cells by Neisseria meningitidis. Mol. Microbiol. 1992, 6, 2785-2795.

237. De Vries, F.P.; Cole, R.; Dankert, J.; Frosch, M.; van Putten, J.P. Neisseria meningitidis producing the Opc adhesin binds epithelial cell proteoglycan receptors. Mol. Microbiol. 1998, 27, $1203-1212$.

238. Virji, M.; Makepeace, K.; Moxon, R. Distinct mechanisms of interactions of Opc-expressing meningococci at apical and basolateral surfaces of human endothelial cells; the role of integrins in apical interactions. Mol. Microbiol. 1994, 14, 173-184.

239. Unkmeir, A.; Latsch, K.; Dietrich, G.; Wintermeyer, E.; Schinke, B.; Schwender, S.; Kim, K.S.; Eigenthaler, M.; Frosch, M. Fibronectin mediates Opc-dependent internalization of Neisseria meningitidis in human brain microvascular endothelial cells. Mol. Microbiol. 2002, 46, 933-946.

240. Sa Cunha, C.E.; Griffiths, N.J.; Murillo, I.; Virji, M. Neisseria meningitidis Opc invasin binds to the cytoskeletal protein alpha-actinin. Cell Microbiol. 2009, 11, 389-405.

241. De Vries, F.P.; van der Ende, A.; van Putten, J.P.; Dankert, J. Invasion of primary nasopharyngeal epithelial cells by Neisseria meningitidis is controlled by phase variation of multiple surface antigens. Infect. Immun. 1996, 64, 2998-3006.

242. Merz, A.J.; Enns, C.A.; So, M. Type IV pili of pathogenic Neisseriae elicit cortical plaque formation in epithelial cells. Mol. Microbiol. 1999, 32, 1316-1332.

243. Chamot-Rooke, J.; Mikaty, G.; Malosse, C.; Soyer, M.; Dumont, A.; Gault, J.; Imhaus, A.F.; Martin, P.; Trellet, M.; Clary, G.; et al. Posttranslational modification of pili upon cell contact triggers N. meningitidis dissemination. Science 2011, 331, 778-782.

244. Ayala, B.P.; Vasquez, B.; Clary, S.; Tainer, J.A.; Rodland, K.; So, M. The pilus-induced Ca2+ flux triggers lysosome exocytosis and increases the amount of Lamp1 accessible to Neisseria IgA1 protease. Cell Microbiol. 2001, 3, 265-275.

245. Ayala, P.; Vasquez, B.; Wetzler, L.; So, M. Neisseria gonorrhoeae porin P1.B induces endosome exocytosis and a redistribution of Lamp1 to the plasma membrane. Infect. Immun. 2002, 70, 5965-5971.

246. Greenfield, S.; Sheehe, P.R.; Feldman, H.A. Meningococcal carriage in a population of "normal" families. J. Infect. Dis. 1971, 123, 67-73. 
247. Hall-Stoodley, L.; Costerton, J.W.; Stoodley, P. Bacterial biofilms: From the natural environment to infectious diseases. Nat. Rev. Microbiol. 2004, 2, 95-108.

248. Apicella, M.A.; Shao, J.; Neil, R.B. Methods for Studying Neisseria meningitidis Biofilms. In Neisseria meningitidis: Advanced Methods and Protocols; Christodoulides, M., Ed.; Humana Press: New York, NY, USA, 2012; Chapter 11, pp. 169-184.

249. Neil, R.B.; Apicella, M.A. Clinical and laboratory evidence for Neisseria meningitidis biofilms. Future. Microbiol. 2009, 4, 555-563.

250. Yi, K.; Rasmussen, A.W.; Gudlavalleti, S.K.; Stephens, D.S.; Stojiljkovic, I. Biofilm formation by Neisseria meningitidis. Infect. Immun. 2004, 72, 6132-6138.

251. Lappann, M.; Haagensen, J.A.; Claus, H.; Vogel, U.; Molin, S. Meningococcal biofilm formation: Structure, development and phenotypes in a standardized continuous flow system. Mol. Microbiol. 2006, 62, 1292-1309.

252. Neil, R.B.; Shao, J.Q.; Apicella, M.A. Biofilm formation on human airway epithelia by encapsulated Neisseria meningitidis serogroup B. Microbes. Infect. 2009, 11, 281-287.

253. Lappann, M.; Vogel, U. Biofilm formation by the human pathogen Neisseria meningitidis. Med. Microbiol. Immunol. 2010, 199, 173-183.

254. Neil, R.B.; Apicella, M.A. Role of HrpA in biofilm formation of Neisseria meningitidis and regulation of the hrpBAS transcripts. Infect. Immun. 2009, 77, 2285-2293.

255. Lappann, M.; Claus, H.; van Alen, T.; Harmsen, M.; Elias, J.; Molin, S.; Vogel, U. A dual role of extracellular DNA during biofilm formation of Neisseria meningitidis. Mol. Microbiol. 2010, 75, $1355-1371$.

256. Edwards, J.L.; Apicella, M.A. I-domain-containing integrins serve as pilus receptors for Neisseria gonorrhoeae adherence to human epithelial cells. Cell Microbiol. 2005, 7, 1197-1211.

257. Harvey, H.A.; Swords, W.E.; Apicella, M.A. The mimicry of human glycolipids and glycosphingolipids by the lipooligosaccharides of pathogenic Neisseria and Haemophilus. J. Autoimmun. 2001, 16, 257-262.

258. James-Holmquest, A.N.; Swanson, J.; Buchanan, T.M.; Wende, R.D.; Williams, R.P. Differential attachment by piliated and nonpiliated Neisseria gonorrhoeae to human sperm. Infect. Immun. 1974, 9, 897-902.

259. Harvey, H.A.; Porat, N.; Campbell, C.A.; Jennings, M.; Gibson, B.W.; Phillips, N.J.; Apicella, M.A.; Blake, M.S. Gonococcal lipooligosaccharide is a ligand for the asialoglycoprotein receptor on human sperm. Mol. Microbiol. 2000, 36, 1059-1070.

260. Liu, J.H.; Li, H.Y.; Cao, Z.G.; Duan, Y.F.; Li, Y.; Ye, Z.Q. Influence of several uropathogenic microorganisms on human sperm motility parameters in vitro. Asian J. Androl. 2002, 4, 179-182.

261. Edwards, J.L.; Butler, E.K. The pathobiology of Neisseria gonorrhoeae lower female genital tract infection. Front. Microbiol. 2011, 2, 102:1-102:12.

262. Jarvis, G.A. Analysis of C3 deposition and degradation on Neisseria meningitidis and Neisseria gonorrhoeae. Infect. Immun. 1994, 62, 1755-1760.

263. Edwards, J.L.; Brown, E.J.; Ault, K.A.; Apicella, M.A. The role of complement receptor 3 (CR3) in Neisseria gonorrhoeae infection of human cervical epithelia. Cell Microbiol. 2001, 3, 611-622. 
264. Edwards, J.L.; Brown, E.J.; Uk-Nham, S.; Cannon, J.G.; Blake, M.S.; Apicella, M.A. A co-operative interaction between Neisseria gonorrhoeae and complement receptor 3 mediates infection of primary cervical epithelial cells. Cell Microbiol. 2002, 4, 571-584.

265. Jennings, M.P.; Jen, F.E.; Roddam, L.F.; Apicella, M.A.; Edwards, J.L. Neisseria gonorrhoeae pilin glycan contributes to CR3 activation during challenge of primary cervical epithelial cells. Cell Microbiol. 2011, 13, 885-896.

266. Van Putten, J.P.; Duensing, T.D.; Carlson, J. Gonococcal invasion of epithelial cells driven by P.IA, a bacterial ion channel with GTP binding properties. J. Exp. Med. 1998, 188, 941-952.

267. Agarwal, S.; Ram, S.; Ngampasutadol, J.; Gulati, S.; Zipfel, P.F.; Rice, P.A. Factor H facilitates adherence of Neisseria gonorrhoeae to complement receptor 3 on eukaryotic cells. J. Immunol. 2010, 185, 4344-4353.

268. Harvey, H.A.; Jennings, M.P.; Campbell, C.A.; Williams, R.; Apicella, M.A. Receptor-mediated endocytosis of Neisseria gonorrhoeae into primary human urethral epithelial cells: The role of the asialoglycoprotein receptor. Mol. Microbiol. 2001, 42, 659-672.

269. Swanson, K.V.; Jarvis, G.A.; Brooks, G.F.; Barham, B.J.; Cooper, M.D.; Griffiss, J.M. CEACAM is not necessary for Neisseria gonorrhoeae to adhere to and invade female genital epithelial cells. Cell Microbiol. 2001, 3, 681-691.

270. Minor, S.Y.; Banerjee, A.; Gotschlich, E.C. Effect of alpha-oligosaccharide phenotype of Neisseria gonorrhoeae strain MS11 on invasion of Chang conjunctival, HEC-1-B endometrial, and ME-180 cervical cells. Infect. Immun. 2000, 68, 6526-6534.

271. Bessen, D.; Gotschlich, E.C. Interactions of gonococci with HeLa cells: Attachment, detachment, replication, penetration, and the role of protein II. Infect. Immun. 1986, 54, 154-160.

272. Grassme, H.; Gulbins, E.; Brenner, B.; Ferlinz, K.; Sandhoff, K.; Harzer, K.; Lang, F.; Meyer, T.F. Acidic sphingomyelinase mediates entry of $N$. gonorrhoeae into nonphagocytic cells. Cell 1997, 91, 605-615.

273. Van Putten, J.P.; Duensing, T.D.; Cole, R.L. Entry of OpaA+ gonococci into HEp-2 cells requires concerted action of glycosaminoglycans, fibronectin and integrin receptors. Mol. Microbiol. 1998, 29, 369-379.

274. Greiner, L.L.; Edwards, J.L.; Shao, J.; Rabinak, C.; Entz, D.; Apicella, M.A. Biofilm Formation by Neisseria gonorrhoeae. Infect. Immun. 2005, 73, 1964-1970.

275. Pruthi, V.; Al-Janabi, A.; Pereira, B.M. Characterization of biofilm formed on intrauterine devices. Indian J. Med. Microbiol. 2003, 21, 161-165.

276. Steichen, C.T.; Shao, J.Q.; Ketterer, M.R.; Apicella, M.A. Gonococcal cervicitis: A role for biofilm in pathogenesis. J. Infect. Dis. 2008, 198, 1856-1861.

277. Falsetta, M.L.; Steichen, C.T.; McEwan, A.G.; Cho, C.; Ketterer, M.; Shao, J.; Hunt, J.; Jennings, M.P.; Apicella, M.A. The composition and metabolic phenotype of Neisseria gonorrhoeae biofilms. Front. Microbiol. 2011, 2, 75:1-75:11.

278. Shaw, J.H.; Falkow, S. Model for invasion of human tissue culture cells by Neisseria gonorrhoeae. Infect. Immun. 1988, 56, 1625-1632.

279. Christodoulides, M.; Everson, J.S.; Liu, B.L.; Lambden, P.R.; Watt, P.J.; Thomas, E.J.; Heckels, J.E. Interaction of primary human endometrial cells with Neisseria gonorrhoeae expressing green fluorescent protein. Mol. Microbiol. 2000, 35, 32-43. 
280. Spurbeck, R.R.; Arvidson, C.G. Inhibition of Neisseria gonorrhoeae epithelial cell interactions by vaginal Lactobacillus species. Infect. Immun. 2008, 76, 3124-3130.

281. Spurbeck, R.R.; Arvidson, C.G. Lactobacillus jensenii surface-associated proteins inhibit Neisseria gonorrhoeae adherence to epithelial cells. Infect. Immun. 2010, 78, 3103-3111.

282. Griffiss, J.M.; Lammel, C.J.; Wang, J.; Dekker, N.P.; Brooks, G.F. Neisseria gonorrhoeae coordinately uses Pili and Opa to activate HEC-1-B cell microvilli, which causes engulfment of the gonococci. Infect. Immun. 1999, 67, 3469-3480.

283. Timmerman, M.M.; Shao, J.Q.; Apicella, M.A. Ultrastructural analysis of the pathogenesis of Neisseria gonorrhoeae endometrial infection. Cell Microbiol. 2005, 7, 627-636.

284. McCormack, W.M. Pelvic inflammatory disease. N. Engl. J. Med. 1994, 330, 115-119.

285. Ward, M.E.; Watt, P.J.; Robertson, J.N. The human fallopian tube: A laboratory model for gonococcal infection. J. Infect. Dis. 1974, 129, 650-659.

286. McGee, Z.A.; Stephens, D.S.; Hoffman, L.H.; Schlech, W.F., III; Horn, R.G. Mechanisms of mucosal invasion by pathogenic Neisseria. Rev. Infect. Dis. 1983, 5, S708-S714.

287. Gorby, G.L.; Schaefer, G.B. Effect of attachment factors (pili plus Opa) on Neisseria gonorrhoeae invasion of human fallopian tube tissue in vitro: Quantitation by computerized image analysis. Microb. Pathog. 1992, 13, 93-108.

288. Velasquez, L.; Garcia, K.; Morales, F.; Heckels, J.E.; Orihuela, P.; Rodas, P.I.; Christodoulides, M.; Cardenas, H. Neisseria gonorrhoeae pilus attenuates cytokine response of human fallopian tube explants. J. Biomed. Biotechnol. 2012, 2012, 491298: 1-491298:7.

289. Dekker, N.P.; Lammel, C.J.; Mandrell, R.E.; Brooks, G.F. Opa (protein II) influences gonococcal organization in colonies, surface appearance, size and attachment to human fallopian tube tissues. Microb. Pathog. 1990, 9, 19-31.

290. Quan, D.N.; Cooper, M.D.; Potter, J.L.; Roberts, M.H.; Cheng, H.; Jarvis, G.A. TREM-2 binds to lipooligosaccharides of Neisseria gonorrhoeae and is expressed on reproductive tract epithelial cells. Mucosal. Immunol. 2008, 1, 229-238.

291. Muenzner, P.; Bachmann, V.; Zimmermann, W.; Hentschel, J.; Hauck, C.R. Human-restricted bacterial pathogens block shedding of epithelial cells by stimulating integrin activation. Science 2010, 329, 1197-1201.

292. Morales, P.; Reyes, P.; Vargas, M.; Rios, M.; Imarai, M.; Cardenas, H.; Croxatto, H.; Orihuela, P.; Vargas, R.; Fuhrer, J.; et al. Infection of human fallopian tube epithelial cells with Neisseria gonorrhoeae protects cells from tumor necrosis factor alpha-induced apoptosis. Infect. Immun. 2006, 74, 3643-3650.

293. Britigan, B.E.; Cohen, M.S.; Sparling, P.F. Gonococcal infection: A model of molecular pathogenesis. N. Engl. J. Med. 1985, 312, 1683-1694.

294. Morello, J.A.; Bohnhoff, M. Serovars and serum resistance of Neisseria gonorrhoeae from disseminated and uncomplicated infections. J. Infect. Dis. 1989, 160, 1012-1017.

295. Rechner, C.; Kuhlewein, C.; Muller, A.; Schild, H.; Rudel, T. Host glycoprotein Gp96 and scavenger receptor SREC interact with PorB of disseminating Neisseria gonorrhoeae in an epithelial invasion pathway. Cell Host. Microbe 2007, 2, 393-403.

296. Van Deuren, M.; Brandtzaeg, P.; van der Meer, J. Update on meningococcal disease with emphasis on pathogenesis and clinical management. Clin. Microbiol. Rev. 2000, 13, 144-166. 
297. Schneider, M.C.; Exley, R.M.; Ram, S.; Sim, R.B.; Tang, C.M. Interactions between Neisseria meningitidis and the complement system. Trends Microbiol. 2007, 15, 233-240.

298. Kugelberg, E.; Gollan, B.; Tang, C.M. Mechanisms in Neisseria meningitidis for resistance against complement-mediated killing. Vaccine 2008, 26, I34-I39.

299. Stephens, D.S.; Edwards, K.M.; Morris, F.M.G. Pili and outer membrane appendages on Neisseria meningitidis in the cerebrospinal fluid of an infant. J. Infect. Dis. 1982, 146, 568.

300. Devoe, I.W. The meningococcus and mechanisms of pathogenicity. Microbiol. Rev. 1982, 46, 162-190.

301. Brandtzaeg, P.; van Deuren, M. Current concepts in the role of the host response in Neisseria meningitidis septic shock. Curr. Opin. Infect. Dis. 2002, 15, 247-252.

302. Jarva, H.; Ram, S.; Vogel, U.; Blom, A.M.; Meri, S. Binding of the complement inhibitor C4bp to serogroup B Neisseria meningitidis. J. Immunol. 2005, 174, 6299-6307.

303. Madico, G.; Welsch, J.A.; Lewis, L.A.; McNaughton, A.; Perlman, D.H.; Costello, C.E.; Ngampasutadol, J.; Vogel, U.; Granoff, D.M.; Ram, S. The meningococcal vaccine candidate GNA1870 binds the complement regulatory protein factor $\mathrm{H}$ and enhances serum resistance. $J$. Immunol. 2006, 177, 501-510.

304. Lewis, L.A.; Ngampasutadol, J.; Wallace, R.; Reid, J.E.; Vogel, U.; Ram, S. The meningococcal vaccine candidate neisserial surface protein $A(N s p)$ binds to factor $H$ and enhances meningococcal resistance to complement. PLoS Pathog. 2010, 6, e1001027:1-e1001027:20.

305. Ram, S.; McQuillen, D.P.; Gulati, S.; Elkins, C.; Pangburn, M.K.; Rice, P.A. Binding of complement factor $\mathrm{H}$ to loop 5 of porin protein 1A: A molecular mechanism of serum resistance of nonsialylated Neisseria gonorrhoeae. J. Exp. Med. 1998, 188, 671-680.

306. Ram, S.; Sharma, A.K.; Simpson, S.D.; Gulati, S.; McQuillen, D.P.; Pangburn, M.K.; Rice, P.A. A novel sialic acid binding site on factor $\mathrm{H}$ mediates serum resistance of sialylated Neisseria gonorrhoeae. J. Exp. Med. 1998, 187, 743-752.

307. Ram, S.; Cullinane, M.; Blom, A.M.; Gulati, S.; McQuillen, D.P.; Monks, B.G.; O’Connell, C.; Boden, R.; Elkins, C.; Pangburn, M.K.; et al. Binding of C4b-binding protein to porin: A molecular mechanism of serum resistance of Neisseria gonorrhoeae. J. Exp. Med. 2001, 193, 281-295.

308. Sjolinder, H.; Eriksson, J.; Maudsdotter, L.; Aro, H.; Jonsson, A.B. Meningococcal outer membrane protein NhhA is essential for colonization and disease by preventing phagocytosis and complement attack. Infect. Immun. 2008, 76, 5412-5420.

309. Estabrook, M.M.; Jack, D.L.; Klein, N.J.; Jarvis, G.A. Mannose-binding lectin binds to two major outer membrane proteins, opacity protein and porin, of Neisseria meningitidis. J. Immunol. 2004, 172, 3784-3792.

310. Devyatyarova-Johnson, M.; Rees, I.H.; Robertson, B.D.; Turner, M.W.; Klein, N.J.; Jack, D.L. The lipopolysaccharide structures of Salmonella enterica serovar Typhimurium and Neisseria gonorrhoeae determine the attachment of human mannose-binding lectin to intact organisms. Infect. Immun. 2000, 68, 3894-3899.

311. Melican, K.; Michea, V.P.; Martin, T.; Bruneval, P.; Dumenil, G. Adhesion of Neisseria meningitidis to dermal vessels leads to local vascular damage and purpura in a humanized mouse model. PLoS. Pathog. 2013, 9, e1003139:1-e1003139:11. 
312. Sa E Cunha, C.; Griffiths, N.J.; Virji, M. Neisseria meningitidis Opc invasin binds to the sulphated tyrosines of activated vitronectin to attach to and invade human brain endothelial cells. PLoS Pathog. 2010, 6, e1000911:1-e1000911:18.

313. Muenzner, P.; Naumann, M.; Meyer, T.F.; Gray-Owen, S.D. Pathogenic Neisseria trigger expression of their carcinoembryonic antigen-related cellular adhesion molecule 1 (CEACAM1; previously CD66a) receptor on primary endothelial cells by activating the immediate early response transcription factor, nuclear factor-kappaB. J. Biol. Chem. 2001, 276, 24331-24340.

314. Soyer, M.; Dumenil, G. A laminar-Flow Chamber Assay for Measuring Bacterial Adhesion under Shear Stress. In Neisseria meningitidis: Advanced Methods and Protocols; Christodoulides, M., Ed.; Humana Press: New York, NY, USA, 2012; Chapter 12, pp. 185-195.

315. Mikaty, G.; Soyer, M.; Mairey, E.; Henry, N.; Dyer, D.; Forest, K.T.; Morand, P.; Guadagnini, S.; Prevost, M.C.; Nassif, X.; et al. Extracellular bacterial pathogen induces host cell surface reorganization to resist shear stress. PLoS Pathog. 2009, 5, e1000314:1-e1000314:14.

316. Coureuil, M.; Lecuyer, H.; Scott, M.G.; Boularan, C.; Enslen, H.; Soyer, M.; Mikaty, G.; Bourdoulous, S.; Nassif, X.; Marullo, S. Meningococcus Hijacks a beta2-adrenoceptor/betaArrestin pathway to cross brain microvasculature endothelium. Cell 2010, 143, 1149-1160.

317. Lecuyer, H.; Nassif, X.; Coureuil, M. Two strikingly different signaling pathways are induced by meningococcal type IV pili on endothelial and epithelial cells. Infect. Immun. 2012, 80, 175-186.

318. Brissac, T.; Mikaty, G.; Dumenil, G.; Coureuil, M.; Nassif, X. The meningococcal minor pilin PilX is responsible for type IV pilus conformational changes associated with signaling to endothelial cells. Infect. Immun. 2012, 80, 3297-3306.

319. Virji, M.; Kayhty, H.; Ferguson, D.J.; Alexandrescu, C.; Heckels, J.E.; Moxon, E.R. The role of pili in the interactions of pathogenic Neisseria with cultured human endothelial cells. Mol. Microbiol. 1991, 5, 1831-1841.

320. Scheuerpflug, I.; Rudel, T.; Ryll, R.; Pandit, J.; Meyer, T.F. Roles of PilC and PilE proteins in pilus-mediated adherence of Neisseria gonorrhoeae and Neisseria meningitidis to human erythrocytes and endothelial and epithelial cells. Infect. Immun. 1999, 67, 834-843.

321. Kupsch, E.M.; Knepper, B.; Kuroki, T.; Heuer, I.; Meyer, T.F. Variable opacity (Opa) outer membrane proteins account for the cell tropisms displayed by Neisseria gonorrhoeae for human leukocytes and epithelial cells. EMBO J. 1993, 12, 641-650.

322. McNeil, G.; Virji, M. Phenotypic variants of meningococci and their potential in phagocytic interactions: The influence of opacity proteins, pili, PilC and surface sialic acids. Microb. Pathog. 1997, 22, 295-304.

323. Swanson, J.; Sparks, E.; Young, D.; King, G. Studies on Gonococcus infection. X. Pili and leukocyte association factor as mediators of interactions between gonococci and eukaryotic cells in vitro. Infect. Immun. 1975, 11, 1352-1361.

324. Soderholm, N.; Vielfort, K.; Hultenby, K.; Aro, H. Pathogenic Neisseria hitchhike on the uropod of human neutrophils. PLoS One 2011, 6, e24353:1-e24353:12.

325. Johnson, M.B.; Criss, A.K. Resistance of Neisseria gonorrhoeae to neutrophils. Front. Microbiol. 2011, 2, 77:1-77:12.

326. Sadarangani, M.; Pollard, A.J.; Gray-Owen, S.D. Opa proteins and CEACAMs: Pathways of immune engagement for pathogenic Neisseria. FEMS Microbiol. Rev. 2011, 35, 498-514. 
327. Criss, A.K.; Seifert, H.S. A bacterial siren song: Intimate interactions between Neisseria and neutrophils. Nat. Rev. Microbiol. 2012, 10, 178-190.

328. Wiertz, E.J.; Delvig, A.; Donders, E.M.; Brugghe, H.F.; van Unen, L.M.; Timmermans, H.A.; Achtman, M.; Hoogerhout, P.; Poolman, J.T. T-cell responses to outer membrane proteins of Neisseria meningitidis: Comparative study of the Opa, Opc, and PorA proteins. Infect. Immun. 1996, 64, 298-304.

329. Lee, H.S.; Boulton, I.C.; Reddin, K.; Wong, H.; Halliwell, D.; Mandelboim, O.; Gorringe, A.R.; Gray-Owen, S.D. Neisserial outer membrane vesicles bind the coinhibitory receptor carcinoembryonic antigen-related cellular adhesion molecule 1 and suppress CD4+ T lymphocyte function. Infect. Immun. 2007, 75, 4449-4455.

330. Boulton, I.C.; Gray-Owen, S.D. Neisserial binding to CEACAM1 arrests the activation and proliferation of CD4+ T lymphocytes. Nat. Immunol. 2002, 3, 229-236.

331. Mandrell, R.E.; Zollinger, W.D. Human immune response to meningococcal outer membrane protein epitopes after natural infection or vaccination. Infect. Immun. 1989, 57, 1590-1598.

332. Pantelic, M.; Kim, Y.J.; Bolland, S.; Chen, I.; Shively, J.; Chen, T. Neisseria gonorrhoeae kills carcinoembryonic antigen-related cellular adhesion molecule 1 (CD66a)-expressing human B cells and inhibits antibody production. Infect. Immun. 2005, 73, 4171-4179.

333. Al-Bader, T.; Jolley, K.A.; Humphries, H.E.; Holloway, J.; Heckels, J.E.; Semper, A.E.; Friedmann, P.S.; Christodoulides, M. Activation of human dendritic cells by the PorA protein of Neisseria meningitidis. Cell Microbiol. 2004, 6, 651-662.

334. Franzoso, S.; Mazzon, C.; Sztukowska, M.; Cecchini, P.; Kasic, T.; Capecchi, B.; Tavano, R.; Papini, E. Human monocytes/macrophages are a target of Neisseria meningitidis Adhesin A (NadA). J. Leukoc. Biol. 2008, 83, 1100-1110.

335. Sjolinder, M.; Altenbacher, G.; Hagner, M.; Sun, W.; Schedin-Weiss, S.; Sjolinder, H. Meningococcal outer membrane protein NhA triggers apoptosis in macrophages. PLoS One 2012, 7, e29586:1-e29586:8.

336. Quattroni, P.; Li, Y.; Lucchesi, D.; Lucas, S.; Hood, D.W.; Herrmann, M.; Gabius, H.J.; Tang, C.M.; Exley, R.M. Galectin-3 binds Neisseria meningitidis and increases interaction with phagocytic cells. Cell Microbiol. 2012, 14, 1657-1675.

337. Jones, C.; Virji, M.; Crocker, P.R. Recognition of sialylated meningococcal lipopolysaccharide by siglecs expressed on myeloid cells leads to enhanced bacterial uptake. Mol. Microbiol. 2003, 49, 1213-1225.

338. Peiser, L.; Makepeace, K.; Pluddemann, A.; Savino, S.; Wright, J.C.; Pizza, M.; Rappuoli, R.; Moxon, E.R.; Gordon, S. Identification of Neisseria meningitidis nonlipopolysaccharide ligands for class A macrophage scavenger receptor by using a novel assay. Infect. Immun. 2006, 74, 5191-5199.

339. Casey, R.; Newcombe, J.; McFadden, J.; Bodman-Smith, K.B. The acute-phase reactant C-reactive protein binds to phosphorylcholine-expressing Neisseria meningitidis and increases uptake by human phagocytes. Infect. Immun. 2008, 76, 1298-1304.

340. Zughaier, S.M.; Tzeng, Y.L.; Zimmer, S.M.; Datta, A.; Carlson, R.W.; Stephens, D.S. Neisseria meningitidis lipooligosaccharide structure-dependent activation of the macrophage CD14/Toll-like receptor 4 pathway. Infect. Immun. 2004, 72, 371-380. 
341. Zimmer, S.M.; Zughaier, S.M.; Tzeng, Y.L.; Stephens, D.S. Human MD-2 discrimination of meningococcal lipid A structures and activation of TLR4. Glycobiology 2007, 17, 847-856.

342. DeMarco, M.L.; Woods, R.J. From agonist to antagonist: Structure and dynamics of innate immune glycoprotein MD-2 upon recognition of variably acylated bacterial endotoxins. Mol. Immunol. 2011, 49, 124-133.

343. Lu, R.; Pan, H.; Shively, J.E. CEACAM1 negatively regulates IL-1beta production in LPS activated neutrophils by recruiting SHP-1 to a SYK-TLR4-CEACAM1 complex. PLoS Pathog. 2012, 8, e1002597:1-e1002597:15.

344. Massari, P.; Visintin, A.; Gunawardana, J.; Halmen, K.A.; King, C.A.; Golenbock, D.T.; Wetzler, L.M. Meningococcal porin PorB binds to TLR2 and requires TLR1 for signaling. J. Immunol. 2006, 176, 2373-2380.

345. Wetzler, L.M. Innate immune function of the neisserial porins and the relationship to vaccine adjuvant activity. Fut. Microbiol. 2010, 5, 749-758.

346. Macleod, H.; Bhasin, N.; Wetzler, L.M. Role of protein tyrosine kinase and Erk1/2 activities in the Toll-like receptor 2-induced cellular activation of murine B cells by neisserial porin. Clin. Vaccine Immunol. 2008, 15, 630-637.

347. Singleton, T.E.; Massari, P.; Wetzler, L.M. Neisserial porin-induced dendritic cell activation is MyD88 and TLR2 dependent. J. Immunol. 2005, 174, 3545-3550.

348. Sjolinder, M.; Altenbacher, G.; Wang, X.; Gao, Y.; Hansson, C.; Sjolinder, H. The meningococcal adhesin NhhA provokes proinflammatory responses in macrophages via toll-like receptor 4-dependent and -independent pathways. Infect. Immun. 2012, 80, 4027-4033.

349. Chu, C.L.; Yu, Y.L.; Kung, Y.C.; Liao, P.Y.; Liu, K.J.; Tseng, Y.T.; Lin, Y.C.; Hsieh, S.S.; Chong, P.C.; Yang, C.Y. The immunomodulatory activity of meningococcal lipoprotein Ag473 depends on the conformation made up of the lipid and protein moieties. PLoS One 2012, 7, e40873:1-e40873:11.

350. Hill, M.; Deghmane, A.E.; Segovia, M.; Zarantonelli, M.L.; Tilly, G.; Blancou, P.; Beriou, G.; Josien, R.; Anegon, I.; Hong, E.; et al. Penicillin binding proteins as danger signals: Meningococcal penicillin binding protein 2 activates dendritic cells through Toll-like receptor 4 . PLoS One 2011, 6, e23995:1-e23995:11.

351. Cecchini, P.; Tavano, R.; Polverino de, L.P.; Franzoso, S.; Mazzon, C.; Montanari, P.; Papini, E. The soluble recombinant Neisseria meningitidis adhesin NadA(Delta351-405) stimulates human monocytes by binding to extracellular Hsp90. PLoS One 2011, 6, e25089:1-e25089:13.

352. Zughaier, S.M. Neisseria meningitidis capsular polysaccharides induce inflammatory responses via TLR2 and TLR4-MD-2. J. Leukoc. Biol. 2011, 89, 469-480.

353. Ingalls, R.R.; Lien, E.; Golenbock, D.T. Membrane-associated proteins of a lipopolysaccharidedeficient mutant of Neisseria meningitidis activate the inflammatory response through toll-like receptor 2. Infect. Immun. 2001, 69, 2230-2236.

354. Pridmore, A.C.; Wyllie, D.H.; Abdillahi, F.; Steeghs, L.; van der Ley, P.; Dower, S.K.; Read, R.C. A lipopolysaccharide-deficient mutant of Neisseria meningitidis elicits attenuated cytokine release by human macrophages and signals via toll-like receptor (TLR) 2 but not via TLR4/MD2. J. Infect. Dis. 2001, 183, 89-96. 
355. Fisette, P.L.; Ram, S.; Andersen, J.M.; Guo, W.; Ingalls, R.R. The Lip lipoprotein from Neisseria gonorrhoeae stimulates cytokine release and NF-kappaB activation in epithelial cells in a Toll-like receptor 2-dependent manner. J. Biol. Chem. 2003, 278, 46252-46260.

356. Liu, X.; Wetzler, L.M.; Nascimento, L.O.; Massari, P. Human airway epithelial cell responses to Neisseria lactamica and purified porin via Toll-like receptor 2-dependent signaling. Infect. Immun. 2010, 78, 5314-5323.

357. Toussi, D.N.; Carraway, M.; Wetzler, L.M.; Lewis, L.A.; Liu, X.; Massari, P. The amino acid sequence of Neisseria lactamica PorB surface-exposed loops influences Toll-like receptor 2-dependent cell activation. Infect. Immun. 2012, 80, 3417-3428.

358. Pron, B.; Taha, M.K.; Rambaud, C.; Fournet, J.C.; Pattey, N.; Monnet, J.P.; Musilek, M.; Beretti, J.L.; Nassif, X. Interaction of Neisseria maningitidis with the components of the blood-brain barrier correlates with an increased expression of PilC. J. Infect. Dis. 1997, 176, 1285-1292.

359. Sjolinder, H.; Jonsson, A.B. Olfactory nerve-A novel invasion route of Neisseria meningitidis to reach the meninges. PLoS One 2010, 5, e14034:1-e14034:10.

360. Christodoulides, M.; Heckels, J.E.; Weller, R.O. The Role of the Leptomeninges in Meningococcal Meningitis. In Emerging Strategies in the Fight against Meningitis; Ferreiros, C., Criado, M.T., Vazquez, J., Eds.; Horizon Press: Norfolk, UK, 2002; pp. 1-37.

361. Mairey, E.; Genovesio, A.; Donnadieu, E.; Bernard, C.; Jaubert, F.; Pinard, E.; Seylaz, J.; Olivo-Marin, J.C.; Nassif, X.; Dumenil, G. Cerebral microcirculation shear stress levels determine Neisseria meningitidis attachment sites along the blood-brain barrier. J. Exp. Med. 2006, 203, 1939-1950.

362. Orihuela, C.J.; Mahdavi, J.; Thornton, J.; Mann, B.; Wooldridge, K.G.; Abouseada, N.; Oldfield, N.J.; Self, T.; Ala'Aldeen, D.A.; Tuomanen, E.I. Laminin receptor initiates bacterial contact with the blood brain barrier in experimental meningitis models. J. Clin. Invest. 2009, 119, 1638-1646.

363. Feurer, D.J.; Weller, R.O. Barrier functions of the leptomeninges: A study of normal meninges and meningiomas in tissue culture. Neuropathol. Appl. Neurobiol. 1991, 17, 391-405.

364. Alcolado, R.; Weller, R.O.; Parrish, E.P.; Garrod, D. The cranial arachnoid and pia mater in man: Anatomical and ultrastructural observations. Neuropathol. Appl. Neurobiol. 1988, 14, 1-17.

365. Kleihues, P.; Cavenee, W.K. Pathology and Genetics of Tumours of the Nervous System; IARC press: Lyon, France, 1997.

366. Hardy, S.J.; Christodoulides, M.; Weller, R.O.; Heckels, J.E. Interactions of Neisseria meningitidis with cells of the human meninges. Mol. Microbiol. 2000, 36, 817-829.

367. Fowler, M.I.; Yin, K.Y.; Humphries, H.E.; Heckels, J.E.; Christodoulides, M. Comparison of the inflammatory responses of human meningeal cells following challenge with Neisseria lactamica and with Neisseria meningitidis. Infect. Immun. 2006, 74, 6467-6478.

368. Lauer, B.A.; Fisher, C.E. Neisseria lactamica meningitis. Am. J. Dis. Child. 1976, 130, 198-199.

369. Del Rio, C.; Stephens, D.S.; Knapp, J.S.; Rice, R.J.; Schalla, W.O. Comparison of isolates of Neisseria gonorrhoeae causing meningitis and report of gonococcal meningitis in a patient with C8 deficiency. J. Clin. Microbiol. 1989, 27, 1045-1049.

370. Virji, M.; Alexandrescu, C.; Ferguson, D.J.; Saunders, J.R.; Moxon, E.R. Variations in the expression of pili: The effect on adherence of Neisseria meningitidis to human epithelial and endothelial cells. Mol. Microbiol. 1992, 6, 1271-1279. 
371. Nassif, X.; Lowy, J.; Stenberg, P.; O’Gaora, P.; Ganji, A.; So, M. Antigenic variation of pilin regulates adhesion of Neisseria meningitidis to human epithelial cells. Mol. Microbiol. 1993, 8 , 719-725.

372. Virji, M.; Stimson, E.; Makepeace, K.; Dell, A.; Morris, H.R.; Payne, G.; Saunders, J.R.; Moxon, E.R. Posttranslational modifications of meningococcal pili. Identification of a common trisaccharide substitution on variant pilins of strain C311. Ann. N. Y. Acad. Sci. 1996, 797, 53-64.

373. Weiser, J.N.; Goldberg, J.B.; Pan, N.; Wilson, L.; Virji, M. The phosphorylcholine epitope undergoes phase variation on a 43-kilodalton protein in Pseudomonas aeruginosa and on pili of Neisseria meningitidis and Neisseria gonorrhoeae. Infect. Immun. 1998, 66, 4263-4267.

374. Marceau, M.; Beretti, J.L.; Nassif, X. High adhesiveness of encapsulated Neisseria meningitidis to epithelial cells is associated with the formation of bundles of pili. Mol. Microbiol. 1995, 17, $855-863$.

375. Humphries, H.E.; Triantafilou, M.; Makepeace, B.L.; Heckels, J.E.; Triantafilou, K.; Christodoulides, M. Activation of human meningeal cells is modulated by lipopolysaccharide (LPS) and non-LPS components of Neisseria meningitidis and is independent of Toll-like receptor (TLR)4 and TLR2 signalling. Cell Microbiol. 2005, 7, 415-430.

376. Dietrich, G.; Kurz, S.; Hubner, C.; Aepinus, C.; Theiss, S.; Guckenberger, M.; Panzner, U.; Weber, J.; Frosch, M. Transcriptome analysis of Neisseria meningitidis during infection. J. Bacteriol. 2003, 185, 155-164.

377. Schubert-Unkmeir, A.; Sokolova, O.; Panzner, U.; Eigenthaler, M.; Frosch, M. Gene expression pattern in human brain endothelial cells in response to Neisseria meningitidis. Infect. Immun. 2007, 75, 899-914.

378. Schubert-Unkmeir, A.; Slanina, H.; Frosch, M. Mammalian cell transcriptome in response to meningitis-causing pathogens. Expert Rev. Mol. Diagn. 2009, 9, 833-842.

379. Echenique-Rivera, H.; Muzzi, A.; Del Tordello, E.; Seib, K.L.; Francois, P.; Rappuoli, R.; Pizza, M.; Serruto, D. Transcriptome analysis of Neisseria meningitidis in human whole blood and mutagenesis studies identify virulence factors involved in blood survival. PLoS Pathog. 2011, 7, e10002027:1-e10002027:18.

380. Del, T.E.; Serruto, D. Functional genomics studies of the human pathogen Neisseria meningitidis. Brief. Funct. Genomics 2013, doi:10.1093/bfgp/elt018.

381. Merz, A.J.; So, M. Interactions of pathogenic Neisseriae with epithelial cell membranes. Annu. Rev. Cell. Dev. Biol. 2000, 16, 423-457.

382. Pujol, C.; Eugene, E.; Morand, P.; Nassif, X. Do pathogenic Neisseriae need several ways to modify the host cell cytoskeleton? Microbes Infect. 2000, 2, 821-827.

383. Virji, M. Pathogenic Neisseriae: Surface modulation, pathogenesis and infection control. Nat. Rev. Microbiol. 2009, 7, 274-286.

384. Kline, K.A.; Falker, S.; Dahlberg, S.; Normark, S.; Henriques-Normark, B. Bacterial adhesins in host-microbe interactions. Cell Host Microbe 2009, 5, 580-592.

385. Hill, D.J.; Virji, M. Meningococcal ligands and molecular targets of the host. In Neisseria meningitidis: Advanced Methods and Protocols; Christodoulides, M., Ed.; Humana Press: New York, NY, USA, 2012; Chapter 9; pp. 143-152. 
386. Miller, F.; Lecuyer, H.; Join-Lambert, O.; Bourdoulous, S.; Marullo, S.; Nassif, X.; Coureuil, M. Neisseria meningitidis colonization of the brain endothelium and cerebrospinal fluid invasion. Cell Microbiol. 2013, 15, 512-519.

387. Serruto, D.; Bottomley, M.J.; Ram, S.; Giuliani, M.M.; Rappuoli, R. The new multicomponent vaccine against meningococcal serogroup B, 4CMenB: Immunological, functional and structural characterization of the antigens. Vaccine 2012, 30, B87-B97.

388. Mcneil, L.K.; Zagursky, R.J.; Lin, S.L.; Murphy, E.; Zlotnick, G.W.; Hoiseth, S.K.; Jansen, K.U.; Anderson, A.S. Role of Factor $\mathrm{H}$ binding protein in Neisseria meningitidis virulence and its potential as a vaccine candidate to broadly protect against meningococcal disease. Microbiol. Mol. Biol. Rev. 2013, 77, 234-252.

389. Marri, P.R.; Paniscus, M.; Weyand, N.J.; Rendon, M.A.; Calton, C.M.; Hernandez, D.R.; Higashi, D.L.; Sodergren, E.; Weinstock, G.M.; Rounsley, S.D.; et al. Genome sequencing reveals widespread virulence gene exchange among human Neisseria species. PLoS One 2010, 5 , e11835:1-e11835:9.

390. Deasy, A.; Dale, A.; Evans, C.; Guccione, E.; Andrews, N.; Gorringe, A.; Read, R. Induced Nasopharyngeal Colonisation with Neisseria lactamica Protects against Carriage of Neisseria meningitidis in Healthy Adult Volunteers. In Proceedings of the XVIIIth International Pathogenic Neisseria Conference (IPNC), Wurzberg, Germany, 9-14th September 2012; p. 100.

(C) 2013 by the authors; licensee MDPI, Basel, Switzerland. This article is an open access article distributed under the terms and conditions of the Creative Commons Attribution license (http://creativecommons.org/licenses/by/3.0/). 